
of Engineers ${ }_{\circledast}$

Engineer Research and

Development Center

\title{
Restoring Bottomland Hardwood Forests on U.S. Army Corps of Engineers Lands
}

2016 Monitoring Report

Jacob F. Berkowitz, Darrell E. Evans, Kevin D. Philley,

March 2018

Jason P. Pietroski, Casey Ehorn, and Nathan R. Beane
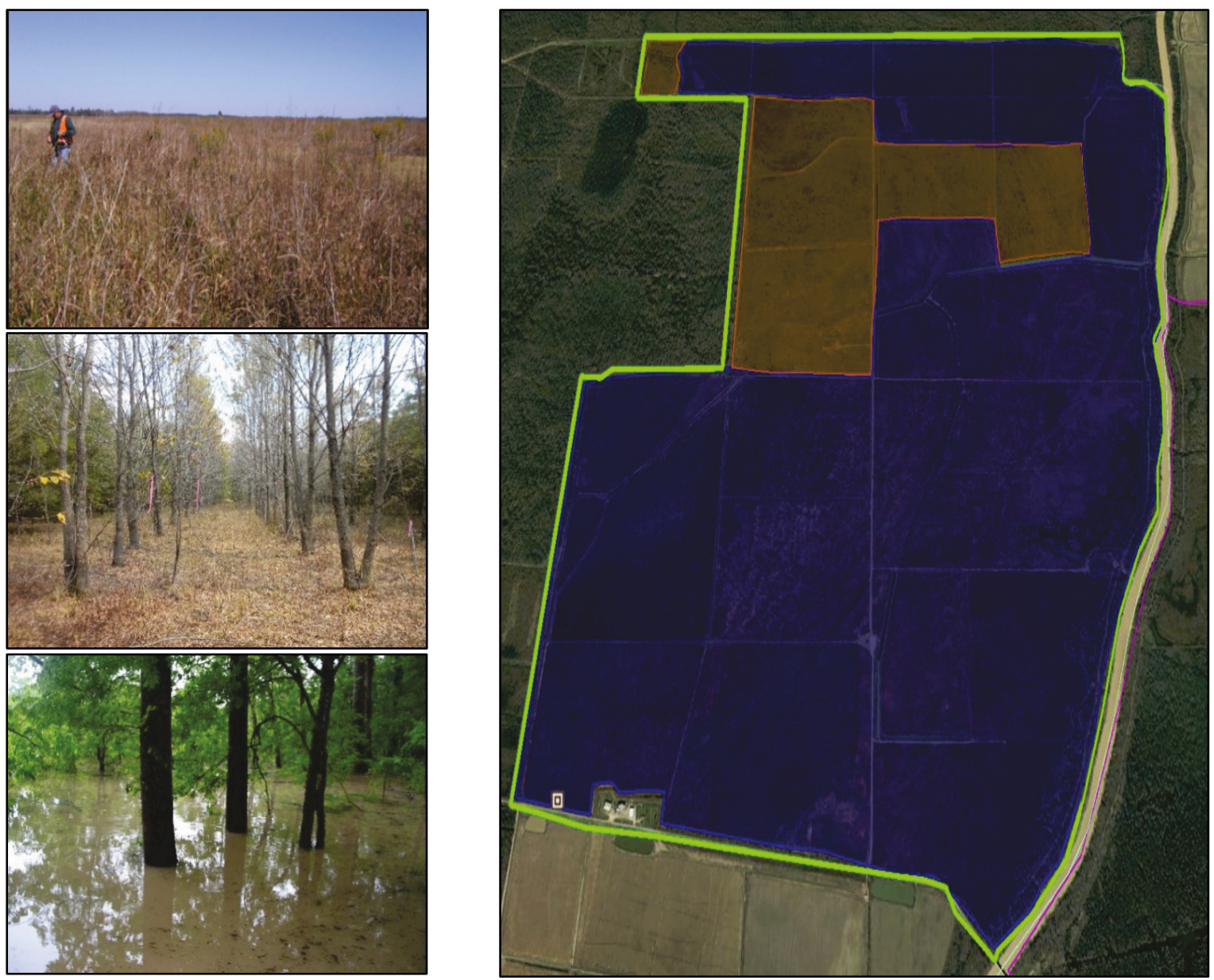
The U.S. Army Engineer Research and Development Center (ERDC) solves the nation's toughest engineering and environmental challenges. ERDC develops innovative solutions in civil and military engineering, geospatial sciences, water resources, and environmental sciences for the Army, the Department of Defense, civilian agencies, and our nation's public good. Find out more at www.erdc.usace.army.mil.

To search for other technical reports published by ERDC, visit the ERDC online library at http://acwc.sdp.sirsi.net/client/default. 


\section{Restoring Bottomland Hardwood Forests on U.S. Army Corps of Engineers Lands}

2016 Monitoring Report

Jacob F. Berkowitz, Darrell E. Evans, Kevin D. Philley, Jason P. Pietroski, and Nathan R. Beane

Environmental Laboratory

U.S. Army Engineer Research and Development Center 3909 Halls Ferry Road

Vicksburg, MS 39108-6499

Casey Ehorn

Nashville District

U.S. Army Corps of Engineers

801 Broadway A415

Nashville, TN 37203

Final report

Approved for public release; distribution is unlimited.

Prepared for U.S. Army Corps of Engineers

Vicksburg District

Under Project W807PM71677228, "Yazoo Basin - Backwater Less Rocky Bayou” 


\section{Abstract}

The U.S. Army Corps of Engineers (USACE) - Vicksburg District manages over 12,000 ha of restored bottomland hardwood forests within the Lower Mississippi Alluvial Valley. Restored forest stand ages within the region vary from five 5 to 26 years, providing opportunities to document increases in wetland function across a restoration chronosequence. Additionally, conducting repeated monitoring at restored sites over multiple years allows for an examination of restoration benefits as forest succession occurs. During 2016, wetland functional assessment data was collected and analyzed from 606 sample locations collected within 12 restored bottomland hardwood forest sites. Results indicate that (1) wetland assessment variables show continued progress toward mature forest conditions; (2) wetland assessment variables follow expected recovery trajectories; (3) wetland functional scores display statistically significant increases across the restoration chronosequence; and (4) wetland functional scores improve over multiple years of monitoring. Results display a functional lag between restored areas undergoing ecological succession and mature (e.g., 8o-year-old) reference forests. However, a subset of wetland functions in restored sites have attained reference conditions in areas approaching or exceeding tree diameter and canopy closure thresholds.

DISCLAIMER: The contents of this report are not to be used for advertising, publication, or promotional purposes. Citation of trade names does not constitute an official endorsement or approval of the use of such commercial products. All product names and trademarks cited are the property of their respective owners. The findings of this report are not to be construed as an official Department of the Army position unless so designated by other authorized documents. 


\section{Contents}

Abstract.................................................................................................................................. if

Figures and Tables......................................................................................................................

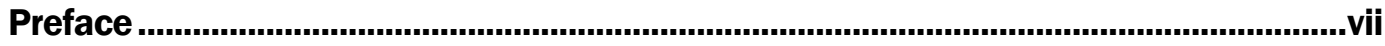

Unit Conversion Factors...............................................................................................

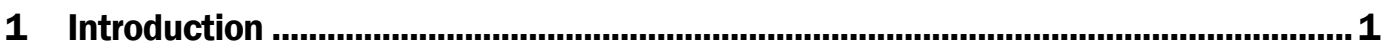

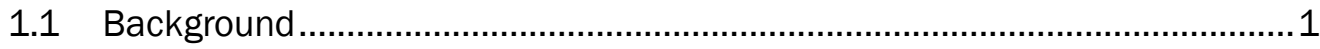

1.2 Objective........................................................................................ 1

1.2.1 Wetland impacts within the region ................................................................... 1

1.2.2 USACE restoration initiatives............................................................................. 2

1.2.3 USACE restoration chronosequence................................................................. 4

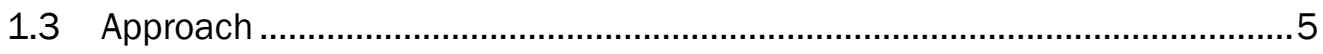

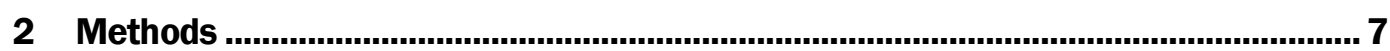

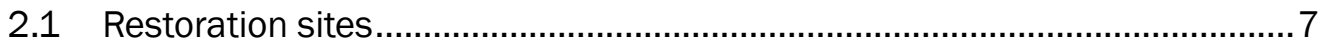

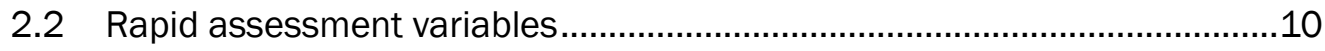

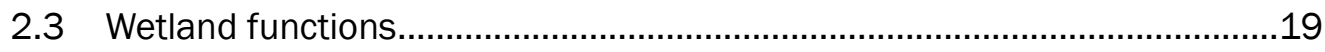

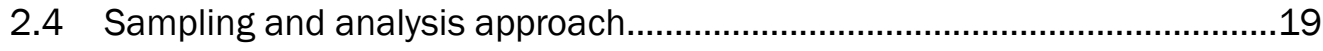

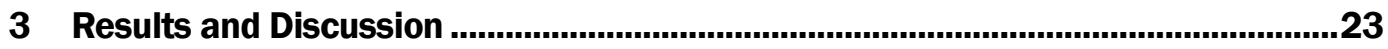

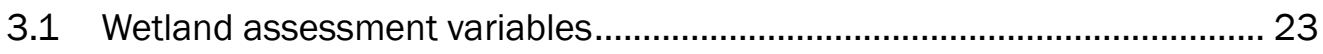

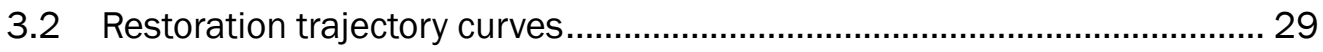

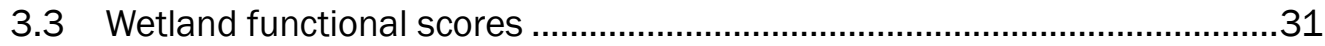

3.4 Intrasite functional increases over time...................................................... 39

3.5 Wetland functions in restored and mature bottomland hardwood

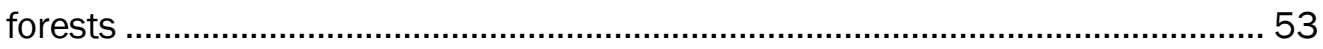

3.6 Management implications of monitoring results..................................... 54

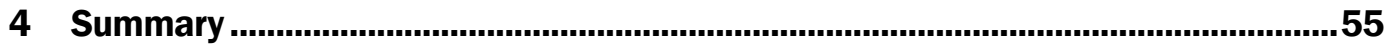

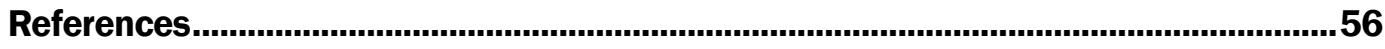

Appendix A: Statistical relationships between restoration site age, wetland assessment variables, and wetland functions ................................................58

\section{Report Documentation Page}




\section{Figures and Tables}

\section{Figures}

Figure 1. Restoration sites are located in the Lower Mississippi Alluvial Valley (adapted from Berkowitz 2013).

Figure 2. Example of row-planted trees in a 15-year-old restored forested wetland

Figure 3. Application of a wetland restoration chronosequence examining the relationship between flood frequency and water quality improvement function. The development of chronosequences supports restoration success monitoring and trajectory development (adapted from Berkowitz and White 2013). The x-axis units represent the percentage of the monitoring period during which the water remained within $30 \mathrm{~cm}$ (12 in.) of the soil surface. 5

Figure 4. HGM guidebook developed to monitor restoration projects within the study area (Smith and Klimas 2002).

Figure 5. Restoration site locations within the Lower Mississippi Alluvial Valley.

Figure 6. Example of the core area determination at the Alligator restoration site.

The red shaded area denotes the area within a $100 \mathrm{~m}$ buffer.

Figure 7. Example of the habitat connection variable at the Polutken restoration

site. The yellow line denotes the portion of the site with suitable habitat

connection

Figure 8. Example of the wetland tract variable at the Stock restoration site. The orange polygons denote the size of suitable wetland features adjacent to the restored area.

Figure 9. Example of flood frequency within the Kennedy restoration site. The area shaded in blue denotes estimated flood frequencies of $<2$ years, while the red shading indicates an estimated flood return interval of 2-5 years.

Figure 10. Diagram depicting the sample plot utilized to collect on-site assessment variables at each sample location. The $0.04 \mathrm{~m}$ circle is used to determine tree basal area, tree density, snag density, and species composition. Sapling shrub density is measured within the 0.004 ha subplots. Ground vegetation cover, $A$ horizon, and $O$ horizon determinations utilize the four onesquare-meter quadrats. The linear transects are used to measure woody debris and log biomass.

Figure 11. Example of microdepressional ponding within a 20-year-old restoration site.

Figure 12. Example of tree diameter measurement within a restored area.

Figure 13. Example of woody debris and log biomass observed at a mature forested location within the region.

Figure 14. Ground vegetation cover and the thickness of $O$ and $A$ horizons was determined within four one-square-meter subplots at each sampling location.

Figure 15. Example of wetland assessment variable standardization and conversion to variables subindex scores. Note that the ground vegetation cover data collected at each sample location as a percentage corresponds to a value on the standardized 0.0 to 1.0 subindex scale. 
Figure 16. Island Lake restoration site (green line) displaying example of transects (red lines) along which sampling locations were established.

Figure 17. Average tree basal area observed across the restoration chronosequence. Error bars represent one standard deviation of the mean; entries with different letter designations were significantly different at $\alpha=0.05$.

Figure 18. Average tree density observed across the restoration chronosequence.

Error bars represent one standard deviation of the mean; entries with different letter designations were significantly different at $\alpha=0.05$.

Figure 19. Average woody debris biomass observed across the restoration chronosequence. Error bars represent one standard deviation of the mean; entries with different letter designations were significantly different at $\alpha=0.05$.

Figure 20. Average ground vegetation cover observed across the restoration chronosequence. Error bars represent one standard deviation of the mean; entries with different letter designations were significantly different at $\alpha=0.05$.

Figure 21. (A) Canopy cover (dashed line) leads to light limitation (solid line), resulting in the shading out of understory species occurring between 15 and 20 years following reforestation (based upon data within Bigelow et al. (2011) and Summers (2010)). (B) Log-transformed data displaying threshold effect of forest age as observed in ground vegetation cover and sapling-shrub density data presented in Berkowitz (2013). Note the apex and subsequent decline occurring at approximately 15 - 20 years following reforestation.

Figure 22. Average sapling shrub density observed across the restoration chronosequence. Error bars represent one standard deviation of the mean; entries with different letter designations were significantly different at $\alpha=0.05$.

Figure 23. Average A (left) and $O$ (right) horizon thickness observed across the restoration chronosequence. Error bars represent one standard deviation of the mean; entries with different letter designations were significantly different at $\alpha=$ 0.05 .

Figure 24. Expected recovery trajectory curves relating forest stand age to anticipated assessment variable measurements (from Smith and Klimas 2002). Note, a 50-year period of analysis is used in USACE planning activities for the purpose of offsetting unavoidable impacts and other mitigation activities.

Figure 25. Detain floodwater functional scores across the restoration chronosequence. Error bars represent one standard deviation of the mean; entries with different letter designations were significantly different at $\alpha=0.05$.

Figure 26. Detain precipitation functional scores across the restoration chronosequence. Error bars represent one standard deviation of the mean; entries with different letter designations were significantly different at $\alpha=0.05$.

Figure 27. Cycle nutrients functional scores across the restoration chronosequence. Error bars represent one standard deviation of the mean; entries with different letter designations were significantly different at $\alpha=0.05$.

Figure 28. Export organic carbon functional scores across the restoration chronosequence. Error bars represent one standard deviation of the mean; entries with different letter designations were significantly different at $\alpha=0.05$.

Figure 29. Remove elements and compounds functional scores across the restoration chronosequence. Error bars represent one standard deviation of the mean; entries with different letter designations were significantly different at $\alpha=$ 0.05 . 
Figure 30. Maintain plant communities functional scores across the restoration chronosequence. Error bars represent one standard deviation of the mean; entries with different letter designations were significantly different at $\alpha=0.05$.

Figure 31. Provide fish and wildlife habitat functional scores across the restoration chronosequence. Error bars represent one standard deviation of the mean; entries with different letter designations were significantly different at $\alpha=$ 0.05 .

Figure 32. Average functional scores across the restoration chronosequence.

Error bars represent one standard deviation of the mean; entries with different letter designations were significantly different at $\alpha=0.05$.

Figure 33. Intrasite changes in functional scores over time - Alligator restoration area.

Figure 34. Intrasite changes in functional scores over time - Big Twist restoration area.

Figure 35. Intrasite changes in functional scores over time - Bolivar restoration area.

Figure 36. Intrasite changes in functional scores over time - Darlove restoration area.

Figure 37. Intrasite changes in functional scores over time - Island Lake restoration area.

Figure 38. Intrasite changes in functional scores over time - Kennedy restoration area.

Figure 39. Intrasite changes in functional scores over time - Lake George restoration area.

Figure 40. Intrasite changes in functional scores over time - Polutken restoration area.

Figure 41. Intrasite changes in functional scores over time - Pushmataha restoration area.

Figure 42. Intrasite changes in functional scores over time - Sky Lake restoration area.

Figure 43. Intrasite changes in functional scores over time - Stock restoration area..

Figure 44. Intrasite changes in functional scores over time - Washington restoration area.

\section{Tables}

Table 1. Restoration site location, size, age, and sampling intensity.

Table 2. Restoration sites with multiple years of monitoring data available.

Table 3. Summary of rapid assessment variables, description, and sampling technique.

Table 4. Wetland functions assessed at each restoration site using the HGM approach.

Table 5. Comparison of wetland functional assessment scores at mature bottomland hardwood forests and 25-year-old restoration sites. 


\section{Preface}

This study was conducted for the U.S. Army Corps of Engineers Vicksburg District (MVK) Under Project number W807PM71677228, "Yazoo Basin Backwater Less Rocky Bayou.” The technical monitor was Mr. Kenneth Parrish (CE-MVK).

The work was performed by the Wetlands and Coastal Ecology Branch (CEERD-EEW) of the Ecosystem Evaluation and Engineering Division (CEERD-EE), U.S. Army Engineer Research and Development Center, Environmental Laboratory (ERDC-EL). At the time of publication, Ms. Patty Tolley was Chief, CEERD-EEW; Mr. Mark Farr was Chief, CEERD-EE. Dr. Jack Davis was the Deputy Director of ERDC-EL and the Director was Dr. Ilker Adiguzel.

The authors would like to thank the following individuals for assistance with field data collection, data entry and analysis, and technical review of the report: Mr. Matt Ferguson, U.S. Army Corps of Engineers, Pacific Ocean, Alaska District (CE-POA); Mr. Tommy Blanchard, Louisiana State University; Mr. Steven Currie and Mr. Brian Durham, both of CEERDEEW; Mr. Gary Young, Mississippi Valley Division, U.S. Army Corps of Engineers (CE-MVD); and Mr. Kent Parrish and Mr. Daniel Sumerall, both of CE-MVK.

The Commander of ERDC was COL Bryan S. Green and the Director was Dr. David W. Pittman. 


\section{Unit Conversion Factors}

\begin{tabular}{|l|l|l|}
\hline Multiply & By & To Obtain \\
\hline hectares & $1.0 \mathrm{E}+04$ & square meters \\
\hline
\end{tabular}




\section{Introduction}

\subsection{Background}

The sections below describe the extent of wetland losses within the Lower Mississippi Alluvial Valley and place U.S. Army Corps of Engineers (USACE) restoration efforts in a larger regional context. Other sections in this chapter discuss the objective of the current study, the development of the wetland assessment approach, and previous research conducted at USACE restoration sites.

\subsection{Objective}

The present report provides monitoring results from 12 bottomland hardwood forest wetland restoration sites. The study documents increases in wetland assessment metrics and wetland functional scores across a restoration chronosequence. Additionally, changes in functional scores are examined across multiple years of restoration monitoring data. A comparison of wetland functions in restored and mature bottomland hardwood forests is included.

\subsubsection{Wetland impacts within the region}

Wetland extent within the Lower Mississippi Valley (LMV) displayed a $74 \%$ decrease from historic values, with only 2.8 of an original 10 million ha remaining intact by the 1980 s (The Nature Conservancy 1992; King et al. 2006). Wetland loss rates exceeded all other portions of the United States, creating an area of concern in terms of both wetland land area and wetland functional losses (Hefner and Brown 1995). Wetland impacts resulted from a variety of factors, including settlement expansion, agriculture and forestry, and flood control activities (Gardiner and Oliver 2005). During the 1970 s and 1980 s, public and private organizations recognized the negative impacts of wetland functional degradation and began promoting wetland restoration designed to repair damaged and degraded ecosystems within the region (US Congress 1985; Haynes et al. 1995; Hobbs and Cramer 2008). In response, an estimated 300,000 ha within the LMV has undergone reforestation, including over 12,000 ha under USACE management (USACE 1989; Allen et al. 2000; King and Keeland 1999; King et al. 2006). 


\subsubsection{USACE restoration initiatives}

USACE - Vicksburg District conducts restoration activities in the Lower Mississippi Alluvial Valley (Figure 1). Restoration projects offset unavoidable impacts to bottomland hardwood wetlands occurring during execution of the Civil Works mission as outlined within Section 906 of the Water Resources Development Act of 1986 and other statutes (Haynes and Moore 1988). During project planning, a 50-year period of analysis is used to make projections of site conditions for the purposes of offsetting impacts and conducting mitigation activities. Specifically, agricultural tracts were purchased and reforested by the Vicksburg District of the U.S. Army Corps of Engineers to provide compensatory mitigation for the unavoidable adverse impacts associated with the construction of several Civil Works projects that were authorized by the Flood Control, Mississippi River and Tributaries Program. These construction projects include the Mississippi River Mainline Levees, Yazoo Backwater Levees, Upper Steele Bayou Project, and the Upper Yazoo Project.

Figure 1. Restoration sites are located in the Lower Mississippi Alluvial Valley (adapted from Berkowitz 2013).

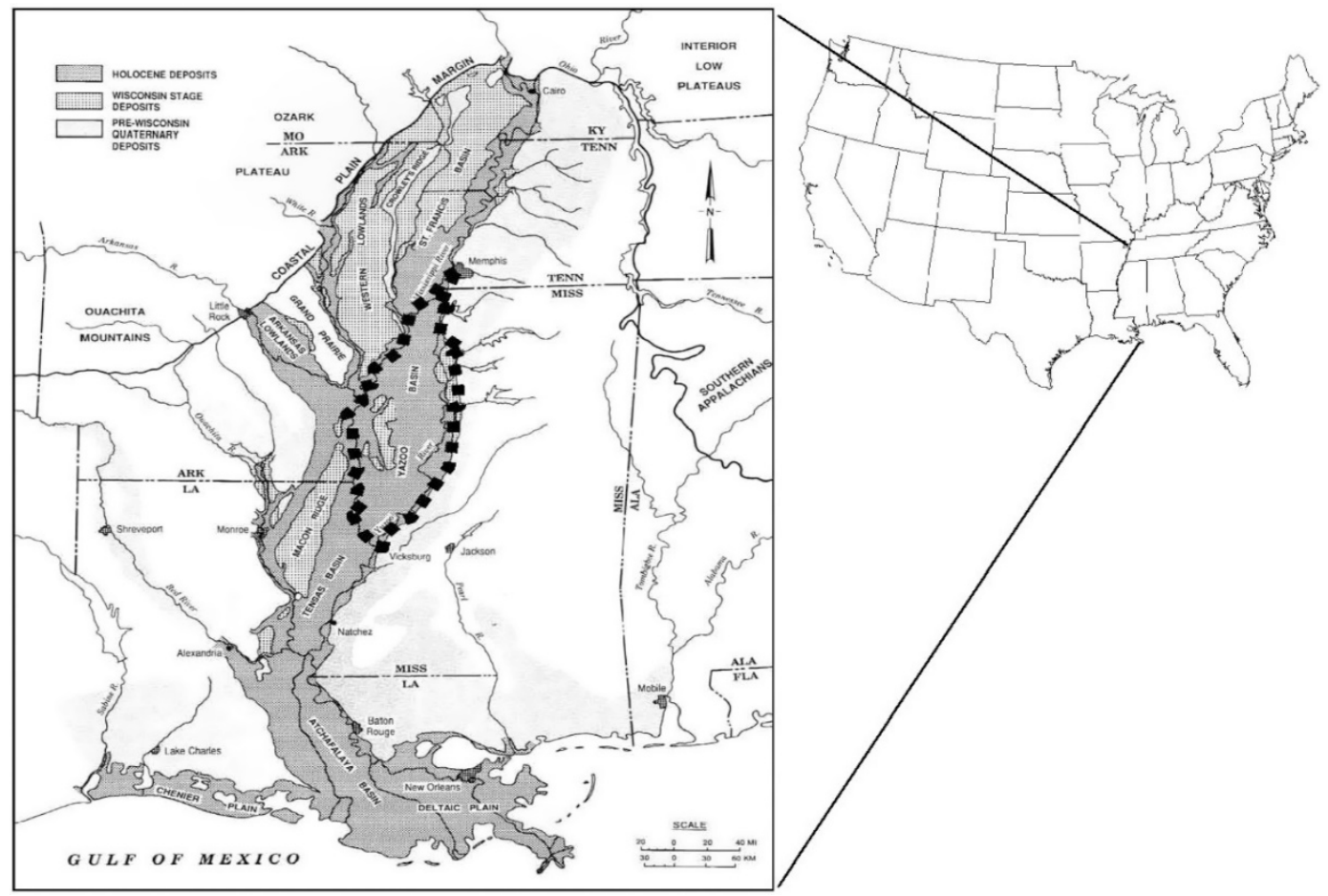


Project implementation and associated unavoidable impacts occurred over a period of years. Consequently, the tools utilized to conduct impact analysis to terrestrial functions have evolved over time, with the best possible impact analysis approaches being applied during project planning and implementation. As a result, the hydrogeomorphic (HGM) approach for assessing ecological function is used as a monitoring tool in the current report despite the fact that initial impact analysis may have been conducted using other means (e.g., Habitat Suitability Indices).

The USACE restoration projects reclaim bottomland hardwood forests previously converted to agriculture, many of which exhibited marginal production due to seasonal high water tables and/or the need for extensive drainage (Berkowitz 2013). Restoration activities include the planting of desirable bottomland hardwood species, selected for their capacity to thrive under wetland soil and hydrologic conditions, and provide wetland biogeochemical, hydrology, and habitat functions (Smith and Klimas 2002; Stanturf et al. 2000; Humphrey et al. 2004). Site afforestation occurred via row planting with a mixture of container and bare-root seedling techniques (Figure 2). Typical seedling spacing dimensions were $3.65 \mathrm{~m}(12 \mathrm{ft})$ by $3.65 \mathrm{~m} \mathrm{(12ft).}$

Figure 2. Example of row-planted trees in a 15-year-old restored forested wetland.

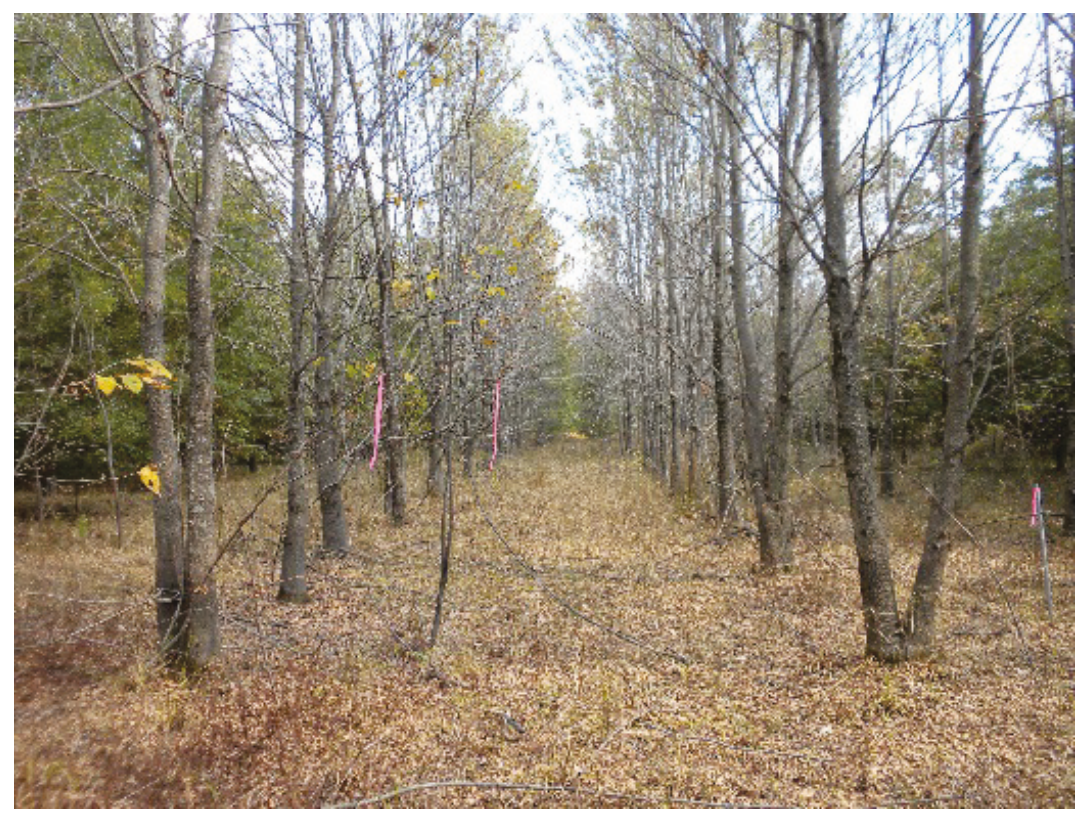


Restoration sites contain access roads but otherwise remain free of development or other alteration, managed as natural areas in perpetuity as designated through fee title agreements with state and federal agencies. Recreational hunting and other non-invasive activities occur on a subset of restoration sites, providing additional public benefit. Over 300,00o ha of agricultural lands underwent reclamation and restoration in the region, with USACE activities accounting for 12,000 ha $(\sim 5 \%)$ of the increase in afforested wetland area (Gardiner and Oliver 2005; King et al. 2006).

The USACE restoration initiatives coincide with large-scale wetlands restoration projects being conducted through the federally supported Natural Resources Conservation Service Wetland Reserve Program; other state and federal agencies; and private sector partnerships led by Ducks Unlimited, The Nature Conservancy, and other groups (Stanturf et al. 2000). Notably, lands acquired by USACE remain under state or federal management, contributing to the extent of bottomland hardwood forests found within the region, including lands maintained by the U.S. Fish and Wildlife Service and the U.S. Forest Service Delta National Forest (Gardiner and Oliver 2005). The restoration of wetlands on public lands promotes long-term protection of terrestrial, wetland, and aquatic resources within a region dominated by private land ownership.

\subsubsection{USACE restoration chronosequence}

The USACE wetland restoration initiative began in the 1990s, with periodic restorative tree planting occurring sequentially with land acquisition. Approximately 6,500 ha underwent restoration by the year 2000, representing some of the oldest large-scale restored bottomland hardwood stands in the region (Lin 2009). An additional 5,400 ha completed restoration by 2011, with restoration projects continuing during 2015-2016. The periodicity of restorative plantings provides a mechanism for examining restoration success across a chronosequence, allowing for an evaluation of project benefits, development of predictive restoration trajectories, and establishment of project milestones (Walker et al. 2010). For example, Berkowitz (2013) utilized the restoration chronosequence to identify restoration assessment metrics that provide rapid response indicators of restoration success. Recent research also demonstrates the applicability of restoration chronosequence for validating wetland assessment approaches (Figure 3; Berkowitz and White 2013). 
Figure 3. Application of a wetland restoration chronosequence examining the relationship between flood frequency and water quality improvement function. The development of chronosequences supports restoration success monitoring and trajectory development (adapted from Berkowitz and White 2013). The x-axis units represent the percentage of the monitoring period during which the water remained within $30 \mathrm{~cm}$ (12 in.) of the soil surface.

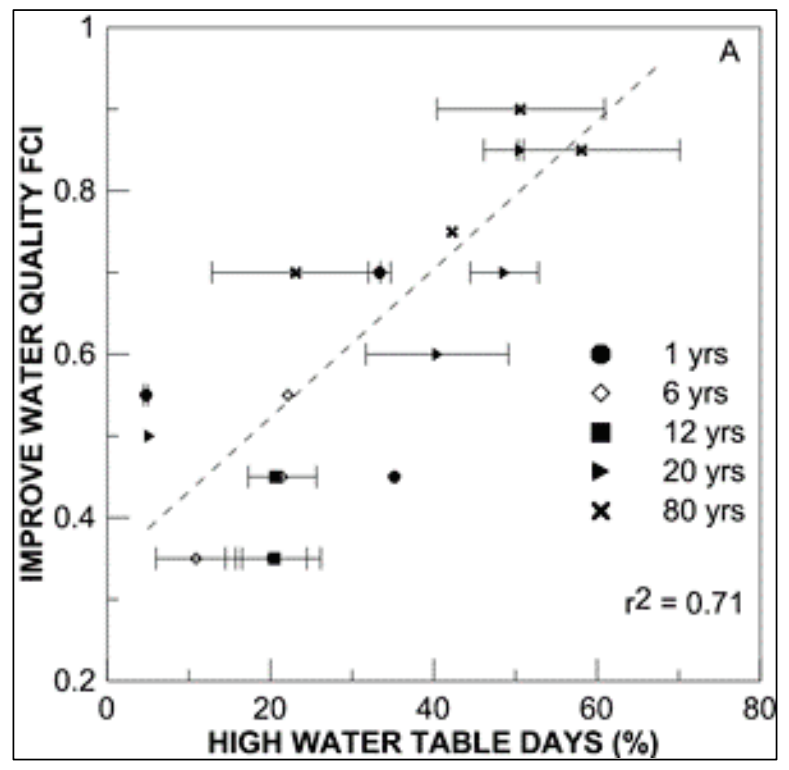

\subsection{Approach}

Following the development of the early restoration sites in the 1990s, the U.S. Army Engineer Research and Development Center (ERDC) designed an assessment approach to conduct monitoring within the restored areas (Lin 2009). The ERDC team selected the Hydrogeomorphic (HGM) monitoring approach because that methodology directly addresses Section 404 of the Clean Water Act and similar statutes; promotes alternatives analysis; assesses unavoidable project impacts; and provides for monitoring restoration project success (Smith et al. 2013). In general, the HGM approach utilizes rapid assessment metrics to infer a wetlands capacity to provide ecosystem functions (Smith et al. 2008). Commonly evaluated functions include measures related to wetland hydrology (e.g., flood water detention), biogeochemistry (e.g., nutrient cycling, water quality improvement), and habitat support (Noble et al. 2014; Berkowitz et al. 2014).

At the request of USACE resource managers, Smith and Klimas (2002) developed and published an HGM guidebook targeting the restoration project area (Figure 4). The HGM guidebook addresses a number of wetland subclasses, including riverine, backwater wetlands, and other wetland types. The current report collectively refers to restoration sites as 
bottomland hardwood forests. The HGM assessment approach has been repeatedly applied at a number of restored bottomland hardwood forests, allowing resource managers to track restoration progress over time. Berkowitz (2013) completed additional work utilizing the HGM guidebook; during which restoration trajectory curves were developed and rapid response indicators were identified for the project area. Further work validated several aspects of the HGM approach by comparing rapid assessment outcomes with direct measures of ecosystem function (Berkowitz and White 2013; Noble et al., 2014). The numerous reports and journal articles conducted within the restoration project area promote confidence in the monitoring approach, including evaluations of restoration success within the Lower Mississippi Alluvial Valley.

Figure 4. HGM guidebook developed to monitor restoration projects within the study area (Smith and Klimas 2002).

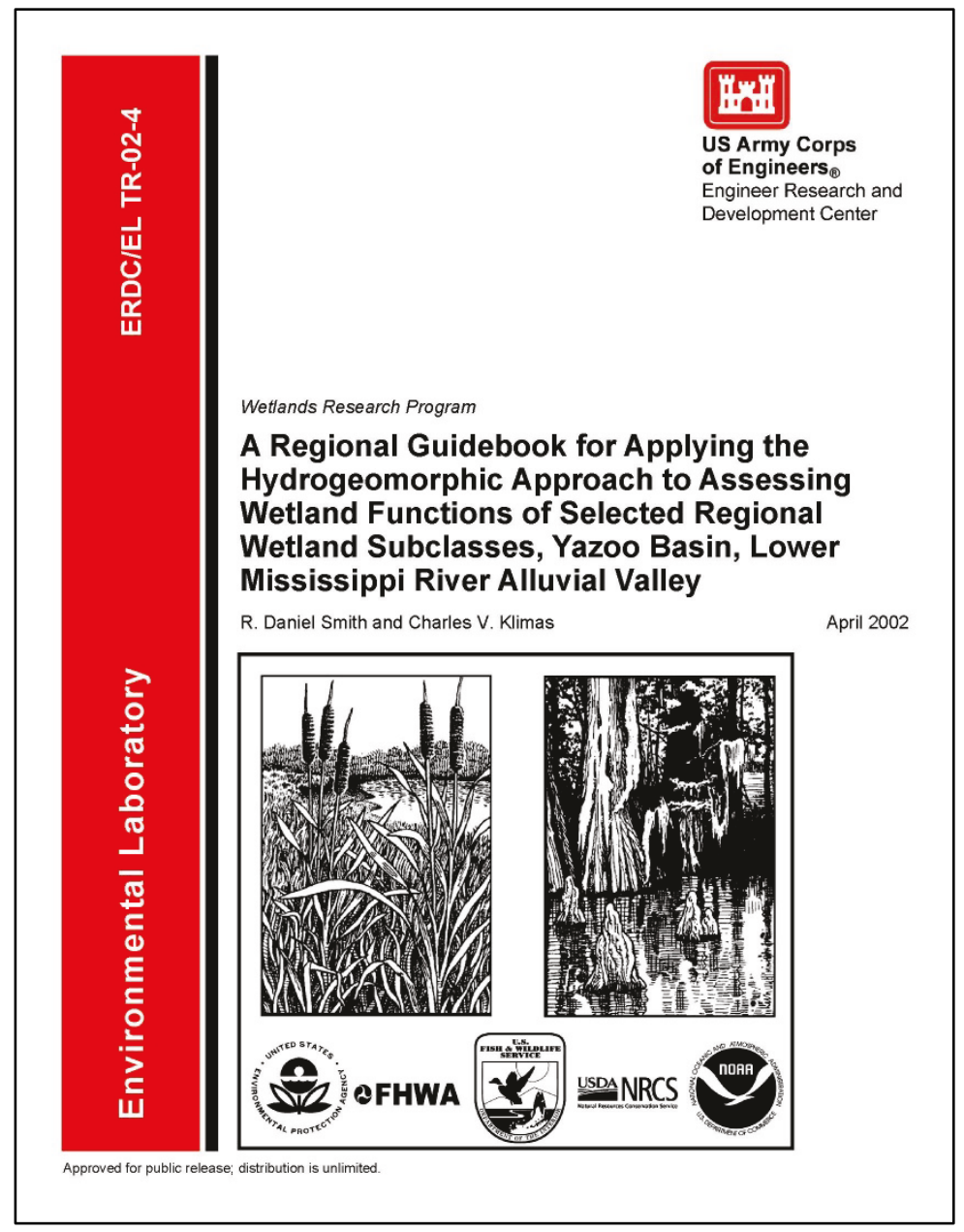




\section{Methods}

The following section briefly describes the restoration sites, the assessment variables monitored, and wetland functions determined. Additional information on the sampling approach and statistical analysis is also provided.

\subsection{Restoration sites}

The current study focused on 12 restored bottomland hardwood restoration sites located within the Lower Mississippi Alluvial Valley. Restoration tracts were selected by identifying frequently flooded agricultural lands within the project area (see section 1.4 above). Potential tracts were evaluated based their reforestation potential, proximity to existing bottomland hardwood habitat, and opportunity to connect or expand existing state- or federally owned conservation lands. Restoration site ages ranged from 5 to 26 years post planting (Table 1). Multiple years of monitoring occurred at a subset of restoration sites, allowing for an analysis of functional increases over time (i.e., Table 2). Figure 5 provides an overview of restoration site locations.

The restored bottomland hardwood forests examined in the current report are subject to overbank or backwater flooding from rivers, streams, or direct precipitation at typical return intervals of five years or less (Smith and Klimas 2002). Backwater flooding describes inundation resulting from impeded drainage, usually due to high water in downstream systems. Typically, backwater flooding occurs when a large stream in flood stage inhibits drainage within adjacent tributaries. Impeded drainage leads to increasing water tables within low-lying areas. In the Yazoo Basin, additional backwater flooding may result from structures associated with flood control projects. Many bottomland hardwood forests in the study area occupy backswamp deposits and other low-lying areas near tributary networks. Characteristic species include green ash (Fraxinus pennsylvanica) and Nuttall oak (Quercus nuttallii), with inclusions of overcup oak (Quercus lyrata), water hickory (Carya aquatica), and other flood-tolerant species. 
Table 1. Restoration site location, size, age, and sampling intensity.

\begin{tabular}{|c|c|c|c|c|c|c|}
\hline Site & Size (ha) & $\begin{array}{l}\text { Restoration } \\
\text { timeframe }\end{array}$ & $\begin{array}{l}\text { Restoration } \\
\text { stand age }\end{array}$ & $\begin{array}{l}\text { Age } \\
\text { class }\end{array}$ & $\begin{array}{c}\text { Sample } \\
\text { locations }\end{array}$ & $\begin{array}{l}\text { Sampling intensity } \\
\text { (ha per sample) }\end{array}$ \\
\hline Alligator & 1013 & 2004-2005 & 12 & 13 & 84 & 12 \\
\hline Big Twist & 2692 & 1995-1997 & 21 & 20 & 69 & 39 \\
\hline Bolivar & 344 & 2011 & 5 & 5 & 37 & 9 \\
\hline Darlove & 229 & 1998-1999 & 18 & 20 & 29 & 8 \\
\hline Island Lake & 217 & 2005 & 11 & 10 & 21 & 10 \\
\hline Kennedy & 1213 & 2011 & 5 & 5 & 60 & 20 \\
\hline Lake George & 3402 & $1990-1997$ & 25 & 25 & 124 & 27 \\
\hline Polutken & 125 & $1997-1998$ & 19 & 20 & 17 & 7 \\
\hline Pushmataha & 874 & 2006 & 10 & 10 & 40 & 22 \\
\hline Sky Lake & 1268 & 2003 & 13 & 13 & 65 & 19 \\
\hline Stock & 330 & 2003 & 13 & 13 & 36 & 9 \\
\hline Washington & 141 & 2004 & 12 & 13 & 24 & 6 \\
\hline Total & 11847 & & & & 606 & \\
\hline
\end{tabular}

Table 2. Restoration sites with multiple years of monitoring data available.

\begin{tabular}{|l|l|l|l|l|}
\hline Site & \multicolumn{4}{|l|}{ Years with available monitoring data } \\
\hline Alligator & 2011 & 2016 & & \\
\hline Big Twist & 2001 & 2003 & 2007 & 2016 \\
\hline Bolivar & 2011 & 2016 & & \\
\hline Darlove & 2001 & 2009 & 2016 & \\
\hline Island Lake & 2011 & 2016 & & \\
\hline Kennedy & 2011 & 2016 & & \\
\hline Lake George & 2001 & 2009 & 2016 & \\
\hline Polutken & 2001 & 2005 & 2009 & 2016 \\
\hline Pushmataha & 2011 & 2016 & & \\
\hline Sky Lake & 1999 & 2003 & 2008 & 2016 \\
\hline Stock & 2003 & 2008 & 2016 & \\
\hline Washington & 2011 & 2016 & & \\
\hline
\end{tabular}


Figure 5. Restoration site locations within the Lower Mississippi Alluvial Valley.

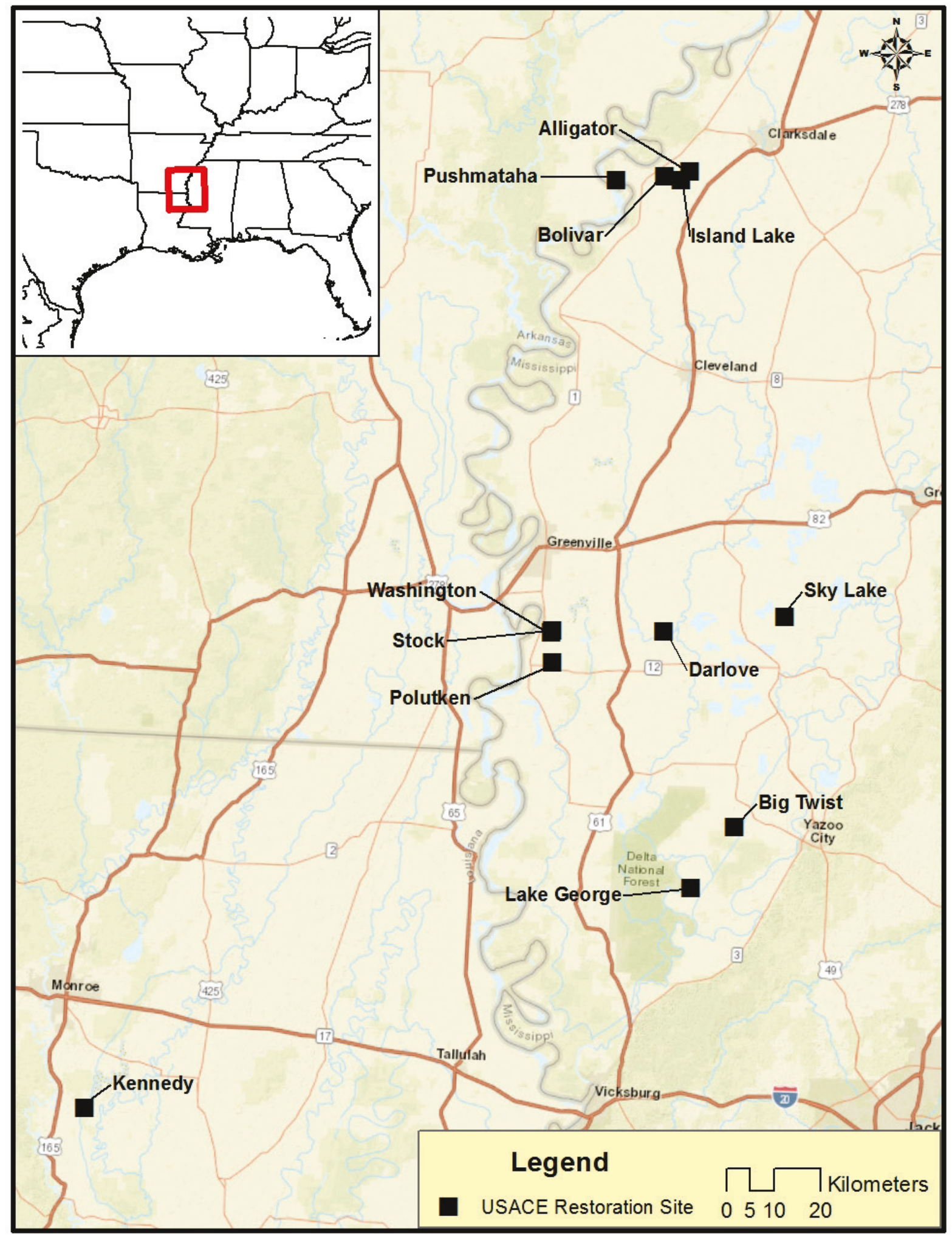




\subsection{Rapid assessment variables}

The HGM assessment approach utilizes 17 variables collected using both on-site and off-site sources (Table 3). Smith and Klimas (2002) provide a full description of assessment variables; examples and brief descriptions are provided below. Off-site sources determine the assessment scores for the core area; habitat connection; wetland tract; and flood frequency variables (Figures 6-9). A combination of off-site sources and on-site observations are used to determine cation exchange capacity and soil integrity variables, which measure the degree and extent of soil disturbance. The restored sites lack soil disturbance post restoration; therefore, cation exchange capacity and soil integrity variables receive a score of 1.o (the highest possible score).

Direct field measurements address each of the remaining variables using data collected within a 0.04 ha sample plot and associated sub-plots and transects established at each sample location (Figure 10). Microdepressional ponding quantifies the percentage of each sample plot characterized by concave features capable of retaining water (Figure 11). Tree basal area examines the diameter of each tree within the 0.04 ha sample plot. The density of trees and snags within the sample plot is determined, along with the species composition of the highest strata (Figure 12). Sapling-shrub density measurements utilize 0.004 ha subplots. Woody debris and log biomass determinations utilize measurements conducted along linear transects (Figure 13). One meter square subplots are used to characterize ground vegetation cover, O horizon biomass, and $\mathrm{A}$ horizon biomass (Figure 14).

Following the measurement of each assessment variable, the variables are standardized and converted into variable subindex scores. Subindex scores vary from 0.0 to 1.0 (Figure 15; Smith and Klimas 2002). Once generated, variable subindex scores are combined to determine wetland functional capacity scores as described below. 
Table 3. Summary of rapid assessment variables, description, and sampling technique.

\begin{tabular}{|c|c|c|}
\hline Rapid assessment variable & Description & Sampling technique \\
\hline Core area & $\begin{array}{l}\text { Portion of wetland lying within } \\
100 m \text { buffer }\end{array}$ & Measured from aerial photo/GIS layer \\
\hline Habitat connections & $\begin{array}{l}\text { Proportion of the wetland } \\
\text { perimeter connected to suitable } \\
\text { habitat }\end{array}$ & Measured from aerial photo/GIS layer \\
\hline Wetland tract & $\begin{array}{l}\text { Contiguous wetland area } \\
\text { adjacent to the wetland }\end{array}$ & Measured from aerial photo/GIS layer \\
\hline Flood frequency & $\begin{array}{l}\text { Frequency of overbank or } \\
\text { backwater flooding }\end{array}$ & $\begin{array}{l}\text { Measured from flood frequency } \\
\text { map/stream gauge data }\end{array}$ \\
\hline Cation exchange capacity & $\begin{array}{l}\text { Cation exchange capacity } \\
\text { change due to soil disturbance }\end{array}$ & Estimated based on soil type \\
\hline Soil integrity & $\begin{array}{l}\text { Proportion of the wetland } \\
\text { exhibiting altered soils }\end{array}$ & $\begin{array}{l}\text { Estimated based on amount of soil } \\
\text { disturbance visible }\end{array}$ \\
\hline Micro-depressional ponding & $\begin{array}{l}\text { Percentage of small topographic } \\
\text { depressions and vernal pool } \\
\text { features }\end{array}$ & $\begin{array}{l}\text { Estimated based on percent of } \\
\text { depressions within sample area }\end{array}$ \\
\hline Tree basal area & $\begin{array}{l}\text { Basal area per hectare; } \\
\text { proportional to tree biomass }\end{array}$ & $\begin{array}{l}\text { Measured DBH of all trees }>7.6 \mathrm{~cm} \text { in } \\
\text { diameter within circular } 0.04 \text { ha plot }\end{array}$ \\
\hline Tree density & Number of trees per ha & $\begin{array}{l}\text { Count of all trees }>7.6 \mathrm{~cm} \text { in diameter } \\
\text { within circular } 0.04 \text { ha plot }\end{array}$ \\
\hline Snag density & $\begin{array}{l}\text { Density of standing dead woody } \\
\text { stems }\end{array}$ & $\begin{array}{l}\text { Count of all snags }>7.6 \mathrm{~cm} \text { in diameter } \\
\text { within circular } 0.04 \text { ha plot }\end{array}$ \\
\hline Tree composition & $\begin{array}{l}\text { Species composition of the } \\
\text { tallest stratum }\end{array}$ & $\begin{array}{l}\text { Percent concurrence with measured } \\
\text { tree quality index within the uppermost } \\
\text { stratum }\end{array}$ \\
\hline Woody debris biomass & $\begin{array}{l}\text { Volume of woody debris biomass } \\
\text { per ha }\end{array}$ & $\begin{array}{l}\text { Count of nonliving stems along a } 3.7 \mathrm{~m} \\
\text { transect }\end{array}$ \\
\hline Log biomass & Volume of log biomass per ha & Count of logs along a $15 \mathrm{~m}$ transect \\
\hline Shrub-sapling density & $\begin{array}{l}\text { Density of saplings and shrubs } \\
\text { per ha }\end{array}$ & $\begin{array}{l}\text { Count of all woody stems within two } \\
0.004 \text { ha plots }\end{array}$ \\
\hline Ground vegetation cover & $\begin{array}{l}\text { Percent cover of herbaceous and } \\
\text { woody vegetation }\end{array}$ & $\begin{array}{l}\text { Visually estimated percentage of ground } \\
\text { covered with herbaceous and woody } \\
\text { vegetation within four } 1 \mathrm{~m}^{2} \text { plots }\end{array}$ \\
\hline O horizon biomass & $\begin{array}{l}\text { Mass of organic matter in the } 0 \\
\text { horizon }\end{array}$ & Measured O horizon thickness \\
\hline A horizon biomass & $\begin{array}{l}\text { Mass of organic matter in the } A \\
\text { horizon }\end{array}$ & Measured A horizon thickness \\
\hline
\end{tabular}


Figure 6. Example of the core area determination at the Alligator restoration site. The red shaded area denotes the area within a $100 \mathrm{~m}$ buffer.

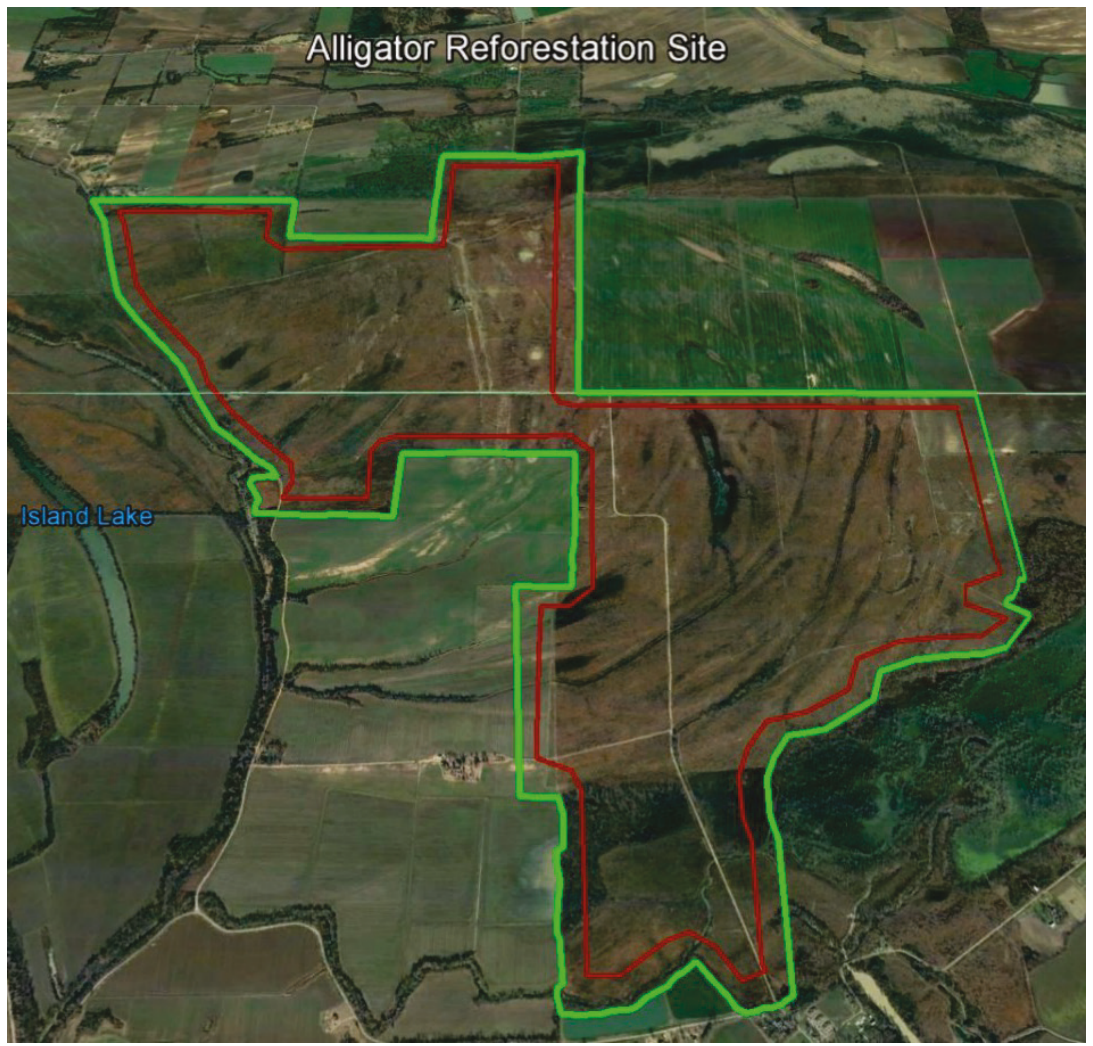

Figure 7. Example of the habitat connection variable at the Polutken restoration site. The yellow line denotes the portion of the site with suitable habitat connection.

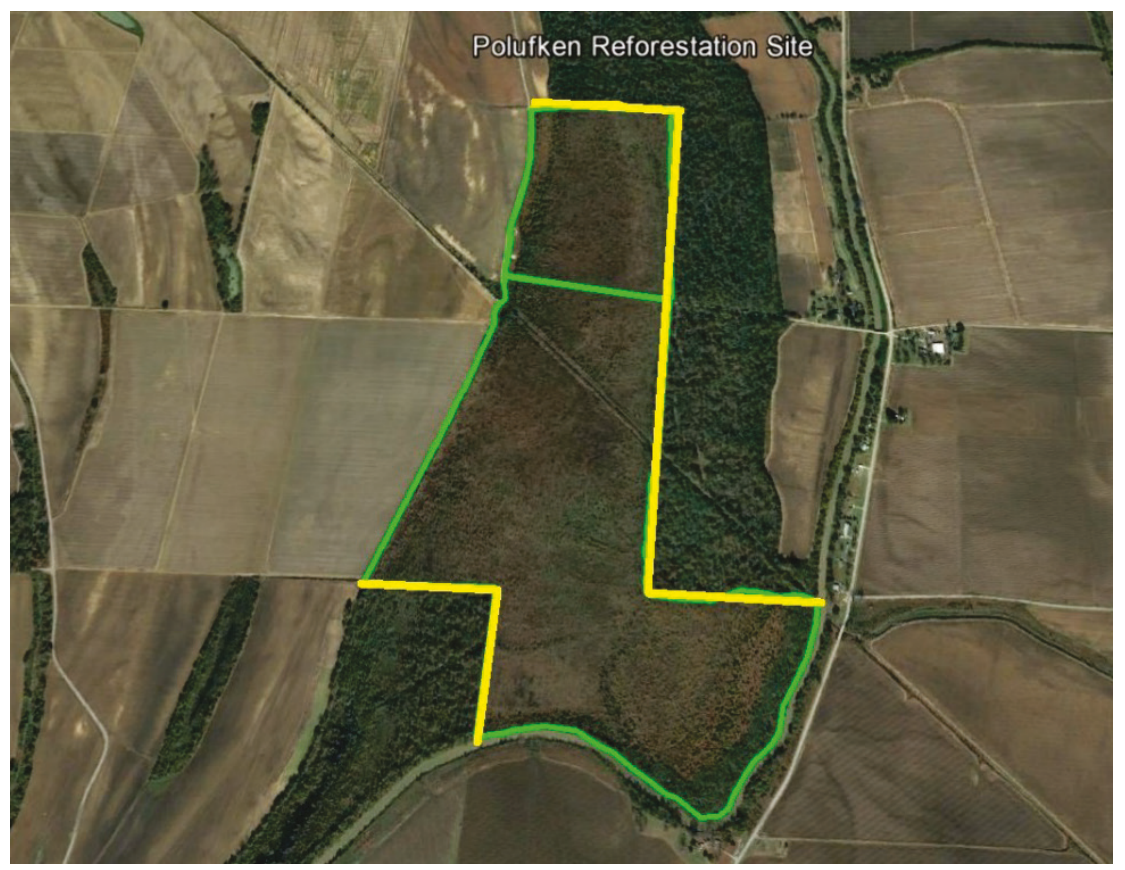


Figure 8. Example of the wetland tract variable at the Stock restoration site. The orange polygons denote the size of suitable wetland features adjacent to the restored area.

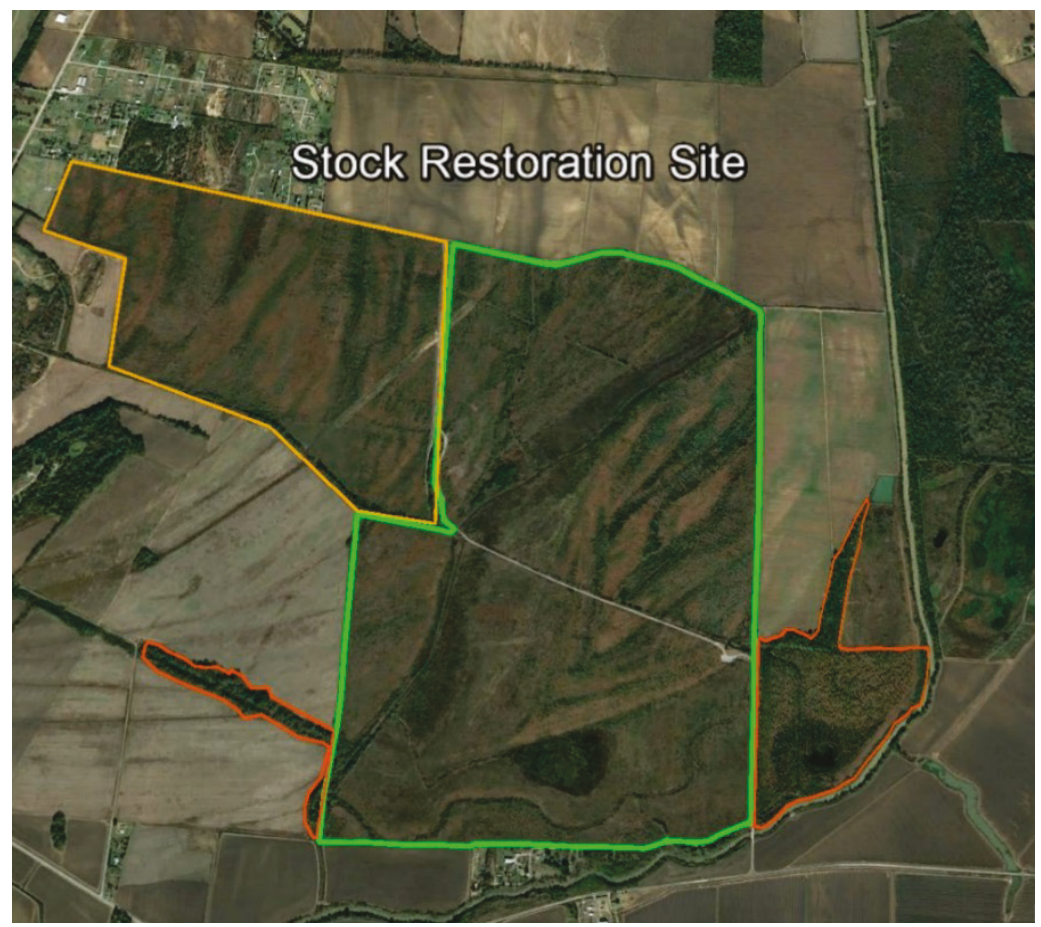

Figure 9. Example of flood frequency within the Kennedy restoration site. The area shaded in blue denotes estimated flood frequencies of $<2$ years, while the red shading indicates an estimated flood return interval of 2-5 years.

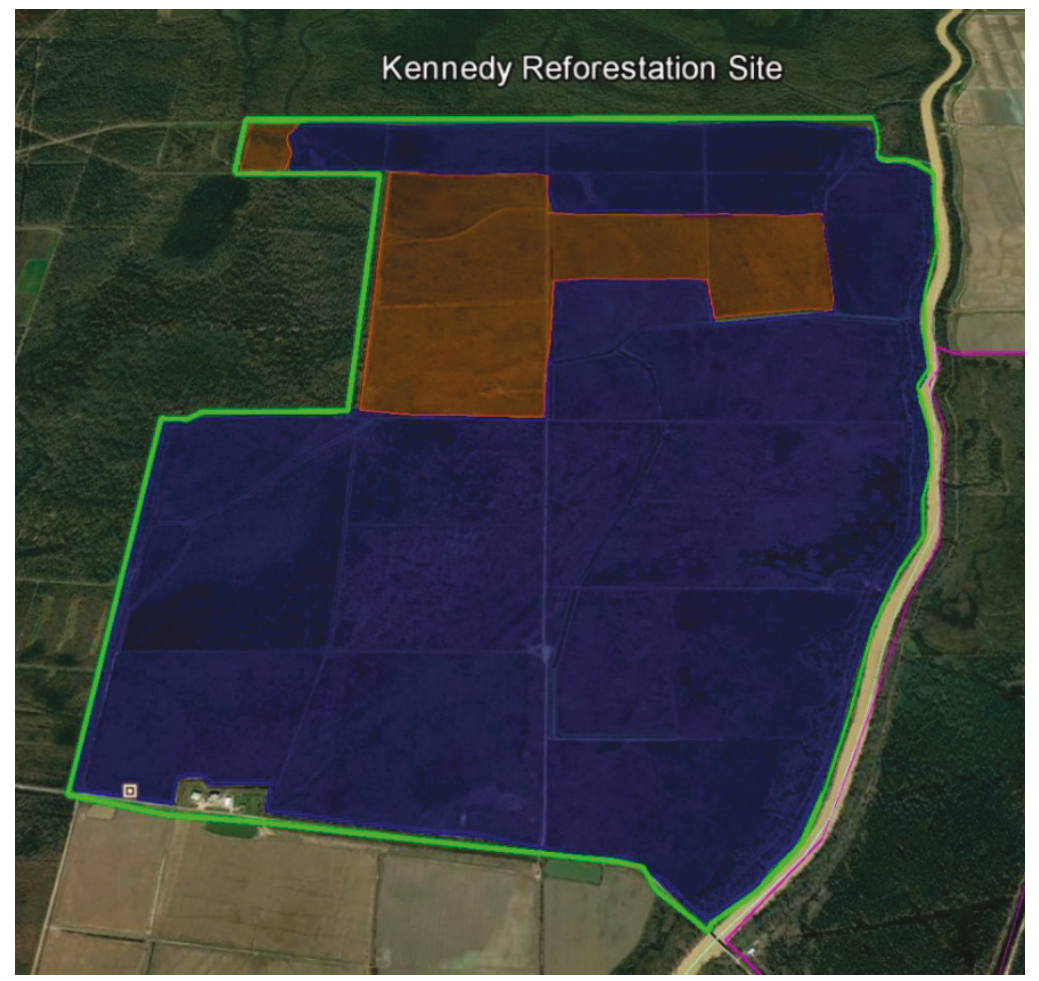


Figure 10. Diagram depicting the sample plot utilized to collect on-site assessment variables at each sample location. The $0.04 \mathrm{~m}$ circle is used to determine tree basal area, tree density, snag density, and species composition. Sapling shrub density is measured

within the 0.004 ha subplots. Ground vegetation cover, A horizon, and 0 horizon determinations utilize the four one-square-meter quadrats. The linear transects are used to measure woody debris and log biomass.

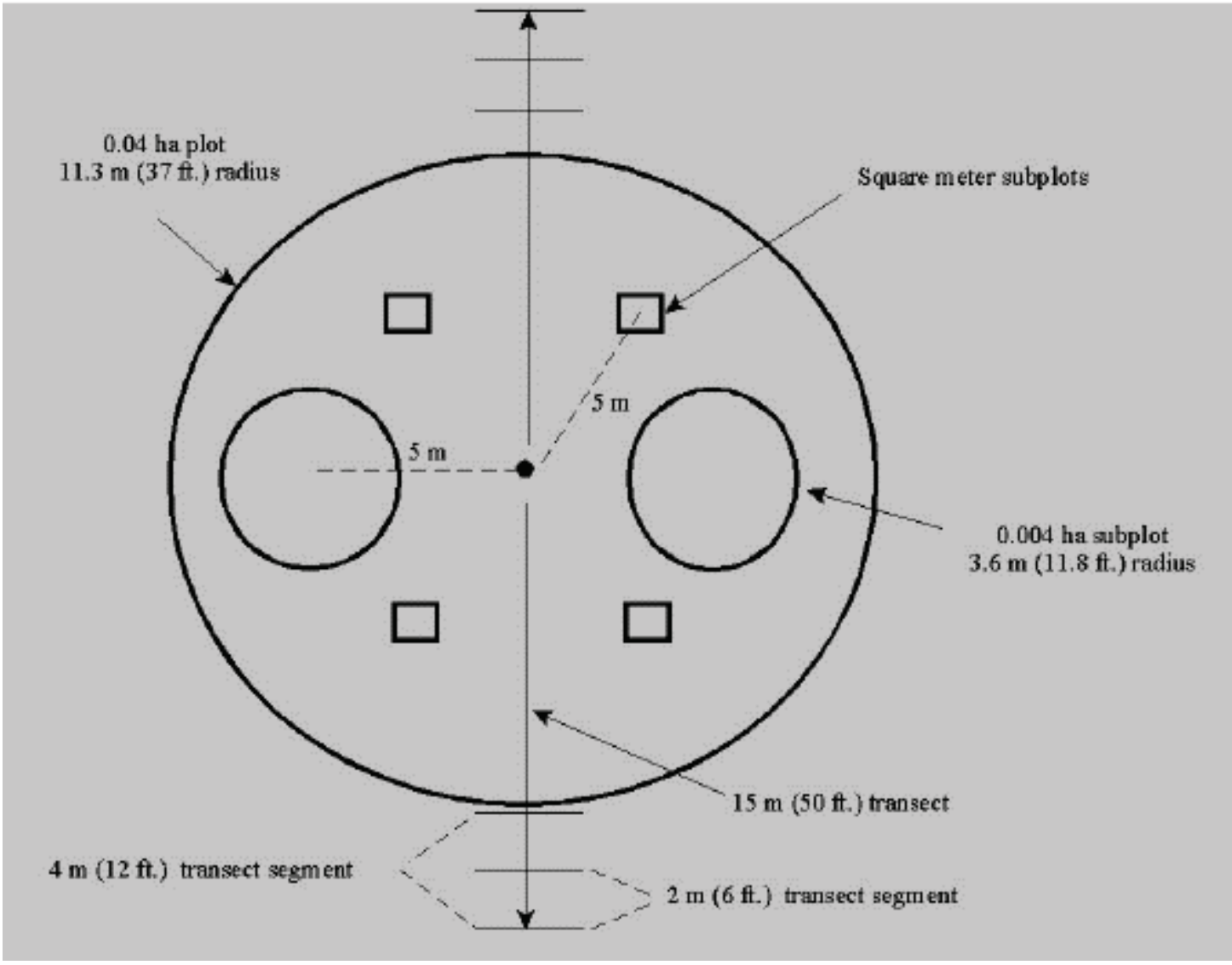


Figure 11. Example of microdepressional ponding within a 20-year-old restoration site.

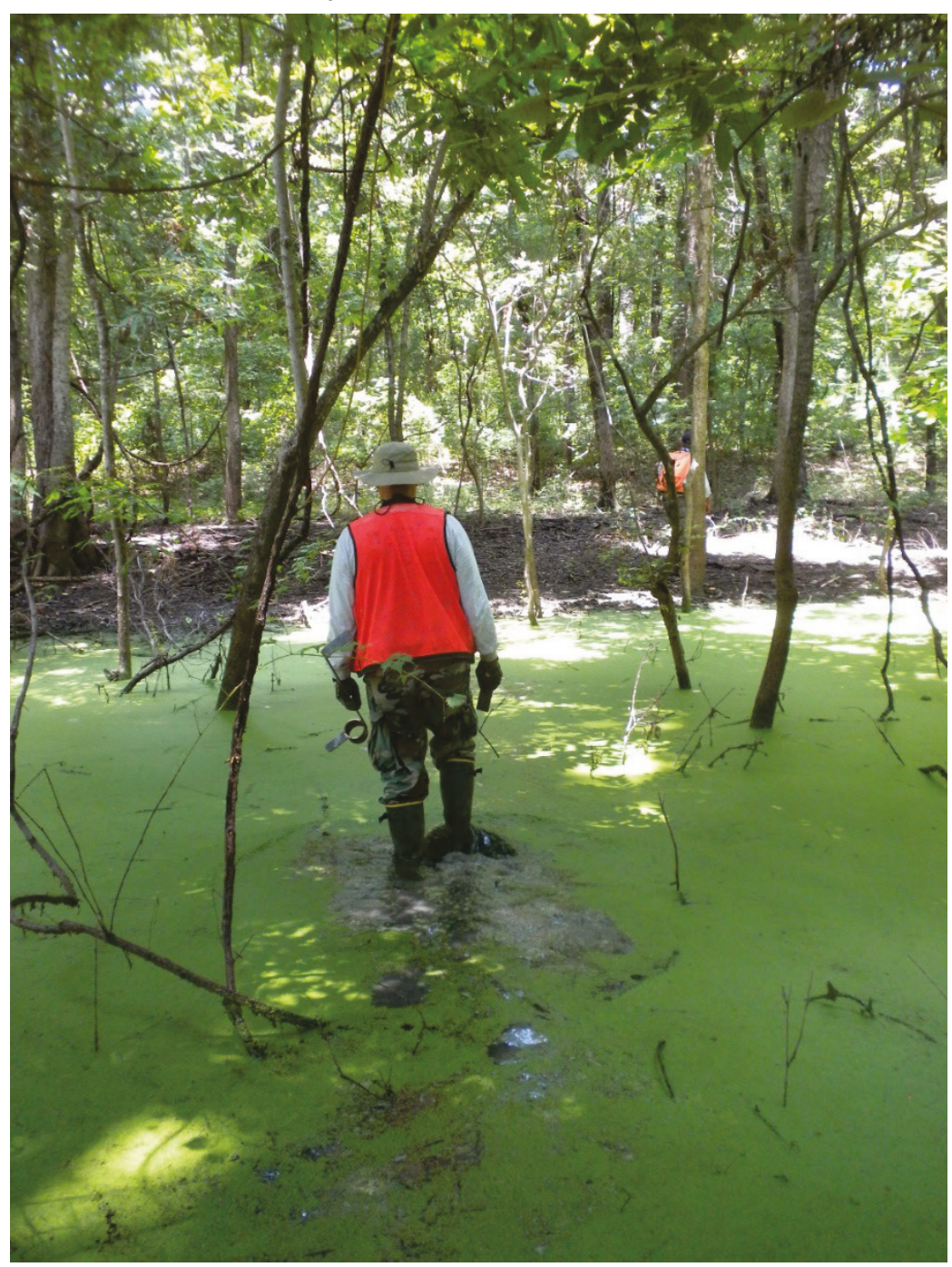


Figure 12. Example of tree diameter measurement within a restored area.

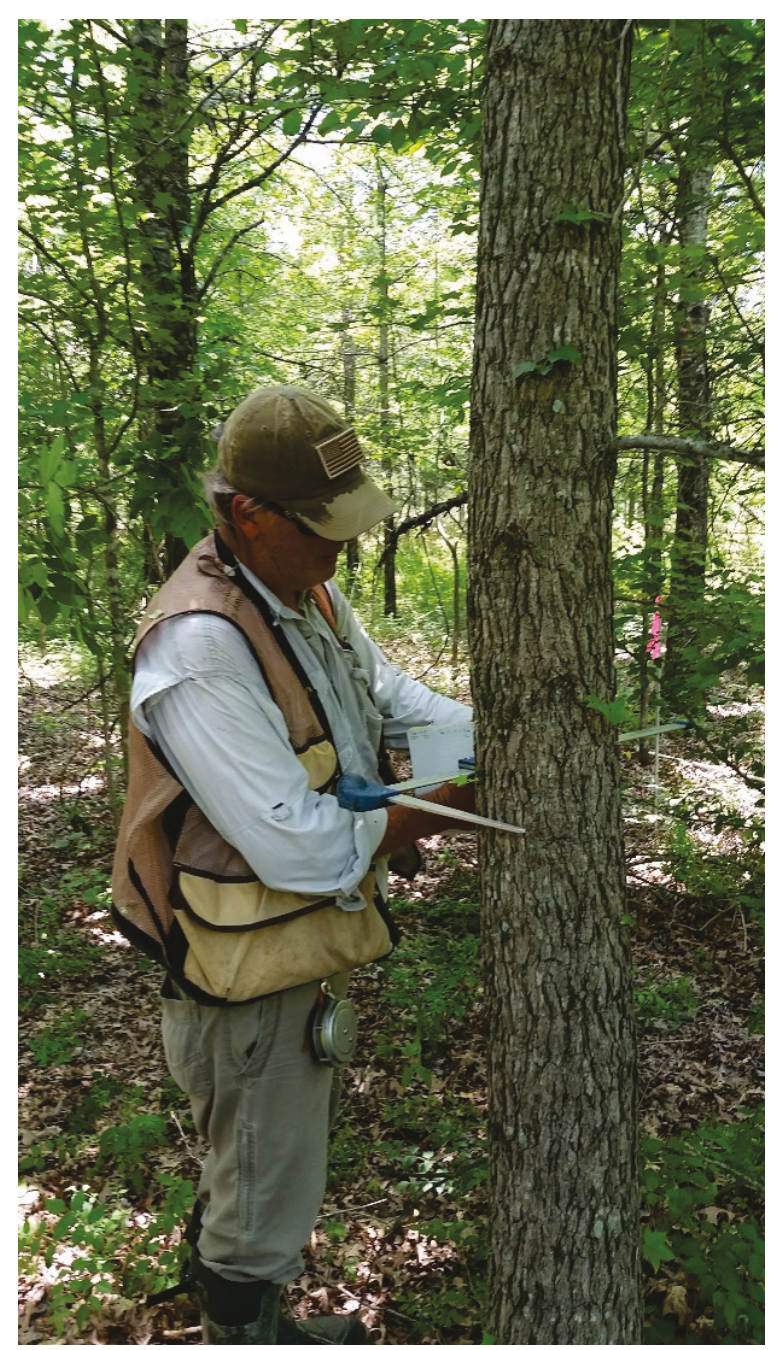


Figure 13. Example of woody debris and log biomass observed at a mature forested location within the region.

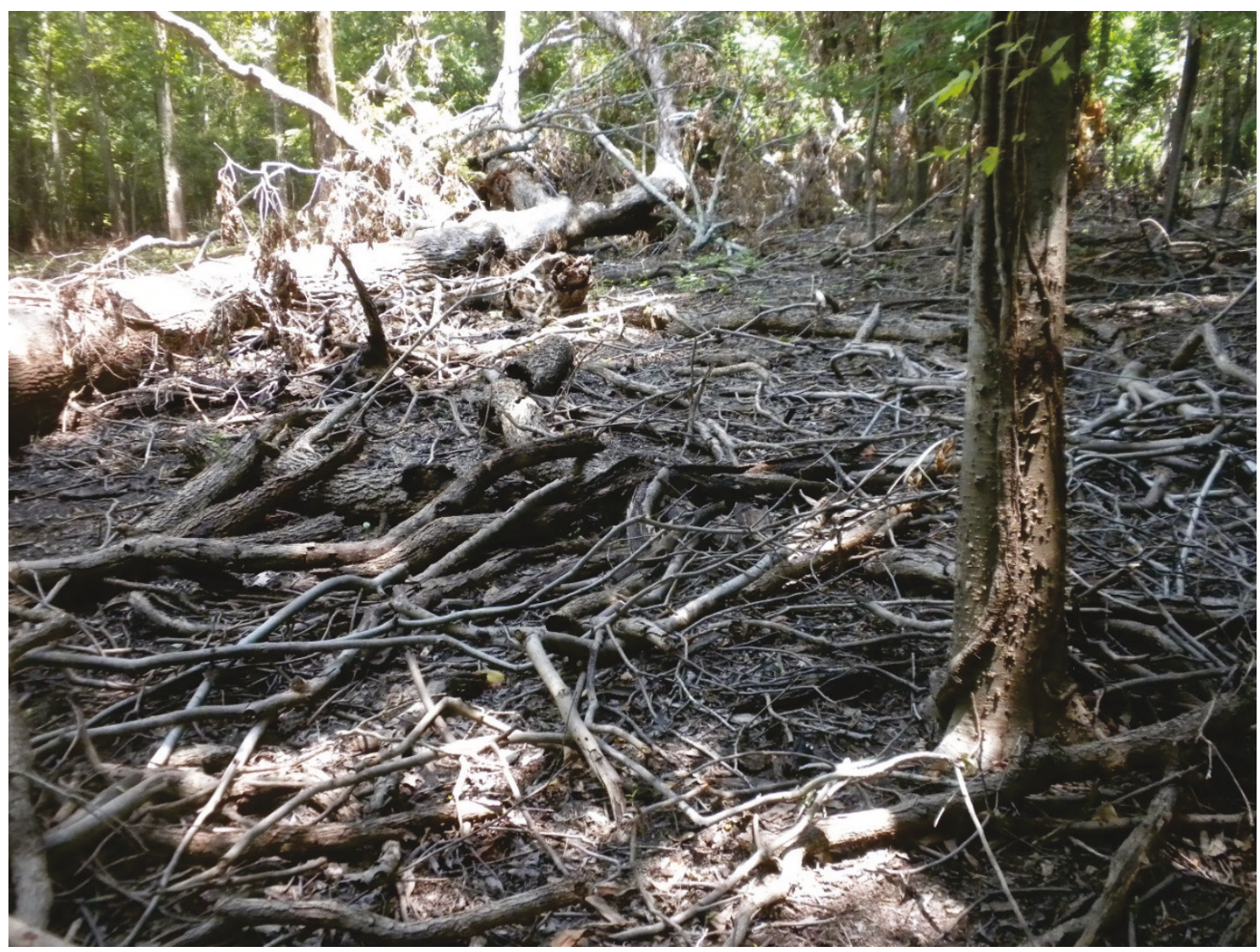


Figure 14. Ground vegetation cover and the thickness of $O$ and $A$ horizons was determined within four one-square-meter subplots at each sampling location.

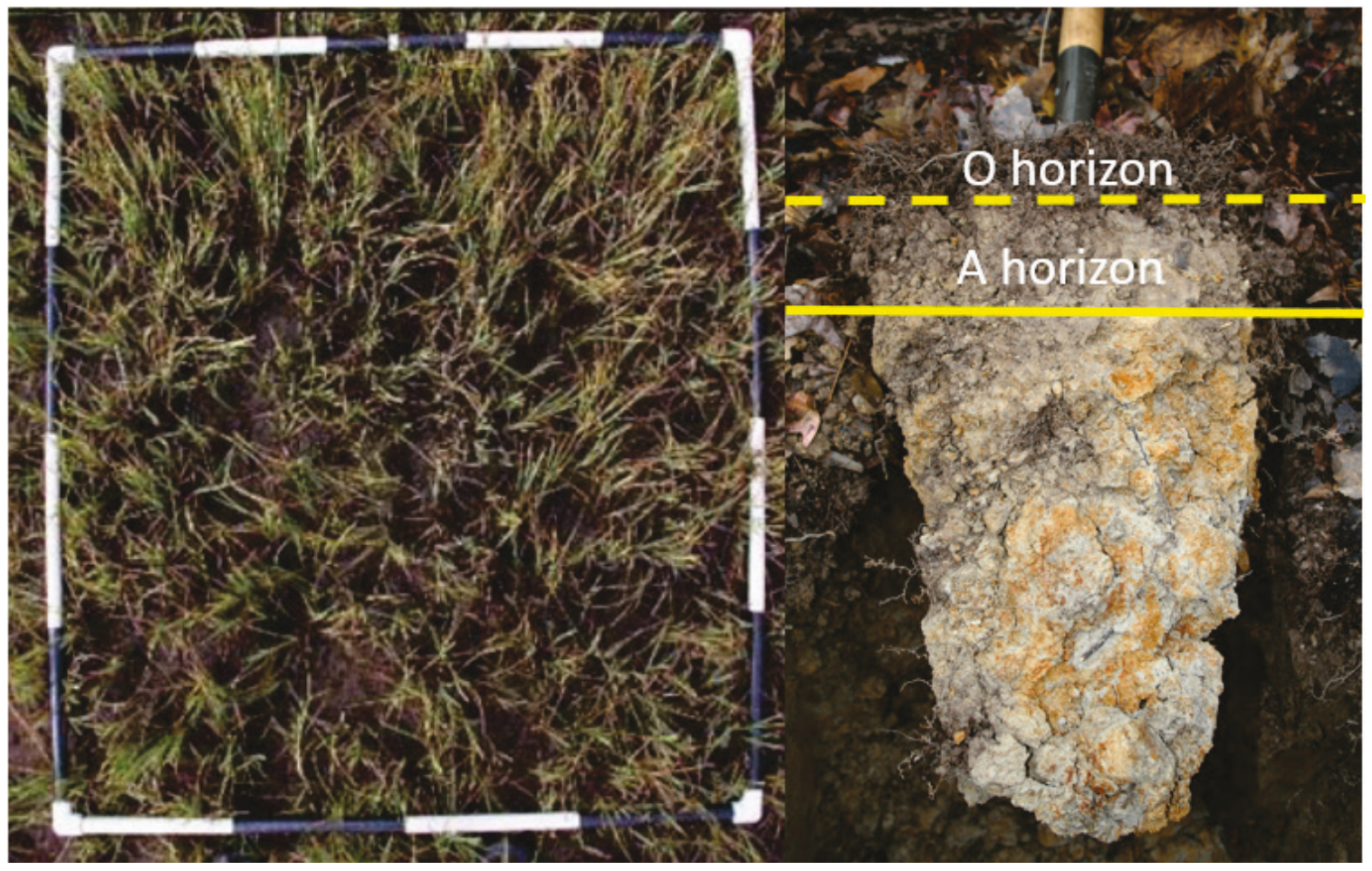

Figure 15. Example of wetland assessment variable standardization and conversion to variables subindex scores. Note that the ground vegetation cover data collected at each sample location as a percentage corresponds to a value on the standardized 0.0 to 1.0 subindex scale.

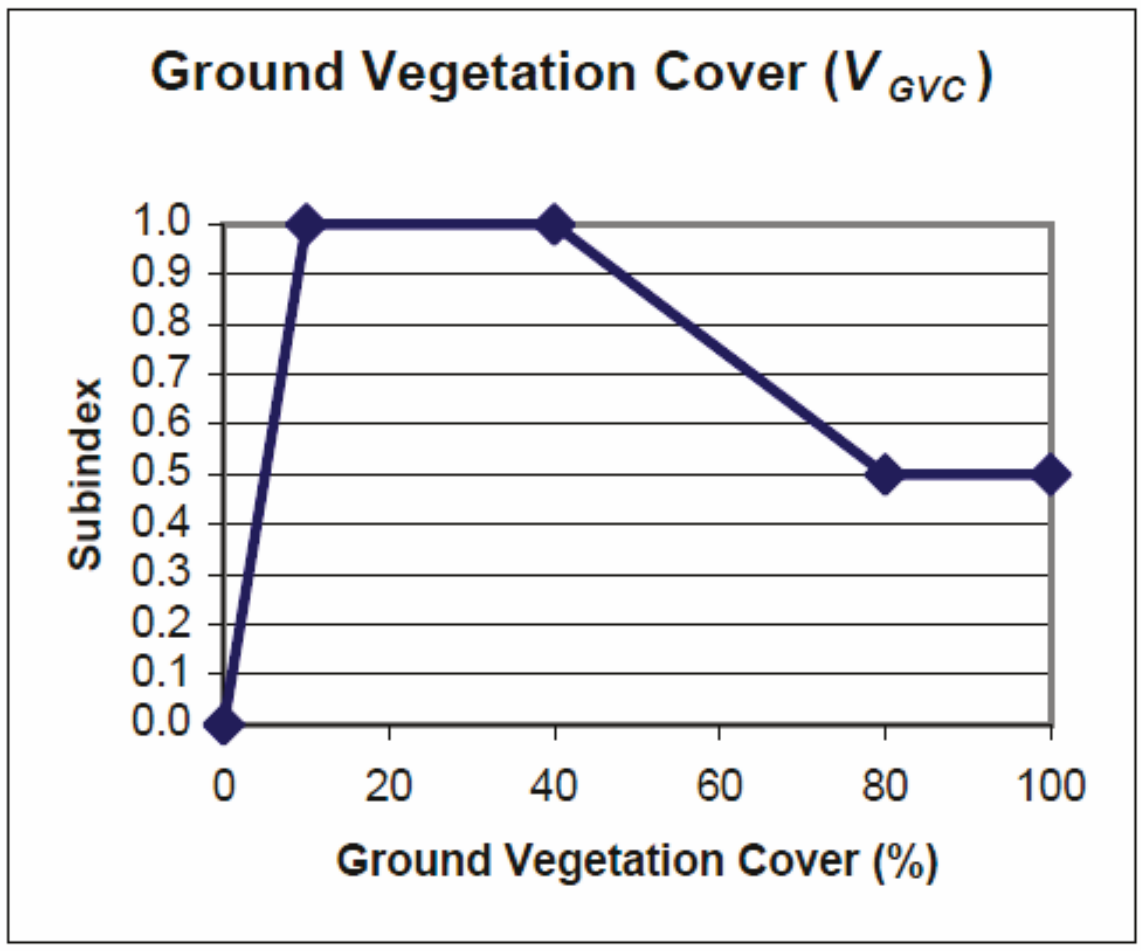




\subsection{Wetland functions}

The HGM guidebook developed for the region addresses seven wetland functions (Table 4). Functional assessment scores utilize empirical equations that combine variable subindex scores, with appropriate weighting factors (Smith et al. 2013). Smith and Klimas (2002) provide a full description of each function. The wetland functions addressed at each restoration site fall into three categories related to wetland hydrology, biogeochemical cycling, and habitat (Noble and Berkowitz 2016). Hydrology functions include a wetlands capacity to detain floodwater and precipitation. Biogeochemical cycling functions include the capacity to cycle nutrients, export organic carbon, and remove elements and compounds. Habitat functions encompass how wetlands maintain characteristic plant and animal communities.

\subsection{Sampling and analysis approach}

Transects were established at each restoration site (Figure 16). When practicable, transects incorporated sample locations monitored during previous assessments (Lin 2009; others). Along sample transects, multiple sample locations were established. The distribution of sample transects and sampling intensity varied depending upon the size and heterogeneity of restoration sites, with more sample points occurring in larger, more diverse locations (Table 1). Each assessment variable was quantified at each sample location (Figure 10; Table 3). Monitoring results were converted to variable subindex scores, and the wetland functional capacity indices were determined based upon the equations presented in Table 4. 
Figure 16. Island Lake restoration site (green line) displaying example of transects (red lines) along which sampling locations were established.

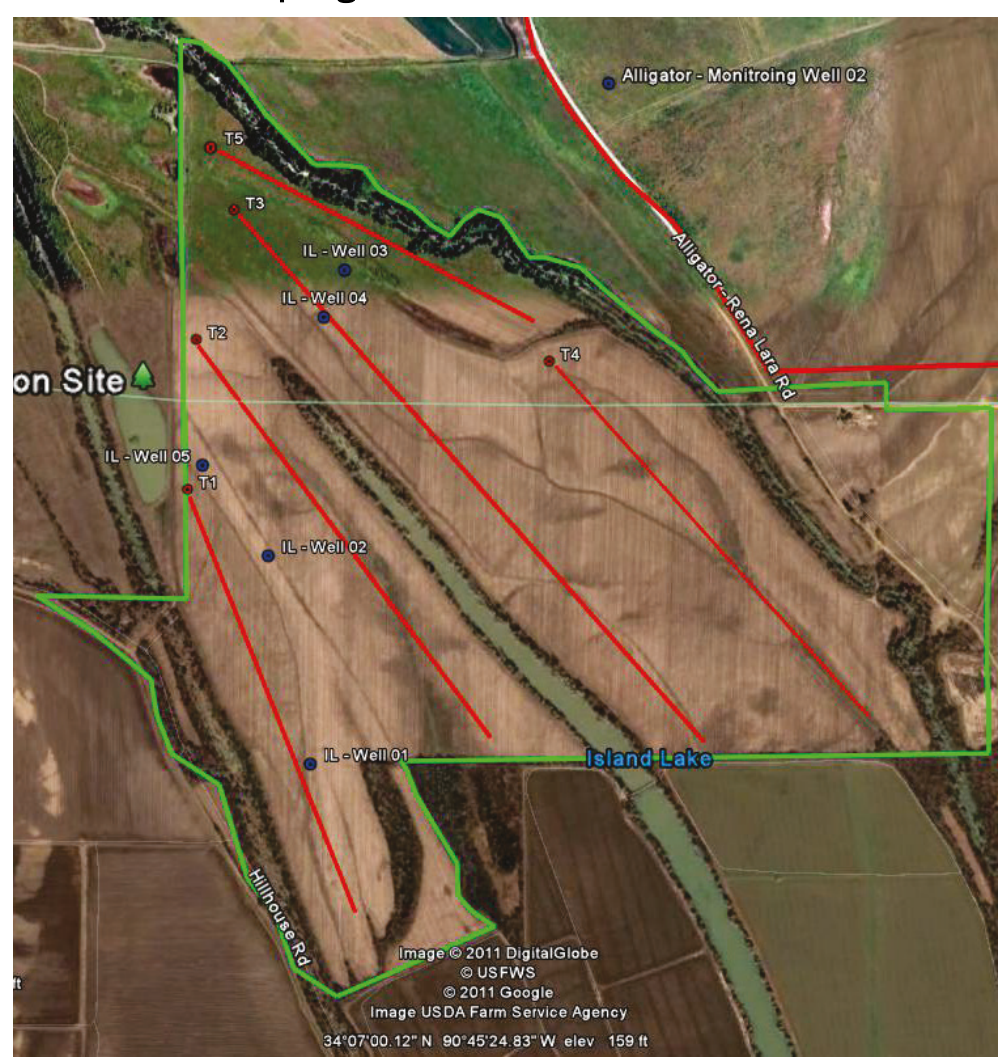


Table 4. Wetland functions assessed at each restoration site using the HGM approach.

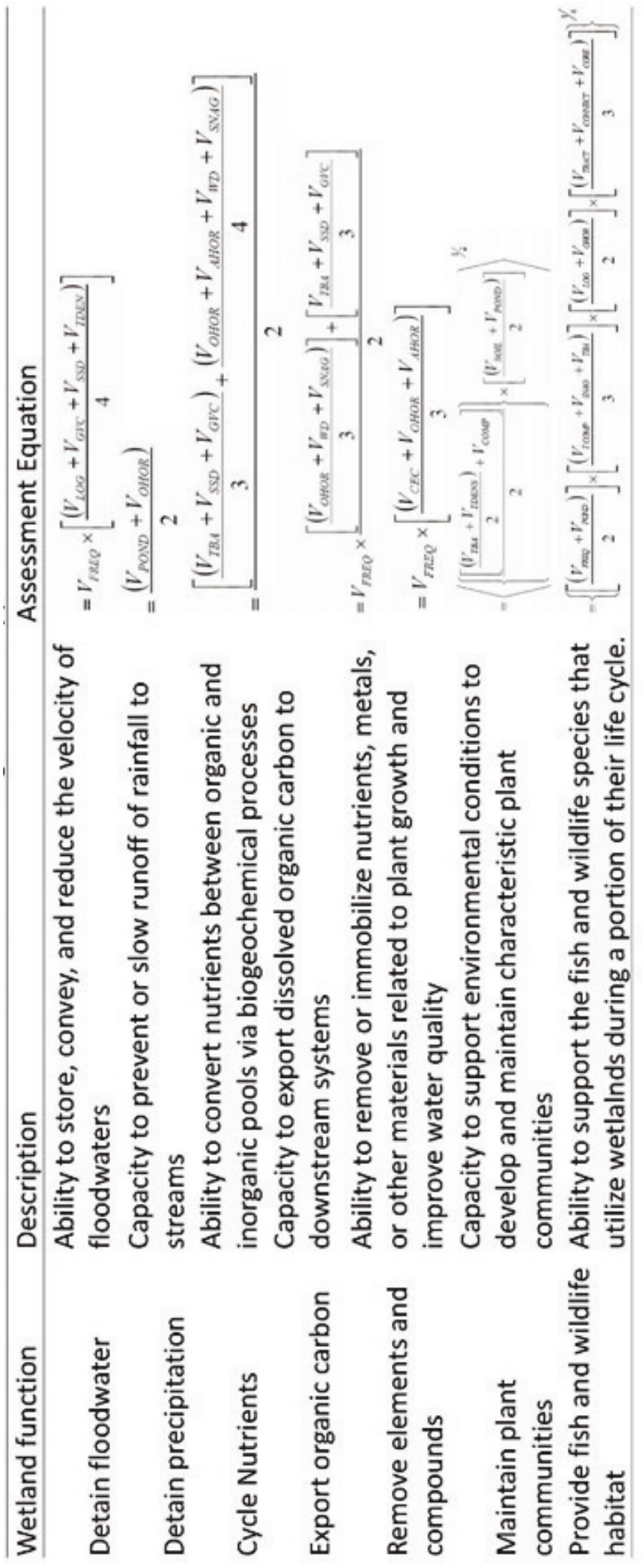


Intra- and intersite variability statistical analysis was conducted for the 606 sample locations evaluated in 2016. Statistical analysis utilized analysis of variance (ANOVA) where assumptions of normality (Shapiro-Wilk test) and homogeneity of variance (Levene's test) were met. Data were square root or $\log$ transformed as needed to meet model assumptions. Post-hoc testing utilized the LSD and Tukey tests. The non-parametric KruskalWallis statistical test evaluated differences between restoration age classes when data failed to meet model assumptions. All statistical significance was evaluated at the $\alpha=0.05$ level. Assessment metrics (variables) and functional scores were considered dependent factors, with age classes applied as grouping variables. Placing sample locations into age classes increased statistical power. Age class (years) and sample size [n] were as follows: 5 [97], 10 [61], 13 [209], 20 [96], 25 [193] (Table 1). 


\section{Results and Discussion}

The sections below evaluate (1) changes in wetland assessment variables across the restoration chronosequence, (2) wetland restoration trajectory response curves, (3) functional score increases over the restoration chronosequence, (4) intrasite increases in wetland function over time, and (5) comparison of restoration site conditions with mature reference forest conditions in the region. Examining monitoring data using this approach highlights the progression of restoration sites and provides supporting evidence of the ecological drivers increasing functional assessment scores as restored forests undergo additional growth and succession.

\subsection{Wetland assessment variables}

At each restoration site, the seventeen assessment variables were evaluated to complete the HGM wetland functional assessment. Based upon the findings of Berkowitz (2013), assessment variables can be classified as (1) rapid response variables, (2) response variables requiring additional time (e.g., > 15 years) to display a measureable effect, and (3) stable variables that remain relatively fixed over time. For example, previous studies documented changes in sapling-shrub density within a few years after restoration occurred, while variables such as tree basal area often require longer time periods to display significant increases (15-20 years; Berkowitz 2013; Smith and Klimas 2002). Conversely, assessment variables including flood frequency, wetland tract size, and habitat connectivity often remain stable over time, due to landscape factors (i.e., property boundaries, presence of levees, etc). As a result, the following analysis focuses on the sub-set of assessment variables expected to change within the restoration project timeframes examined in the restoration chronosequence ( $\mathrm{o}-$ 26 years; Table 1). Appendix A provides statistical analysis data (p-values) for each of the assessment variables examined within the chronosequence.

During the 2016 sampling effort, staff noted substantial increases in tree diameter and other factors across the restoration sites compared to site evaluations conducted in previous years (Table 2). Evaluating the restoration chronosequence, statistically significant increases in tree basal occurred (Figure 17). The HGM assessment technique evaluates trees with a diameter at breast height $\geq 10 \mathrm{~cm}$ ( 4 in.). This diameter was first encountered at a subset of 10-year stands, with significant increases documented in 13-20-year stands, and further improvements at the 25-year 
restoration increment. Tree density data displayed similar results, with incremental increases in tree density occurring within the restoration sites (Figure 18). As noted above, the HGM assessment approach examines trees with diameters $\geq 10 \mathrm{~cm}$ ( $4 \mathrm{in}$.). As a result, Figure 18 represents a combination of (1) incorporation of planted trees entering the 10centimeter-size class and (2) recruitment of naturally regenerated trees into restored areas. Tree densities remained statistically significant across all age classes ten years after restorative planting occurred. The observed increases in tree basal area and density support the predictions of Berkowitz (2013), who categorized them as response variables, providing reliable measures of restoration success after a period of approximately 15-20 years post-restoration.

Woody debris biomass inputs are expected to increase in response to higher basal area and tree density values, which provide additional sources of woody debris (e.g., loss of branches). Monitoring results indicate a linear rise in woody debris across the restoration chronosequence, with significantly more woody debris detected 13,20 , and 25 years postrestoration (Figure 19). Further additions of high woody debris biomass are anticipated as stand development continues into the stem exclusion phase of forest succession (Oliver and Larson 1996).

Ground vegetation cover follows predicted patterns post-restoration in which coverage increases following cessation of agricultural activities (e.g., plowing, crop removal), then decreases as transient species are recruited to taller strata and canopy cover approaches closure, reducing the quantity and quality of available light (Figures 20 and 21). These values coincide with results reported in Berkowitz (2013), in which ground cover displayed initial increases to approximately $75 \%$ after 15 years of restoration. Older ( $>20$ years) forests exhibited ground cover values near 20\%. Saplingshrub density data displayed similar patterns, with initial increases followed by sharp declines as restoration site succession progressed (Figure 22). Within 25 years, sapling shrub densities returned to values observed during post restoration conditions. Both ground vegetation cover and sapling shrub density were identified as rapid response variables in Berkowitz (2013). The current dataset further supports those findings.

In summary, the assessment variables examined display expected responses to restoration. Rapid response variables (e.g., ground vegetation cover, sapling shrub density) show initial increases followed by anticipated 
decline. Response variables (e.g., tree basal area, woody debris) continue significant increases as predicted across the restoration chronosequence. Monitoring efforts must focus on the subset of variables with the potential for change detection as forest succession continues across the restored wetlands (Berkowitz 2013). As a result, static variables (e.g., flood frequency) are not included in the current analysis.

Soil horizon development (A and O horizon) both display increases over the restoration chronosequence, with significant differences detected 25 years post-restoration (Figure 23). Results appear more variable than previously observed by Berkowitz (2013); however, the long-term trends suggest that restored areas continue to progress.
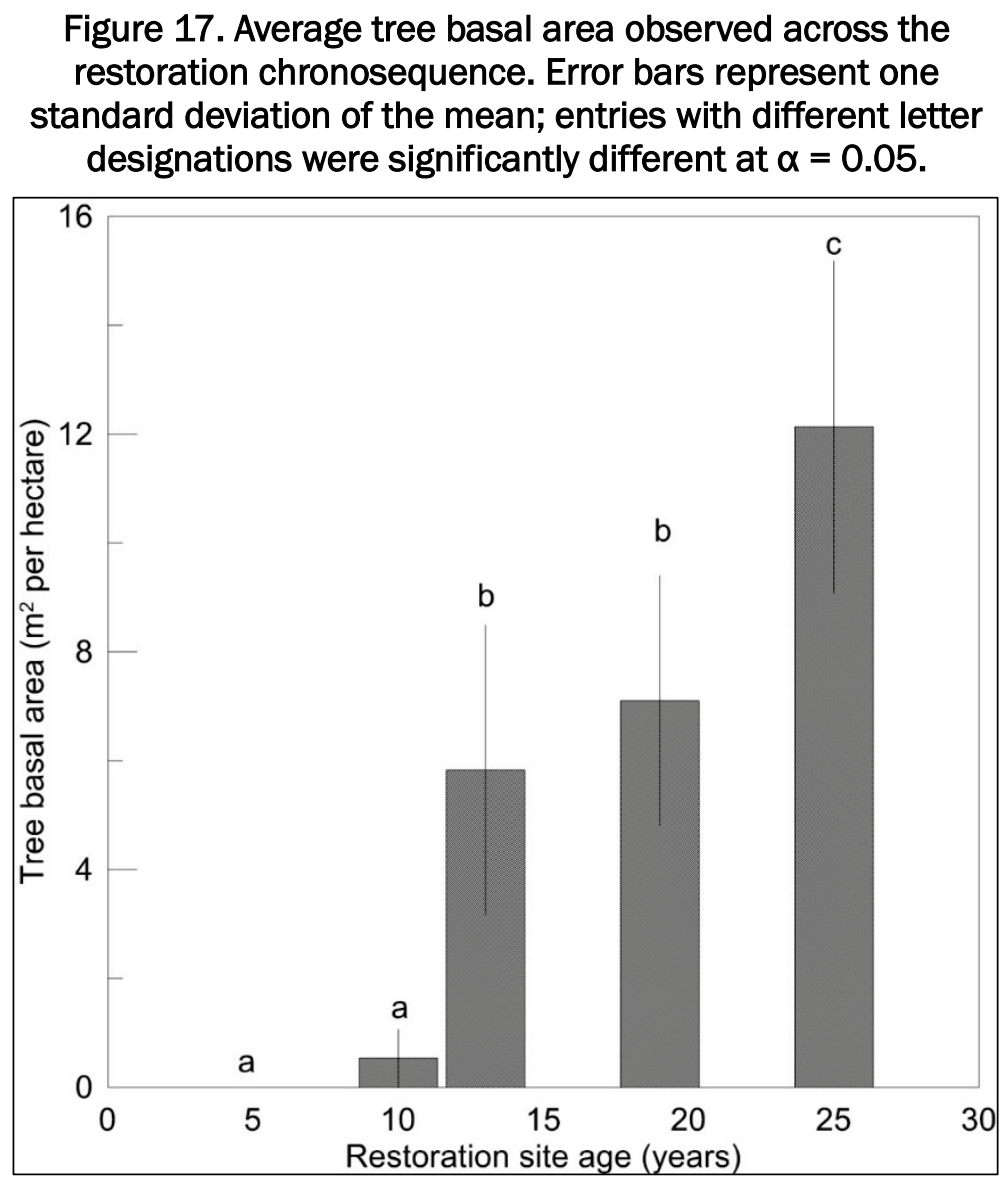
Figure 18. Average tree density observed across the restoration chronosequence. Error bars represent one standard deviation of the mean; entries with different letter designations were significantly different at $\alpha=0.05$.

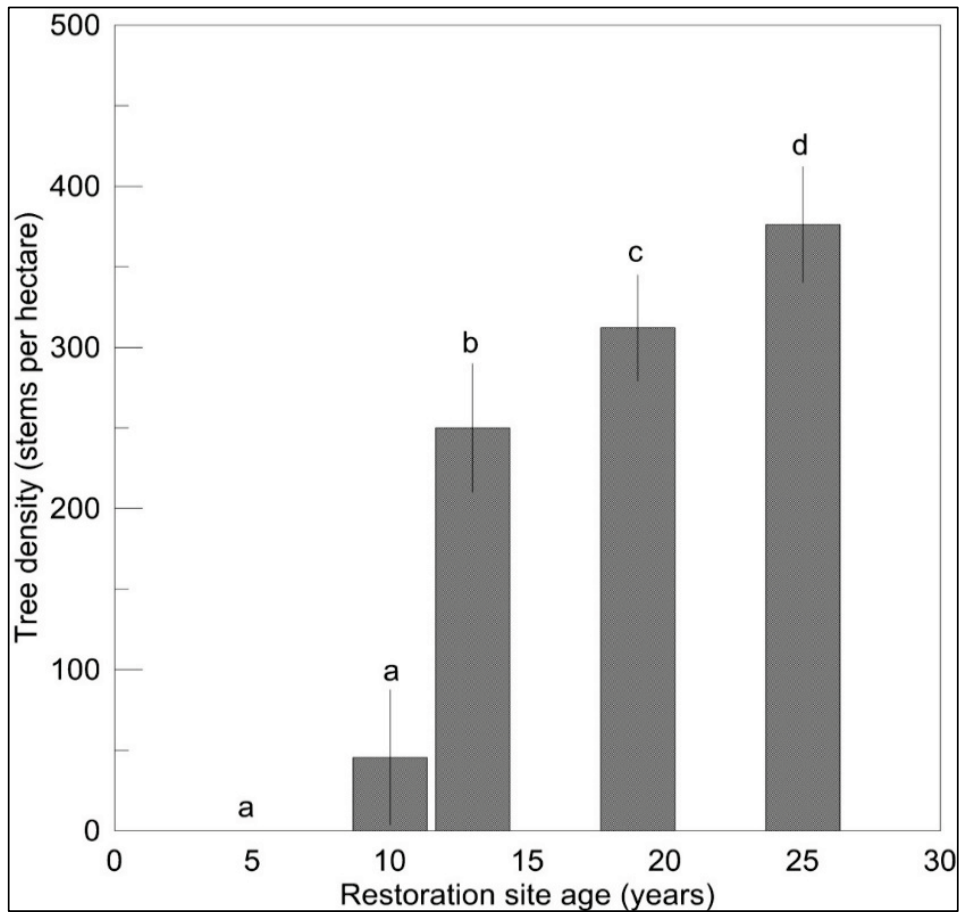

Figure 19. Average woody debris biomass observed across the restoration chronosequence. Error bars represent one standard deviation of the mean; entries with different letter designations were significantly different at $\alpha=0.05$.

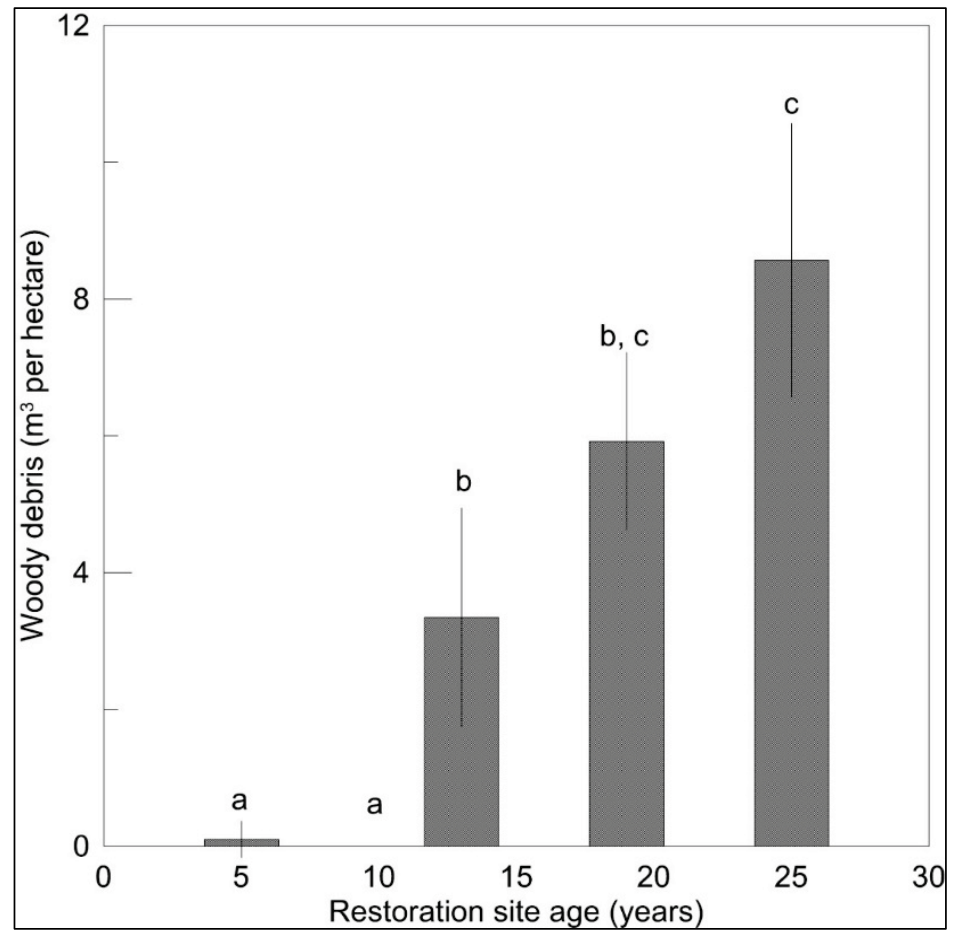


Figure 20. Average ground vegetation cover observed across the restoration chronosequence. Error bars represent one standard deviation of the mean; entries with different letter designations were significantly different at $\alpha=0.05$.

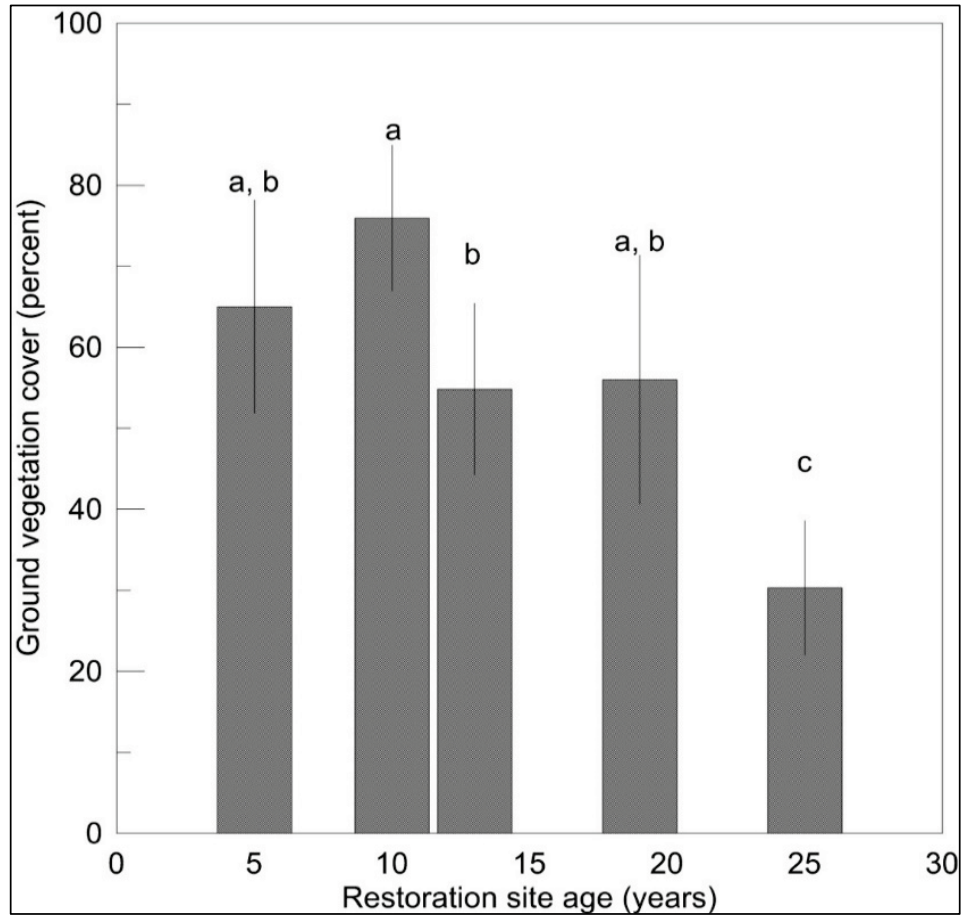

Figure 21. (A) Canopy cover (dashed line) leads to light limitation (solid line), resulting in the shading out of understory species occurring between 15 and 20 years following reforestation (based upon data within Bigelow et al. (2011) and Summers (2010)). (B) Log-transformed data displaying threshold effect of forest age as observed in ground vegetation cover and sapling-shrub density data presented in Berkowitz (2013). Note the apex and subsequent decline occurring at approximately $15-20$ years following reforestation.
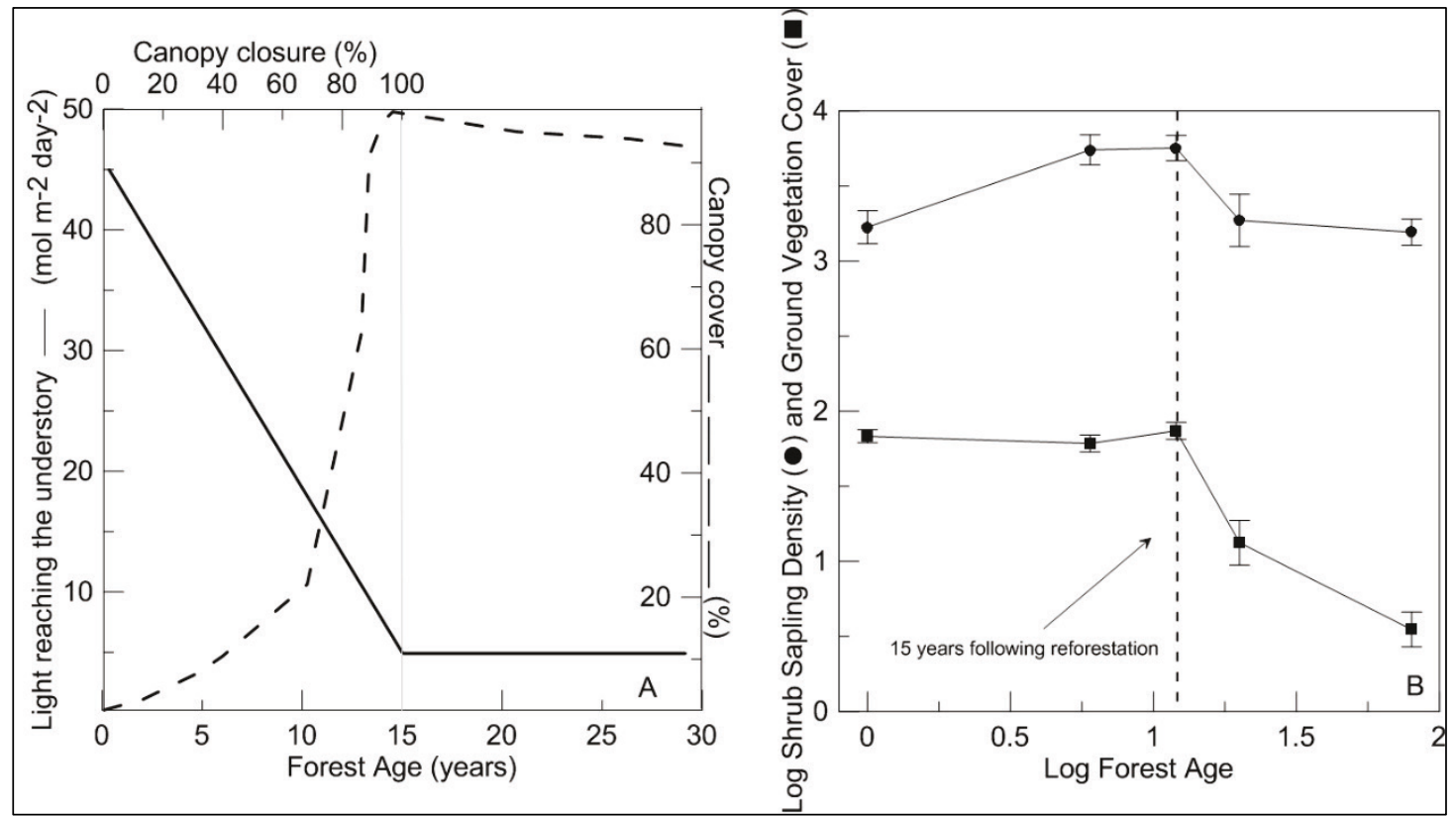
Figure 22. Average sapling shrub density observed across the restoration chronosequence. Error bars represent one standard deviation of the mean; entries with different letter designations were significantly different at $\alpha=0.05$.

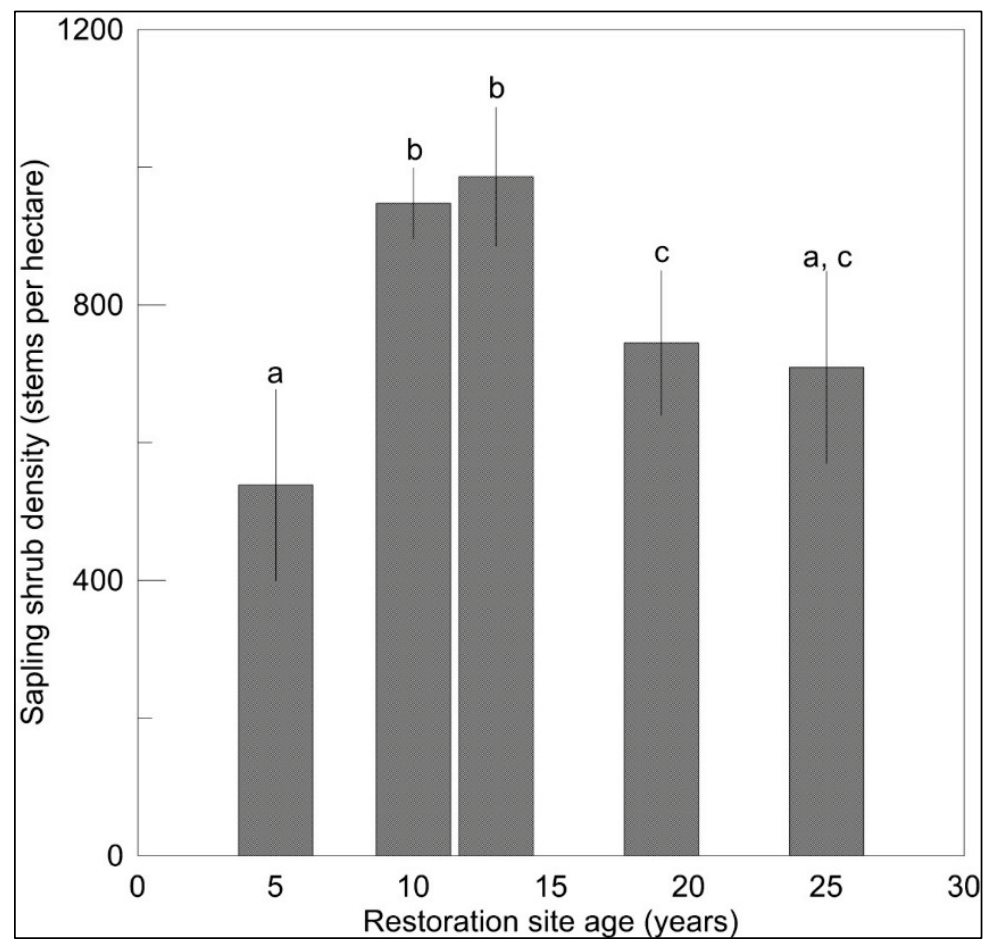

Figure 23. Average A (left) and 0 (right) horizon thickness observed across the restoration chronosequence. Error bars represent one standard deviation of the mean; entries with different letter designations were significantly different at $\alpha=0.05$.

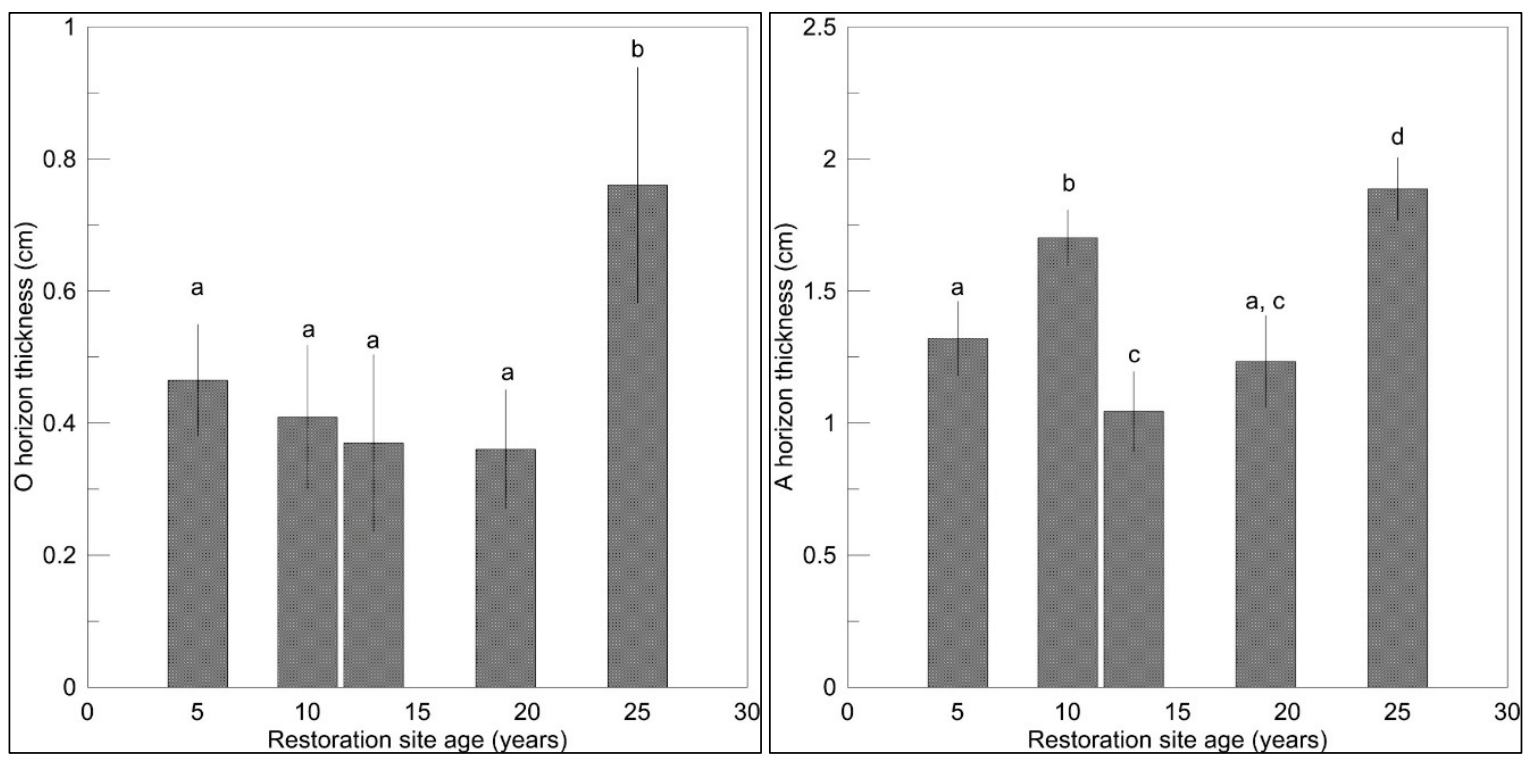




\subsection{Restoration trajectory curves}

Smith and Klimas (2002) developed anticipated restoration (i.e., recovery) trajectory curves for a subset of the assessment variables included in the HGM wetland functional assessment (Figure 24). An analysis of restoration site progress based upon the estimated trajectory curves is provided below, comparing restoration sites with anticipated outcomes. It should be noted that the estimated trajectories provided in Smith and Klimas (2002) represent generalized approximations, not specific to wetland type or restoration technique. Log biomass and snag density are not expected to increase within the first 20 years of restoration; as a result, they are not evaluated in the current analysis.

Average tree basal area measurements agree with or exceeded expected results across the restoration chronosequence (Figure 24). Tree basal areas of $0.53 \pm 0.26 \mathrm{~m}^{2} / \mathrm{ha}$ (average and standard deviation) were observed in 10-year-old stands, outpacing the predicted onset of trees with a diameter at breast height $\geq 10 \mathrm{~cm}$ ( 4 in.). Thirteen years post restoration, average basal areas increased to $5.8 \pm 0.5 \mathrm{~m}^{2} / \mathrm{ha}$, exceeding the $3.6 \mathrm{~m}^{2} / \mathrm{ha}$ predicted. Basal areas continue to increase with stand age, with average values of $12.1 \pm 3.1 \mathrm{~m}^{2} /$ ha corresponding well with the anticipated basal areas of $15 \mathrm{~m}^{2} /$ ha within 25 years of restoration.

Examining tree density recovery trajectory curves, tree densities follow predicted results in the early years after restoration planting (Figure 24). For example, 13-year-old stands displayed average tree densities of $250 \pm$ 36 stems/ha, which compares well with the predicted value of 240 stems/ ha. Notably, the tree density is expected to decrease in subsequent years as restoration sites near canopy closure initiate stem exclusion (Figure 24; Berkowitz 2013). In fact, canopy closure was observed at a subset of older restoration sites during the $\mathbf{2 0 1 6}$ data collection effort. The average tree density of $376 \pm 36$ stems/ha was documented at 25-year-old restored sites. This data demonstrates that restoration plantings were conducted at the appropriate density, as indicated within 20- and 25-year-old stands, which currently display the desired density observed at fully mature reference wetlands in the region ( 300 stems/ha; Lockhart et al. 2010). 
Figure 24. Expected recovery trajectory curves relating forest stand age to anticipated assessment variable measurements (from Smith and Klimas 2002). Note, a 50-year period of analysis is used in USACE planning activities for the purpose of offsetting unavoidable impacts and other mitigation activities.
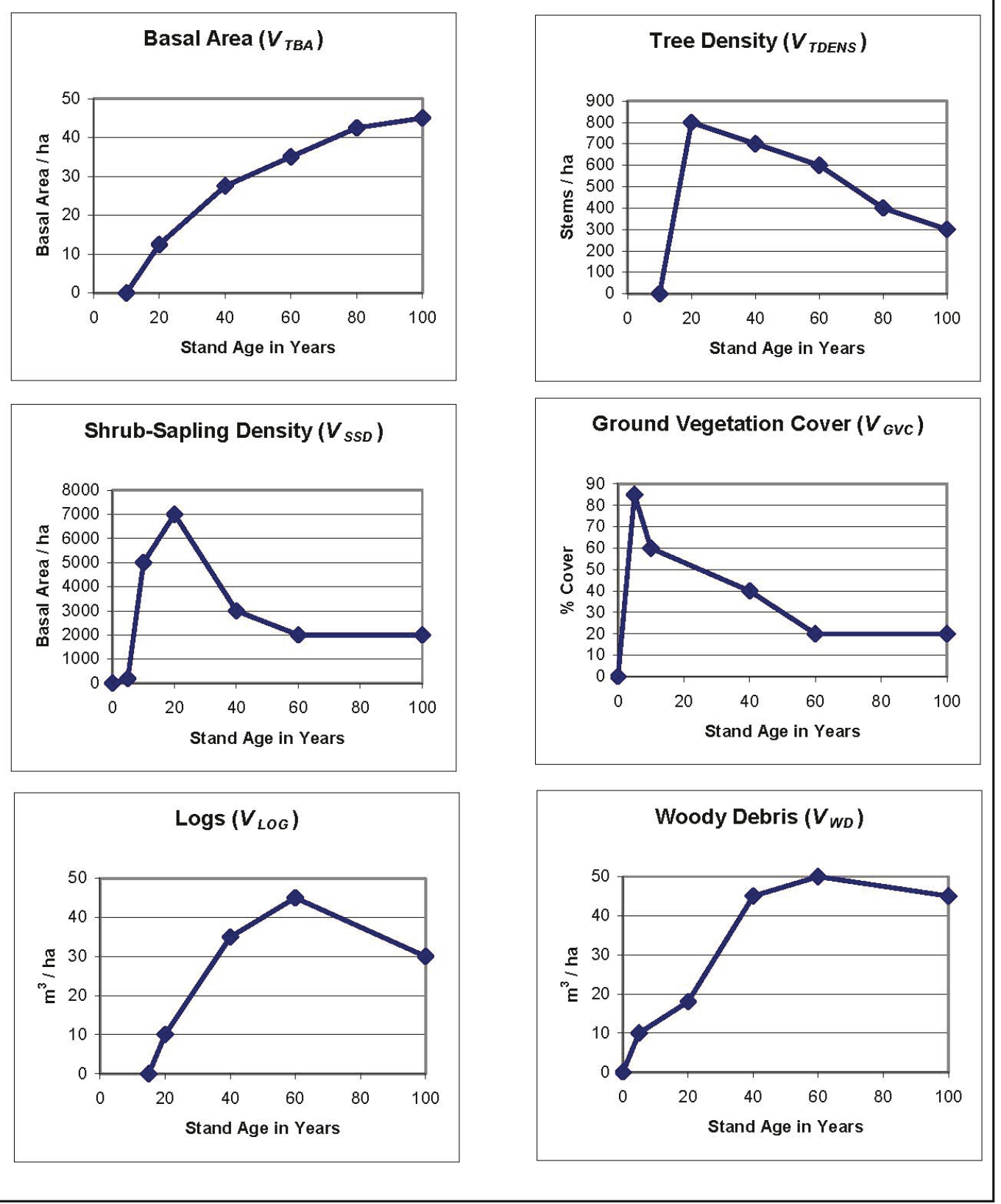

Similar results are observed in ground vegetation cover data, with 13- and 20-year-old restoration sites ( $55 \pm 10 \%$ and $56 \pm 15 \%$, respectively) in alignment with the $58 \%$ and $53 \%$ groundcovers predicted by Smith and Klimas (2002; Figure 24). The 25-year restoration sites (30 \pm 8\%) appear to outpace the expected declines in ground vegetation cover (50\%) with 
older restoration sites trending towards the $20 \%$ cover anticipated in mature bottomland hardwood forests.

Sapling-shrub densities follow the pattern outlined in Smith and Klimas (2002), in which densities increase following restoration, with a subsequent decline (Figures 21 and 24). However, the observed values from field sampling remain well below the predicted values at all restoration stand age classes. Woody debris data also lag behind predicted values, with average values of $9 \pm 2 \mathrm{~m}^{3} / \mathrm{ha}$ after 25 years, well behind the anticipated $20 \mathrm{~m}^{3} / \mathrm{ha}$. However, with the observed onset of canopy closure, a rapid increase in woody debris is anticipated within the next five years (Figure 21).

O horizon development is expected to occur over 40 years post restoration, resulting in $\mathrm{O}$ horizon over $2 \mathrm{~cm}$ thick. Soil data collected 10 years postrestoration agree with projected results, with average $\mathrm{O}$ horizon thickness of $0.41 \pm 0.1 \mathrm{~cm}$ corresponding with the $0.33 \mathrm{~cm}$ expected (Smith and Klimas 2002; data not shown). Older restoration sites lagged slightly behind anticipated findings, with $\mathrm{O}$ horizons averaging $0.79 \pm 0.2 \mathrm{~cm}$ after 25 years, compared to the expected value of $1.0 \mathrm{~cm}$. Despite the lag, a subset of monitoring locations exceed soil horizon depths, with values reaching as high as $2.8 \mathrm{~cm}$, which exceeds the 15 year/cm O horizon development rate reported by Buol et al. (2001).

In summary, several of the assessment variables examined meet (e.g., tree basal area) or exceed (e.g., ground vegetation cover) the anticipated milestones based on estimated recovery trajectory curves and remain on pace to reach reference standard conditions. Each of the variables display appropriate patterns (e.g., sapling shrub density, woody debris), although in some cases, observed values fail to reach trajectory curve predictions. These variable scores are expected to further develop as forest succession continues. Tree density data demonstrate that appropriate stocking rates were implemented during restoration, resulting in tree densities corresponding to mature forests as reported in Smith and Klimas (2002). Additional data examining log and snag density variables can be incorporated into future monitoring efforts as restoration sites enter the stem exclusion phase of forest succession.

\subsection{Wetland functional scores}

Seven wetland functions were evaluated at each restoration site based upon the assessment equations outlined in Table 4 (Smith and Klimas 2002). 
Functional scores vary from 0.0, representing a lack of functional benefits, to 1.0, which indicates functions equivalent to mature reference standard bottomland hardwood forests in the region (Smith et al. 2013). The following section examines changes in each functional score across the restoration chronosequence. A discussion of the drivers behind functional increases is also provided. Appendix A provides statistical analysis data (p-values) for each of the assessment functions examined within the chronosequence.

The detain floodwater function displayed statistically significant increases across the restoration chronosequence, most notably within the 20- and 25-year age classes (Figure 25). The increases in functional scores result from improvements in ground vegetation, sapling shrub density, and tree density assessment variable scores (Table 4). The functional scores are anticipated to improve further as these variables continue to improve time. Additional functional boosts will result from the incorporation of $\log$ biomass scores as forest succession continues.

The detain precipitation function also showed significant increases across the restoration chronosequence (Figure 26 ), with $>13 \%$ of the 606 restoration sample locations currently exhibiting the maximum possible score (1.0). As a result, more than one in six of the restored sample locations examined are providing this function at levels expected in mature, reference standard bottomland hardwood forests in the region. The amount of micro-depressional ponding and the $\mathrm{O}$ horizon biomass influence the detain precipitation function. Functional scores continue to increase; however, the rate remains limited at locations by the time required for organic matter accumulation in surface soil horizons and forest succession to increase concave landscape features via tree throw and other mechanisms.

The cycle nutrients function displayed significant increases during the monitoring period, especially at 20- and 25-year restoration intervals (Figure 27). The average nutrient cycling function in the oldest restored areas exceeded 0.5, demonstrating continued improvement over previous monitoring efforts. Seven assessment variables related to carbon accumulation and processing (e.g., tree basal area, O horizon thickness) drive the nutrient cycling functional score. As a result, continued tree growth, soil horizon development, and the generation of woody debris and snags will result in higher nutrient cycling scores in the future. 
The export organic carbon function scores showed similar results, with significantly higher values documented at 25-year-old restoration sites (Figure 28). Notably, flood frequency represents a major component of the export organic carbon function, accounting for $50 \%$ of the assessment score. As a result, export organic carbon functional scores will remain limited at restoration sites with flood frequency return intervals $>2$ years. Conversely, some locations (e.g., Kennedy restoration site) that display flood frequency return intervals $<2$.o years show increased functional outcomes shortly after restoration. This explains the higher values observed at the 5-year-old restored sites in Figure 28. The remaining assessment variables serve as proxy measures of carbon availability (e.g., woody debris biomass). With increasing site maturity, above- and belowground carbon stocks will continue to grow, resulting in higher export organic carbon functional scores over time.

The remove elements and compounds function display results similar to the export organic functions discussed above, with the flood frequency return interval accounting for $50 \%$ of the functional assessment score (Table 4). The remaining variables (i.e., soil cation exchange capacity, $\mathrm{O}$ and A horizon thickness) each account for $16 \%$ of the functional assessment score. As a result, restored locations with flood return intervals $<2$ years receive higher scores for the remove elements and compounds function. This accounts for the high scores observed within the 5- and 10-year restoration intervals. Notably, the 13-, 20-, and 25-year restoration intervals with frequent flood return intervals $>2$ years show statistically significant increases in functional scores (Figure 29) due to improvements in the soil horizon variables. Functional scores are expected to increase further as soil horizon development continues. 
Figure 25. Detain floodwater functional scores across the restoration chronosequence. Error bars represent one standard deviation of the mean; entries with different letter designations were significantly different at $\alpha=0.05$.

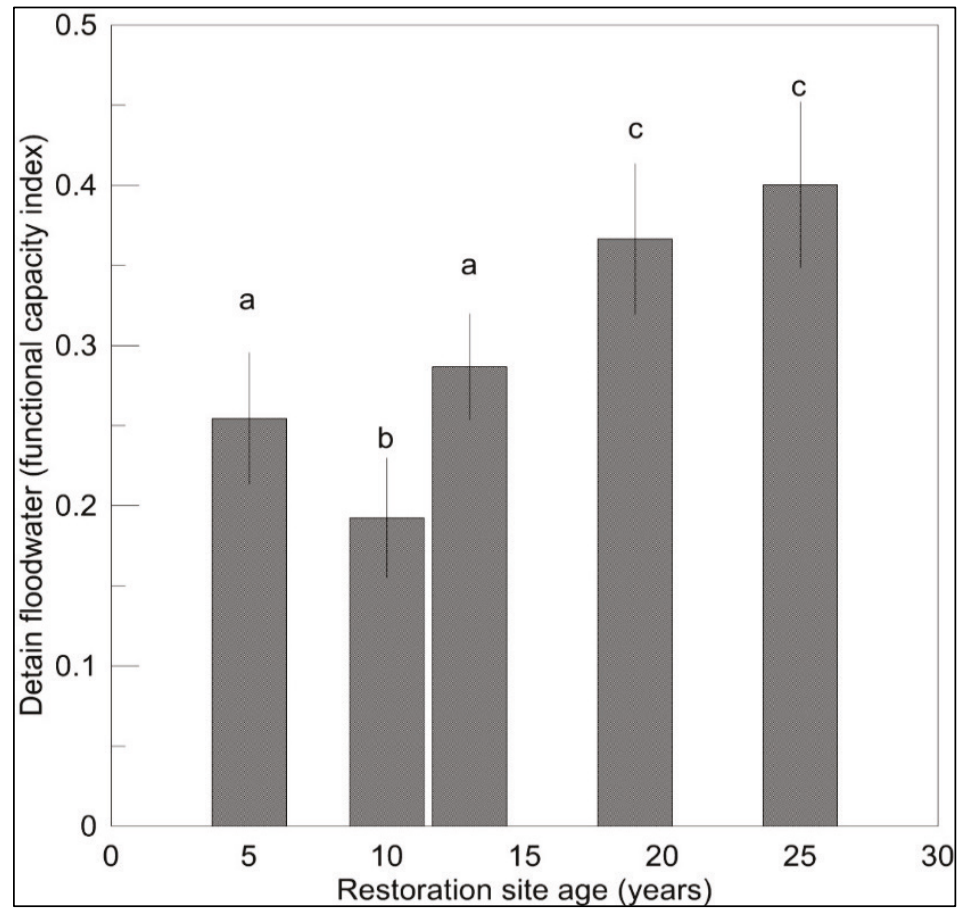

Figure 26. Detain precipitation functional scores across the restoration chronosequence. Error bars represent one standard deviation of the mean; entries with different letter designations were significantly different at $\alpha=0.05$.

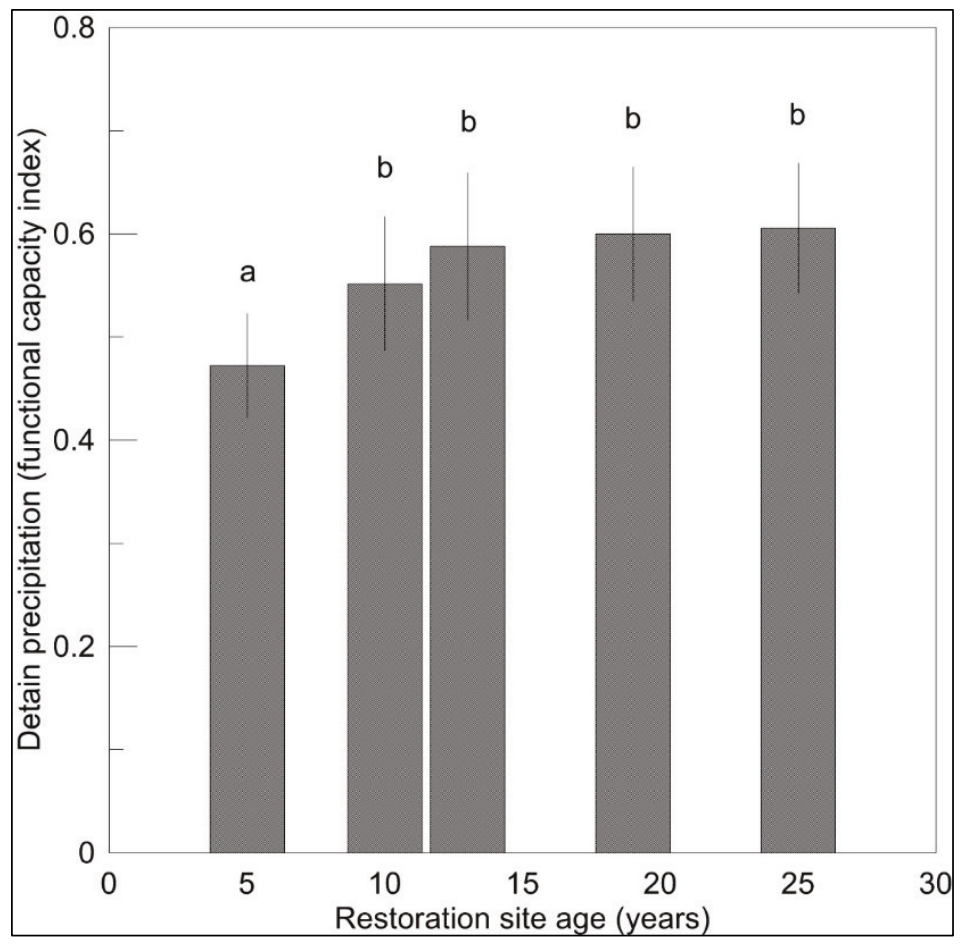


Figure 27. Cycle nutrients functional scores across the restoration chronosequence. Error bars represent one standard deviation of the mean; entries with different letter designations were significantly different at $\alpha=0.05$.

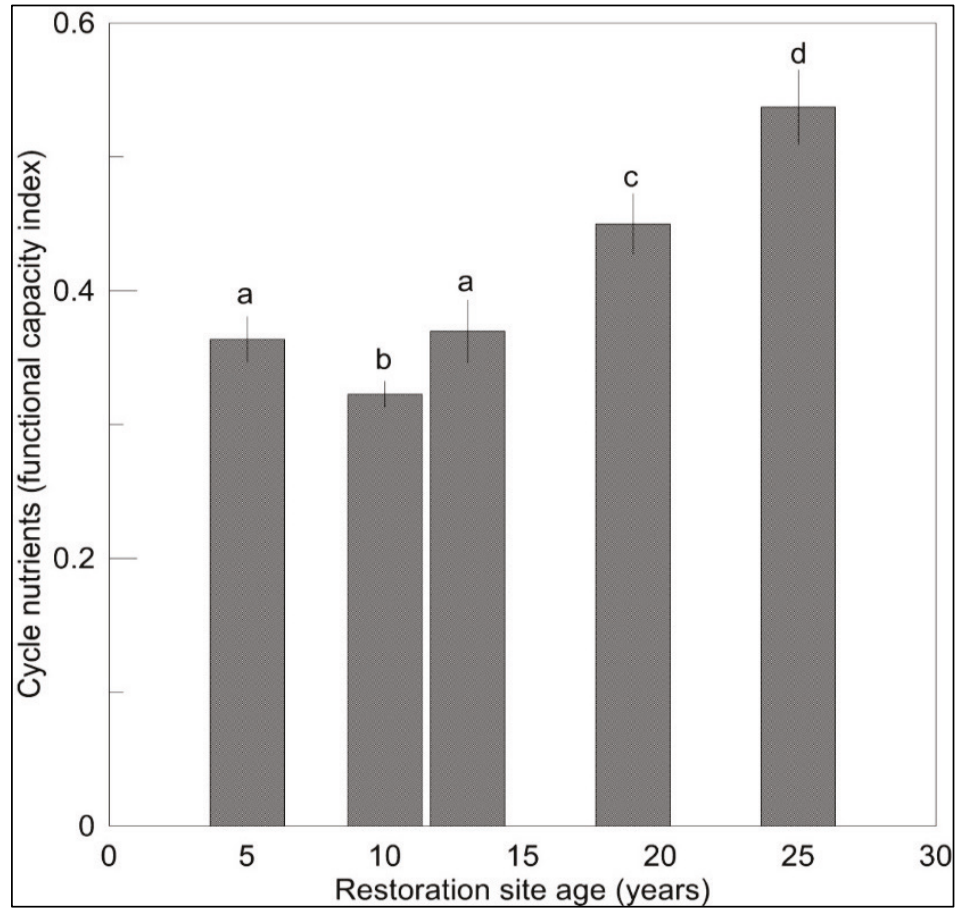

Figure 28. Export organic carbon functional scores across the restoration chronosequence. Error bars represent one standard deviation of the mean; entries with different letter designations were significantly different at $\alpha=0.05$.

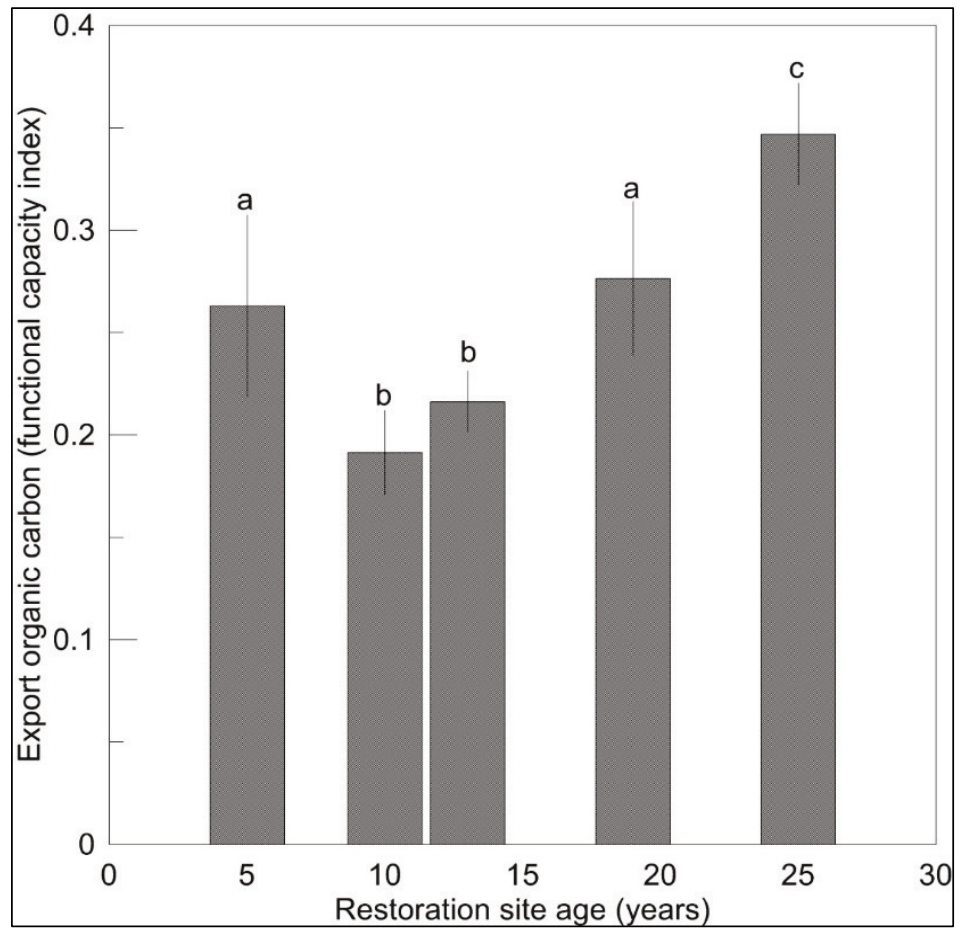


Figure 29. Remove elements and compounds functional scores across the restoration chronosequence. Error bars represent one standard deviation of the mean; entries with different letter designations were significantly different at $\alpha=0.05$.

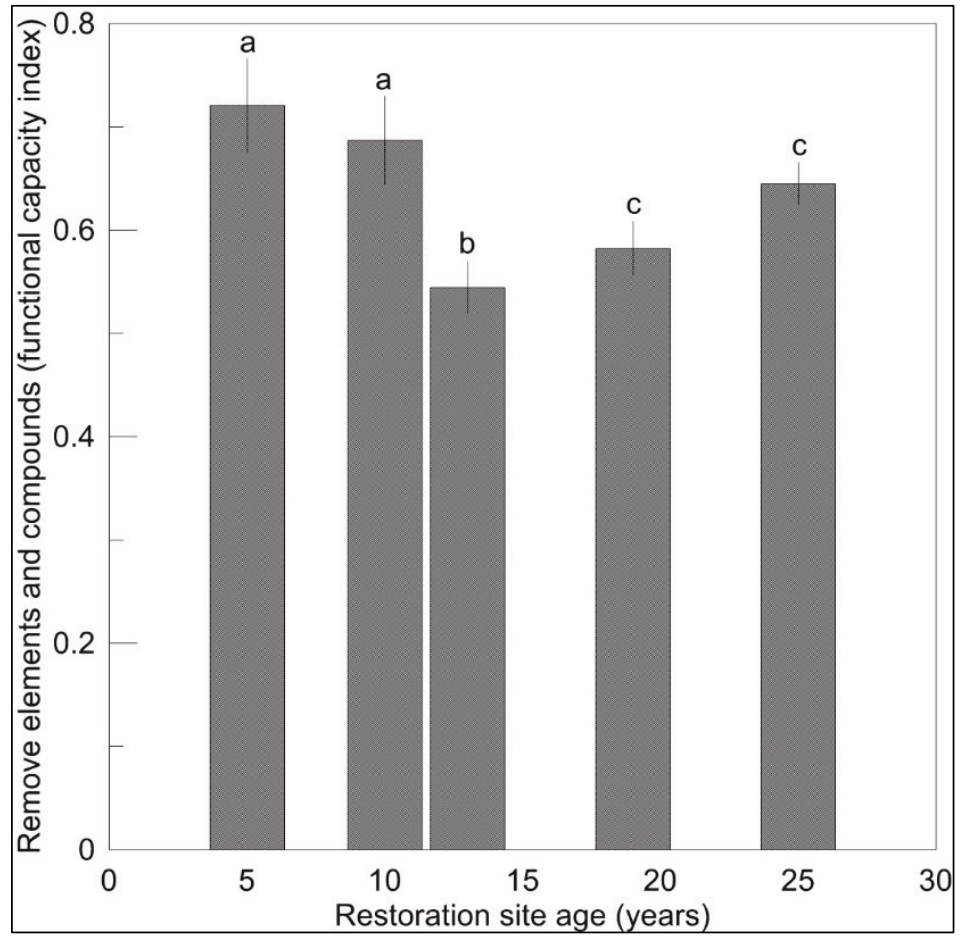

The maintain plant communities functions exhibited statistically significant increases across the restoration chronosequence, with $30 \%$ of monitoring locations exceeding functional capacity index scores of 0.80 (Figure 30). Steady increases in functional assessment scores resulted from improvements in tree basal area and density (Table 4). Additionally, maintained plant community assessment scores are supported by high values for the species composition variables, which remain maximized (value $=1.0$ ) at all restored sites due to selection of appropriate species during restoration plantings. These factors result in the highest scores for the seven functions examined in the wetland assessment. Functional scores are expected to show continued increases as additional tree growth occurs.

The provide fish and wildlife habitat (habitat) functional scores display statistically significant improvements across the restoration chronosequence, with average increases from o.o to 5.3 over the 25-year monitoring period (Figure 31). Young restoration sites receive a habitat score of 0.0 due to the absence of trees and snags $\geq 10 \mathrm{~cm}$ (4 in.; Table 4). Scores will steadily increase with ongoing improvements in tree basal area. 
The incorporation of snags and log biomass will drive further functional increases as forest succession proceeds.

In summary, each of the assessment functions examined displayed significant improvements in functional assessment outcomes across the restoration chronosequence. To further distill the study outcomes, Figure 32 displays the average functional score across the restoration chronosequence. In some cases, resource managers prefer to evaluate restoration success based upon a single value, as opposed to examining changes in each functional score independently. This approach has advantages (simplicity), but also limits a resource manager's ability to target specific functions of interest (e.g., habitat) or implement strategies to further improve one or more functional outcomes. For example, functional scores (e.g., habitat) that include tree basal area, woody debris, and log biomass may benefit from restoration site management, such as forest thinning, to improve tree growth rates, while providing additional woody debris biomass. Conversely, the detain precipitation function (based upon microdepressional ponding and flood frequency) remains more difficult to improve through forest management activities.

Examining the average functional score, statistically significant increases occurred within the 13-20, and 25-year restoration age intervals. These findings reiterate the positive effect of (1) sub-canopy and canopy tree development and (2) above- and belowground biomass production (e.g., woody debris accumulation, soil horizon development) on functional scores. As described in the sections above, wetland functions are expected to show continued improvements as associated assessment variables scores develop further. 
Figure 30. Maintain plant communities functional scores across the restoration chronosequence. Error bars represent one standard deviation of the mean; entries with different letter designations were significantly different at $\alpha=0.05$.

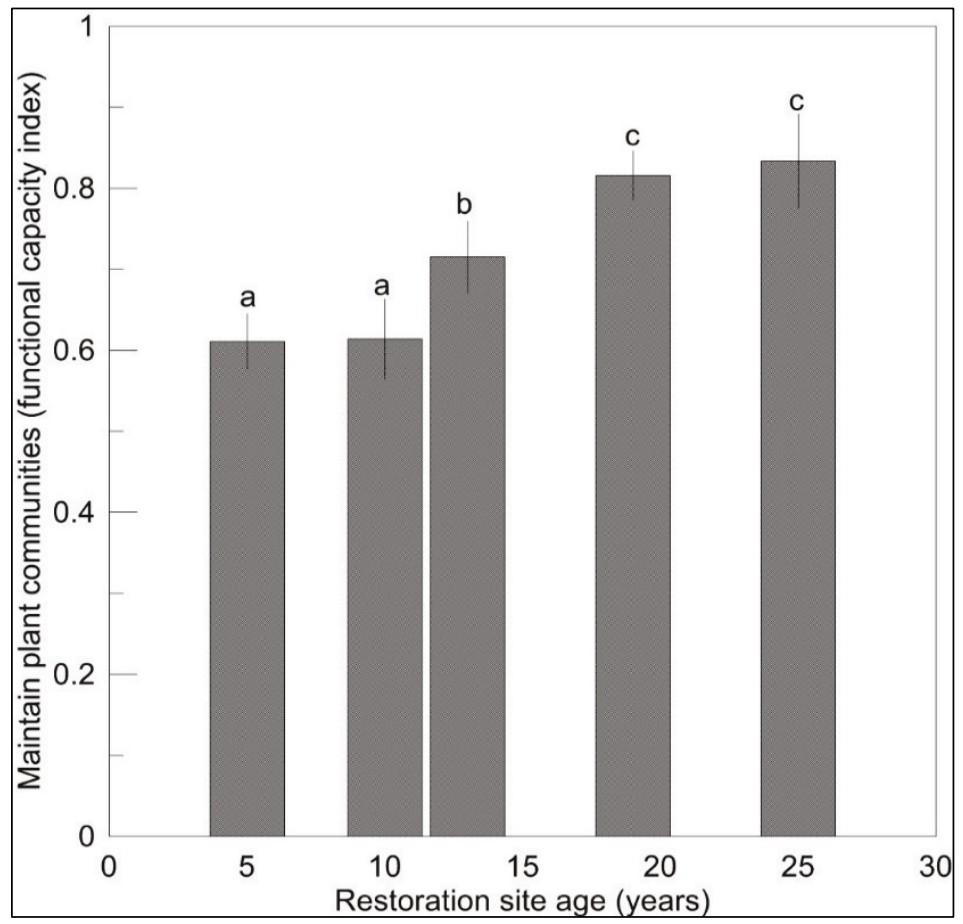

Figure 31. Provide fish and wildlife habitat functional scores across the restoration chronosequence. Error bars represent one standard deviation of the mean; entries with different letter designations were significantly different at $\alpha=0.05$.

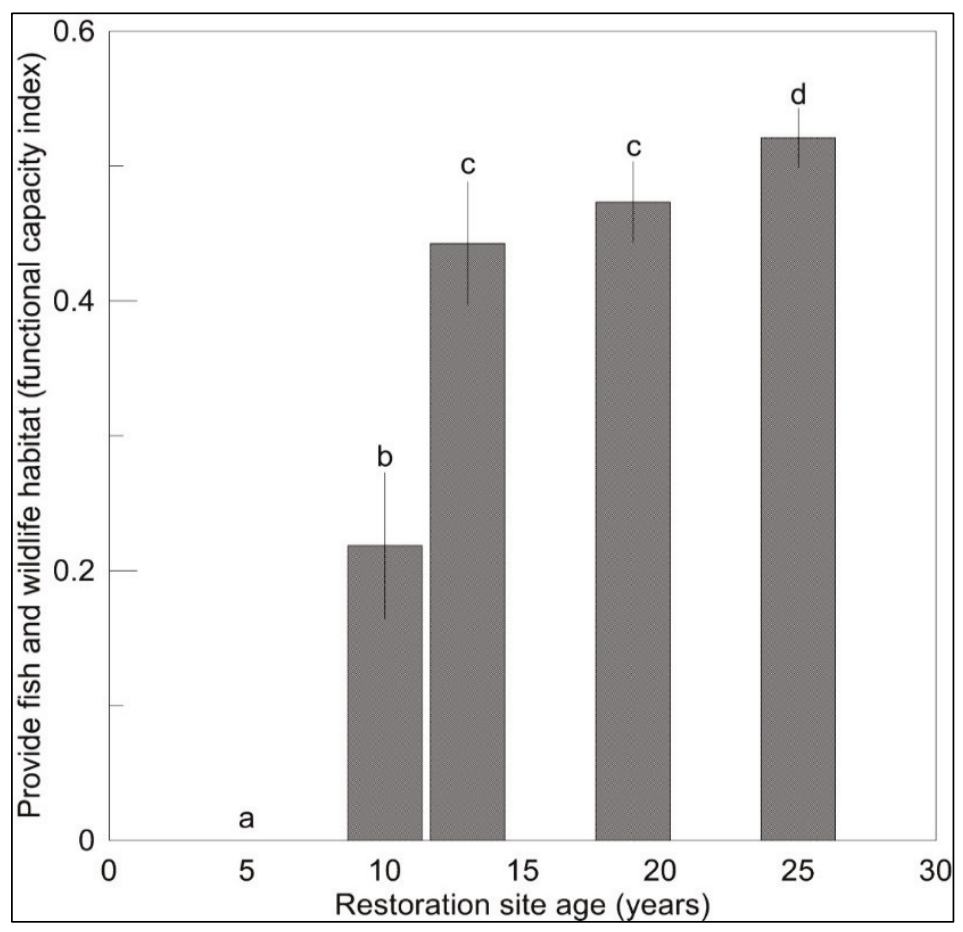


Figure 32. Average functional scores across the restoration chronosequence. Error bars represent one standard deviation of the mean; entries with different letter designations were significantly different at $\alpha=0.05$.

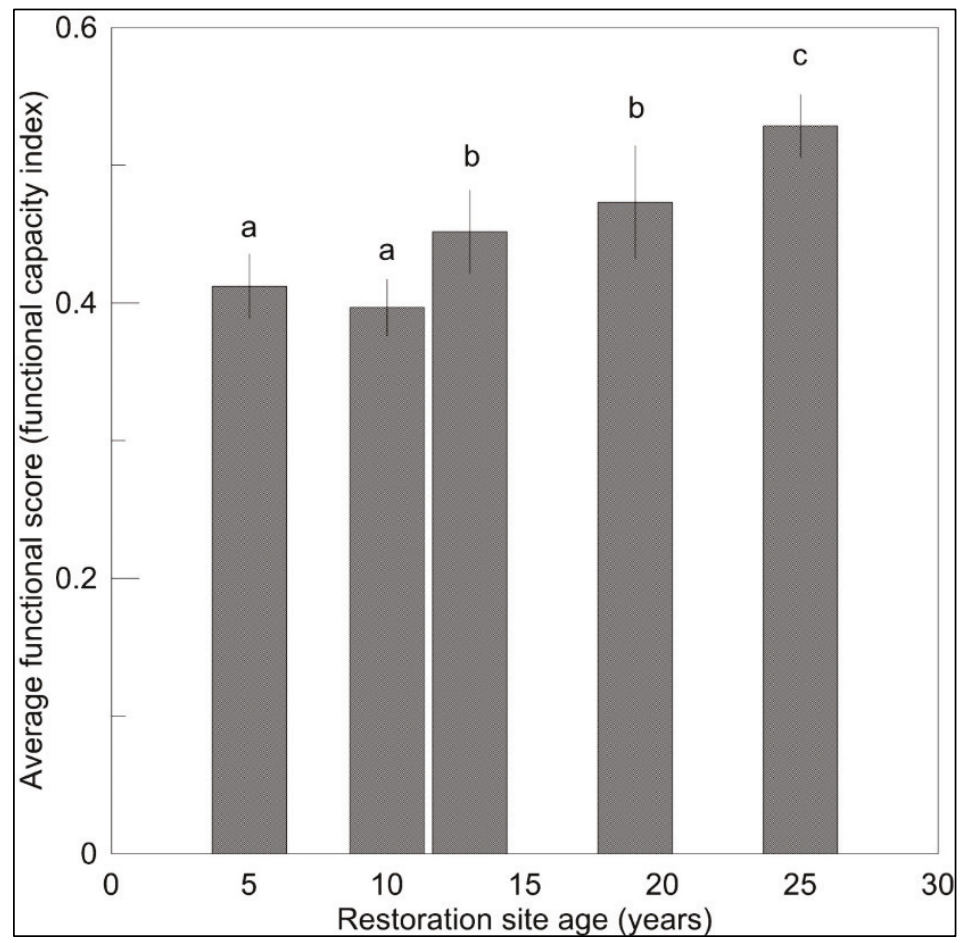

\subsection{Intrasite functional increases over time}

The results of previous monitoring efforts conducted at each of the 12 restoration sites allow for an examination of functional changes over time (Table 2; Lin 2003; 2005; 2008; 2009; Evans 2012). The section below provides summary data from each restoration site (Figures 33-44). Statistical analysis was not conducted due to low sampling size (i.e., intensity) and a lack of available raw data from early monitoring efforts. Additionally, all seven assessment variables were not reported at all restoration sites during previous monitoring efforts, limiting the number of functions evaluated. In general, each of the restoration sites displays substantial increases in wetland function over the monitoring period. For example, the maintain plant community functional capacity index increased by an average of 0.43 during the monitoring period across all restoration sites.

Compared to the most recent sampling (2007-2011), the average functional score increased by 0.20 over a 4-9 year period. Increases in tree basal area, tree density, and other sources of aboveground biomass drove the recent gains in wetland functional scores observed during the 2016 
monitoring effort. As a result, wetland functional scores are expected to show continued improvements as forest succession progresses. A few sites display small decreases (average $=0.05$ ) in a subset of functional scores compared with previously reported monitoring results. These decreases can be attributed to improvements in flood frequency estimates and other factors related to data collection and analysis. During future monitoring efforts, assessment scores will be adjusted as needed based upon any additional improvement in flood frequency data and analysis capabilities. 
Figure 33. Intrasite changes in functional scores over time - Alligator restoration area.

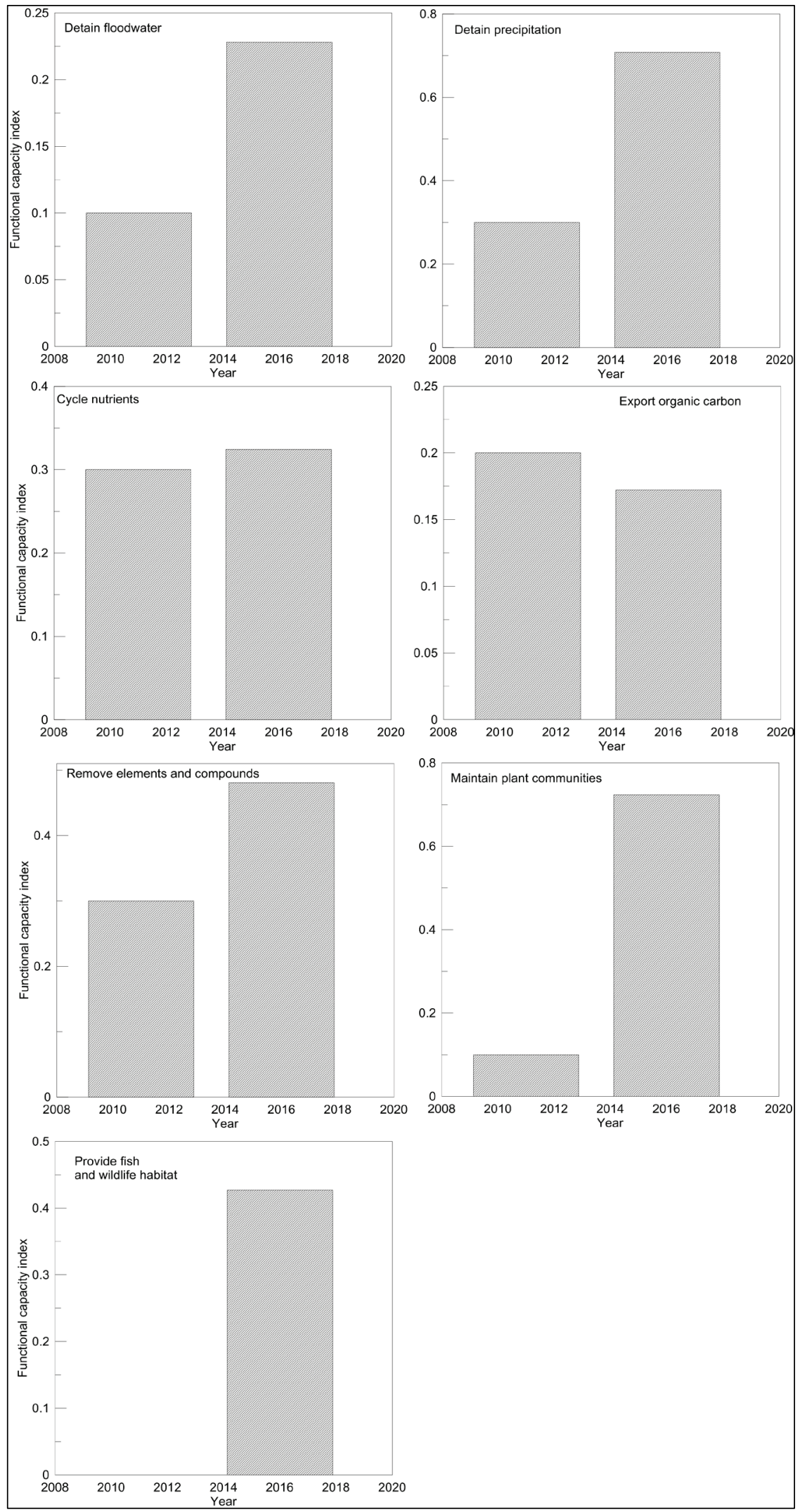


Figure 34. Intrasite changes in functional scores over time Big Twist restoration area.

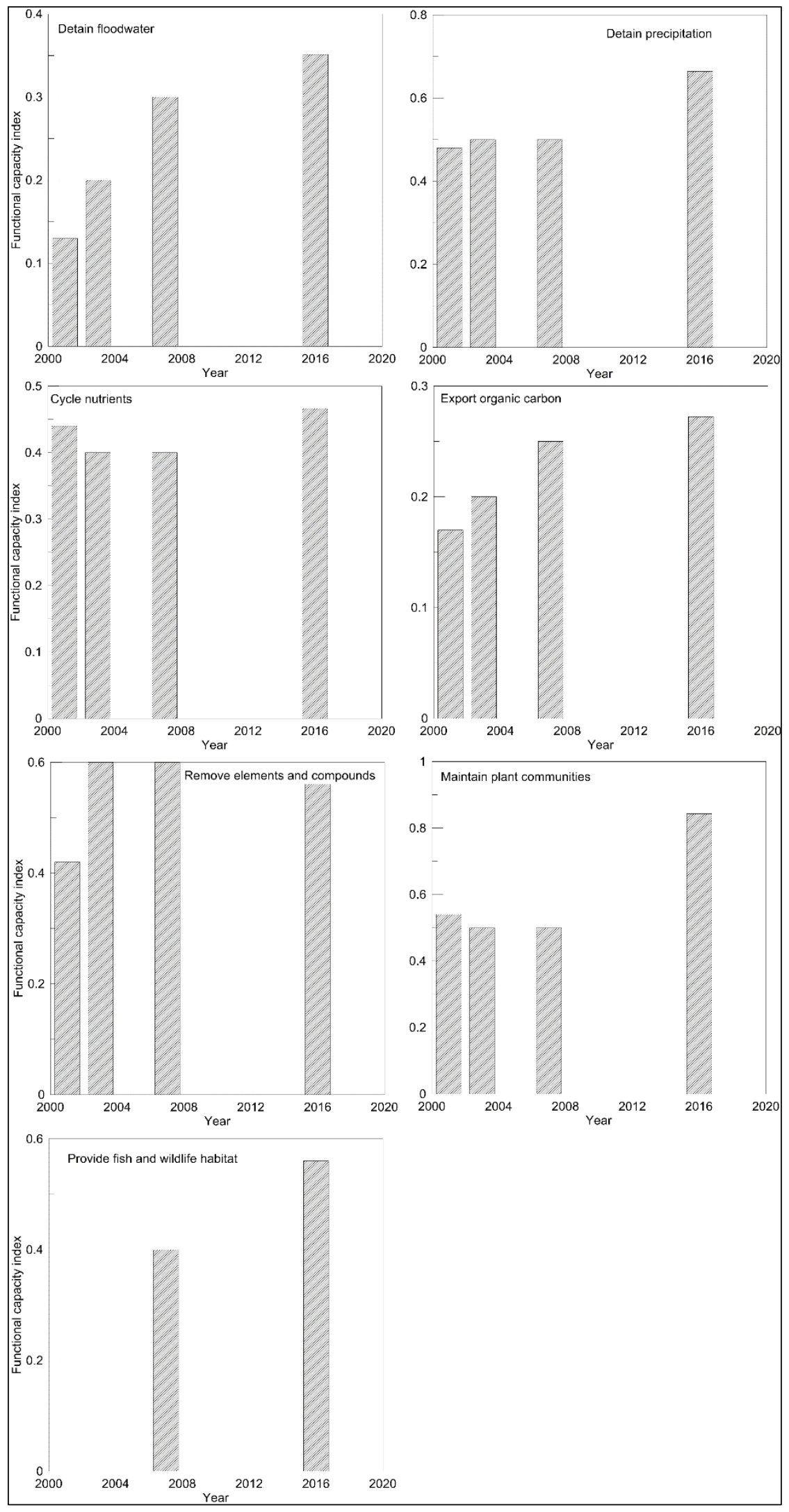


Figure 35. Intrasite changes in functional scores over time - Bolivar restoration area.

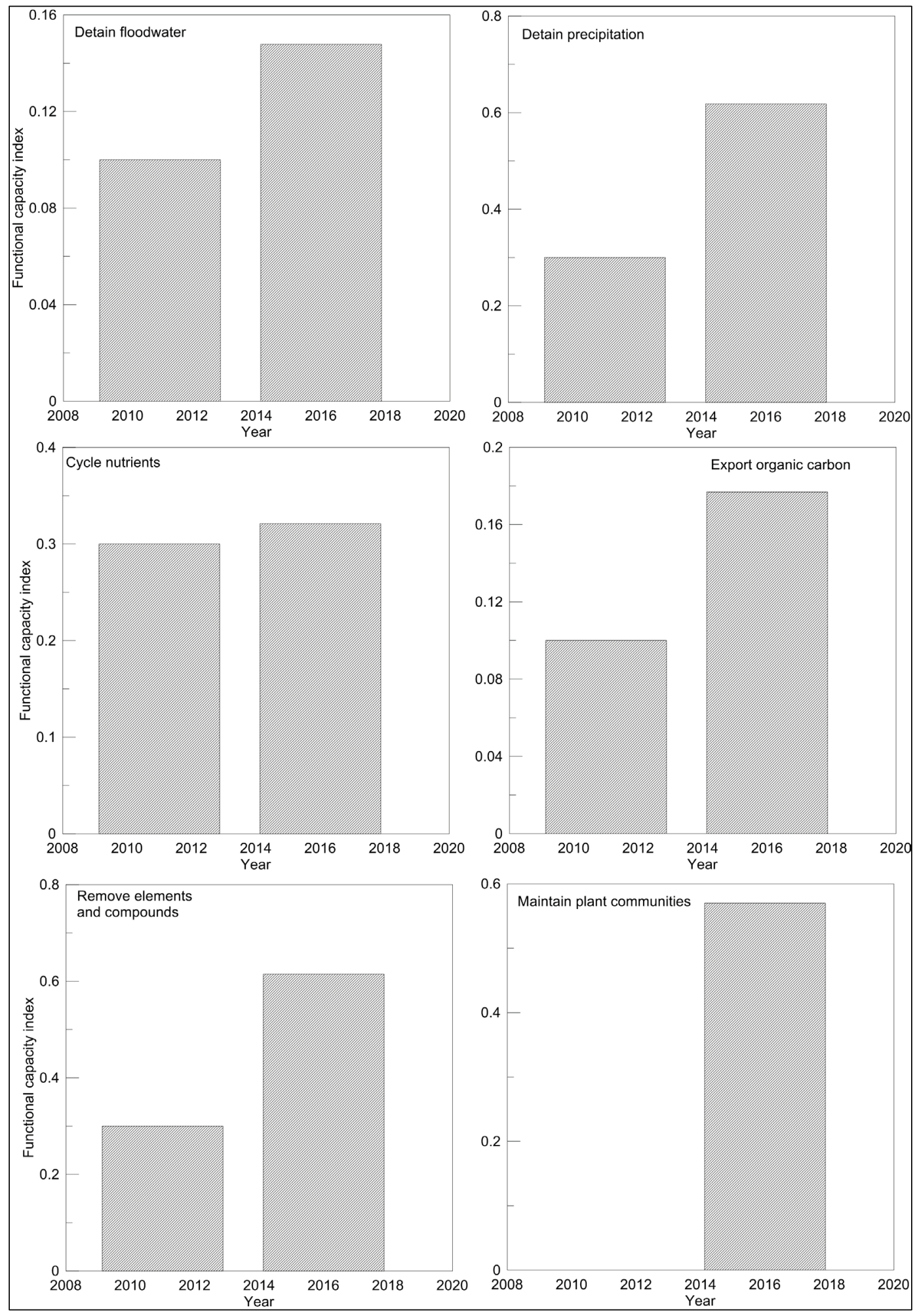


Figure 36. Intrasite changes in functional scores over time - Darlove restoration area.

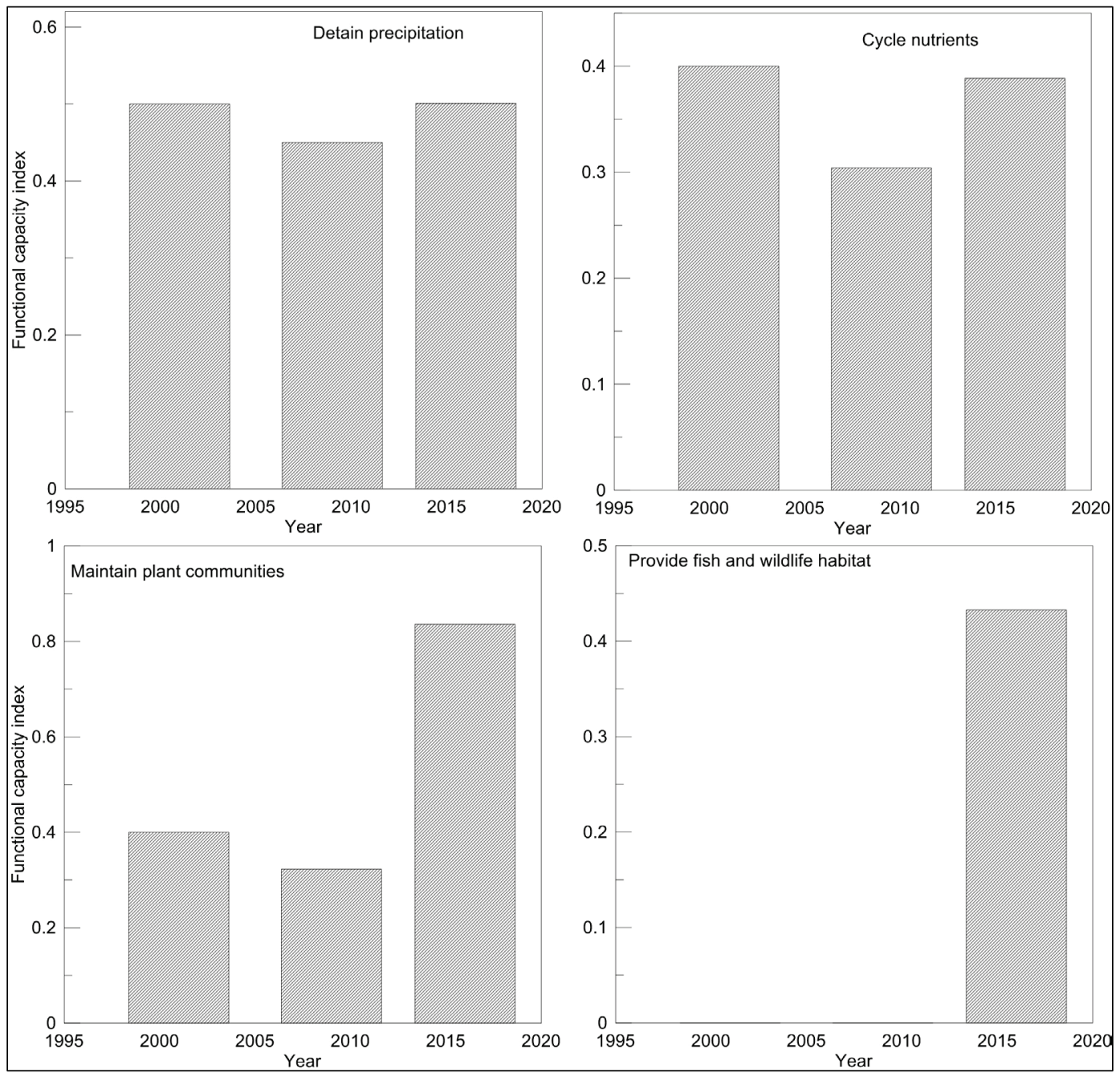


Figure 37. Intrasite changes in functional scores over time - Island Lake restoration area.

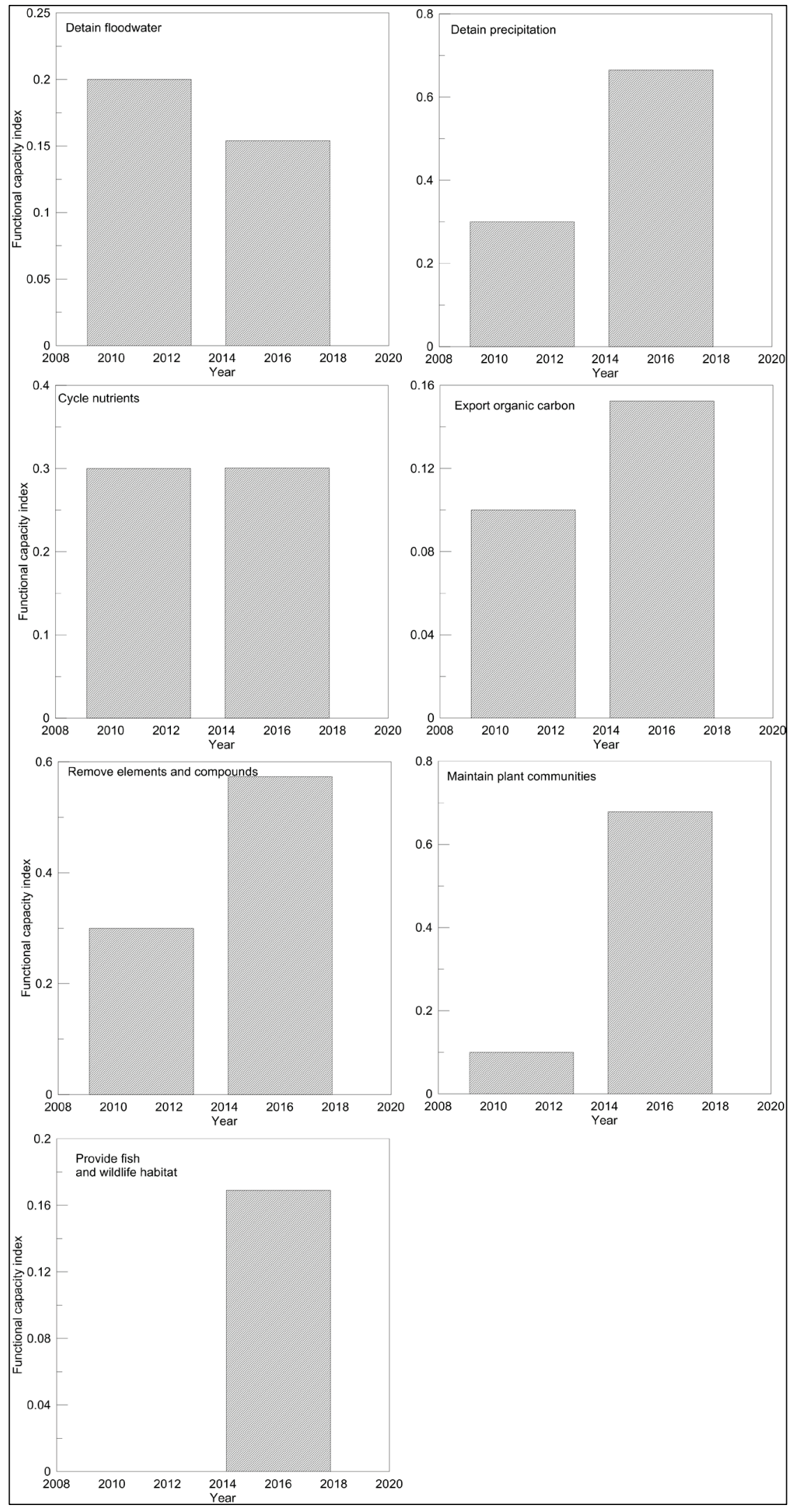


Figure 38. Intrasite changes in functional scores over time - Kennedy restoration area.

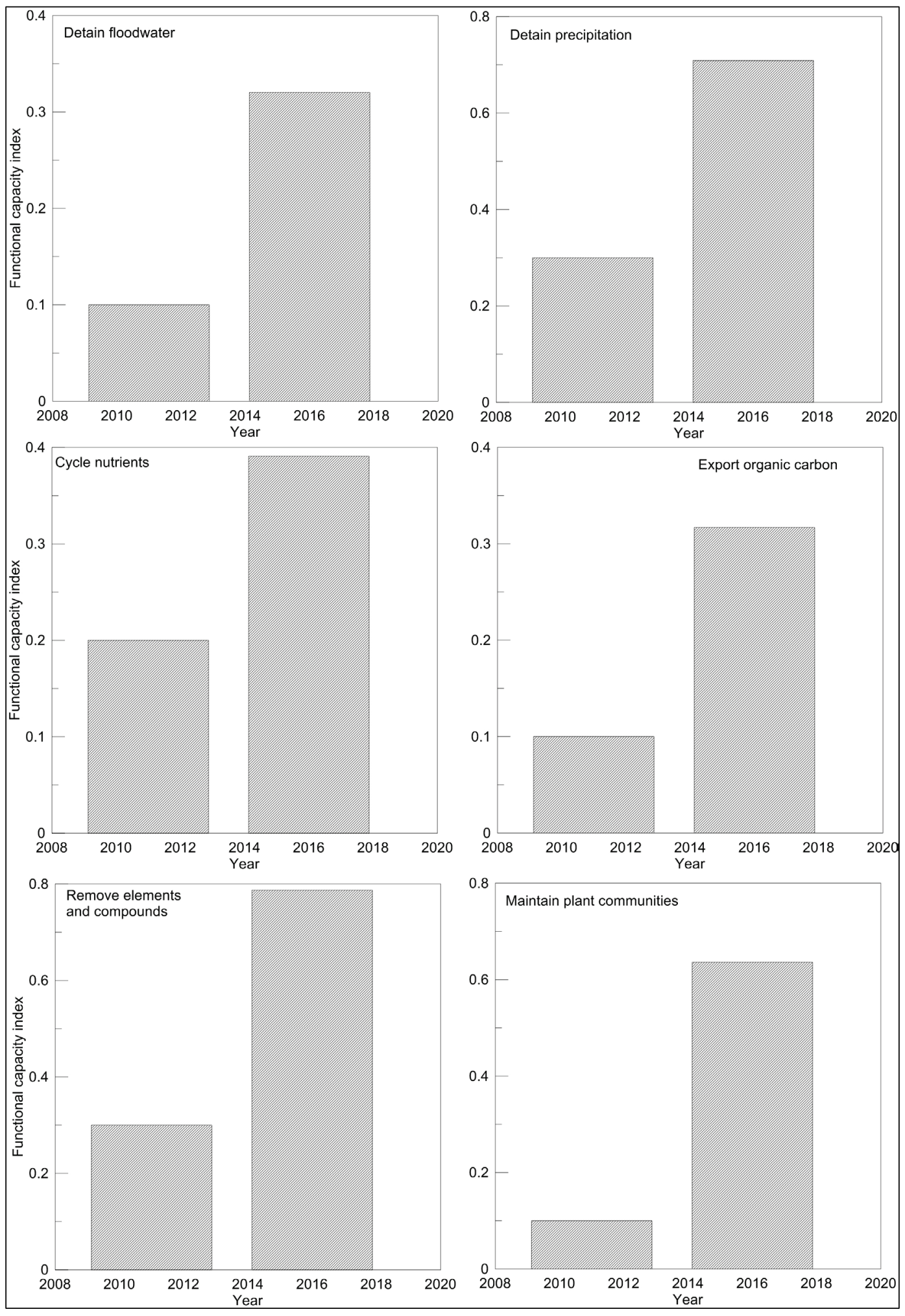


Figure 39. Intrasite changes in functional scores over time Lake George restoration area.

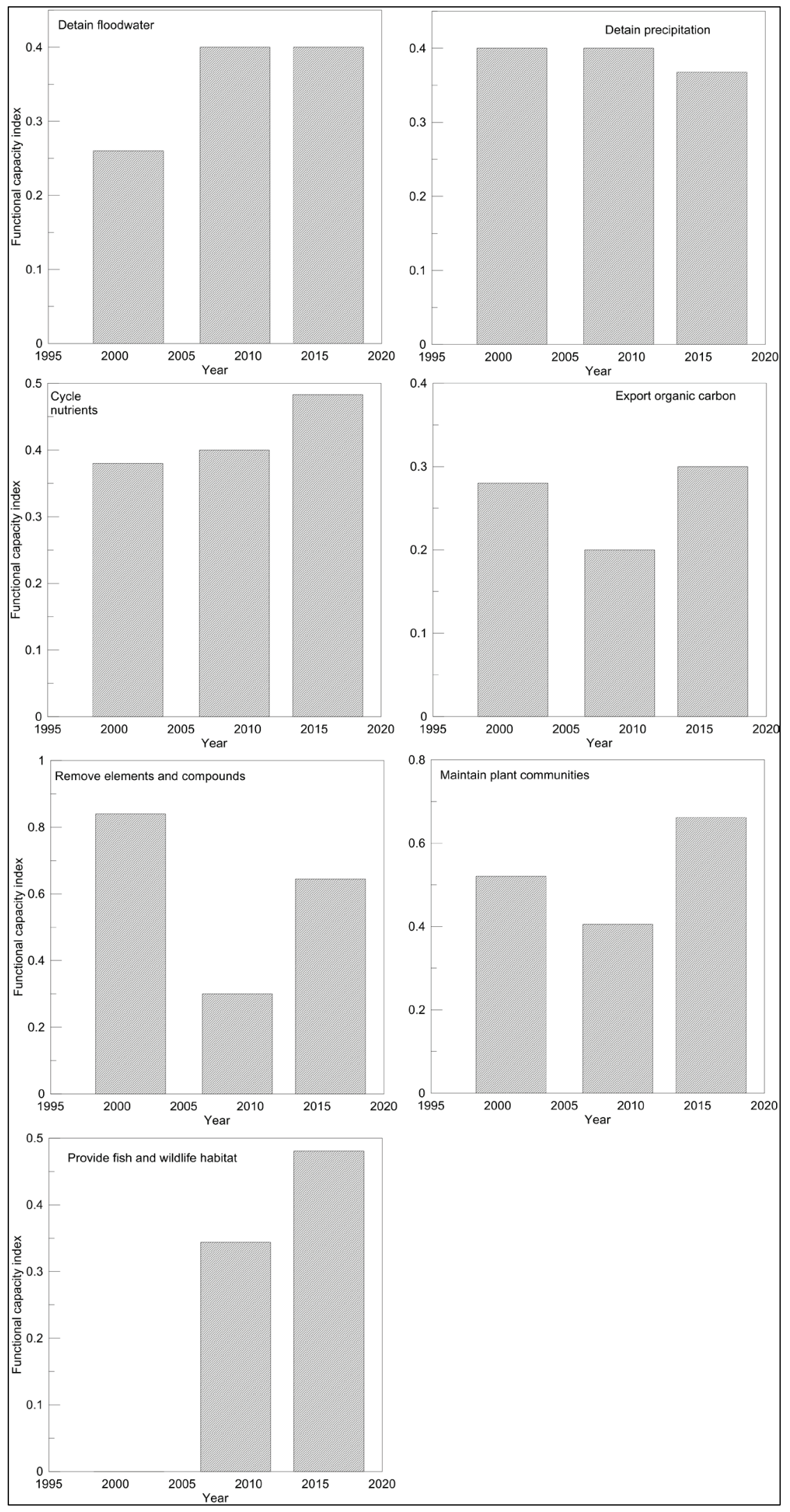


Figure 40. Intrasite changes in functional scores over time - Polutken restoration area.

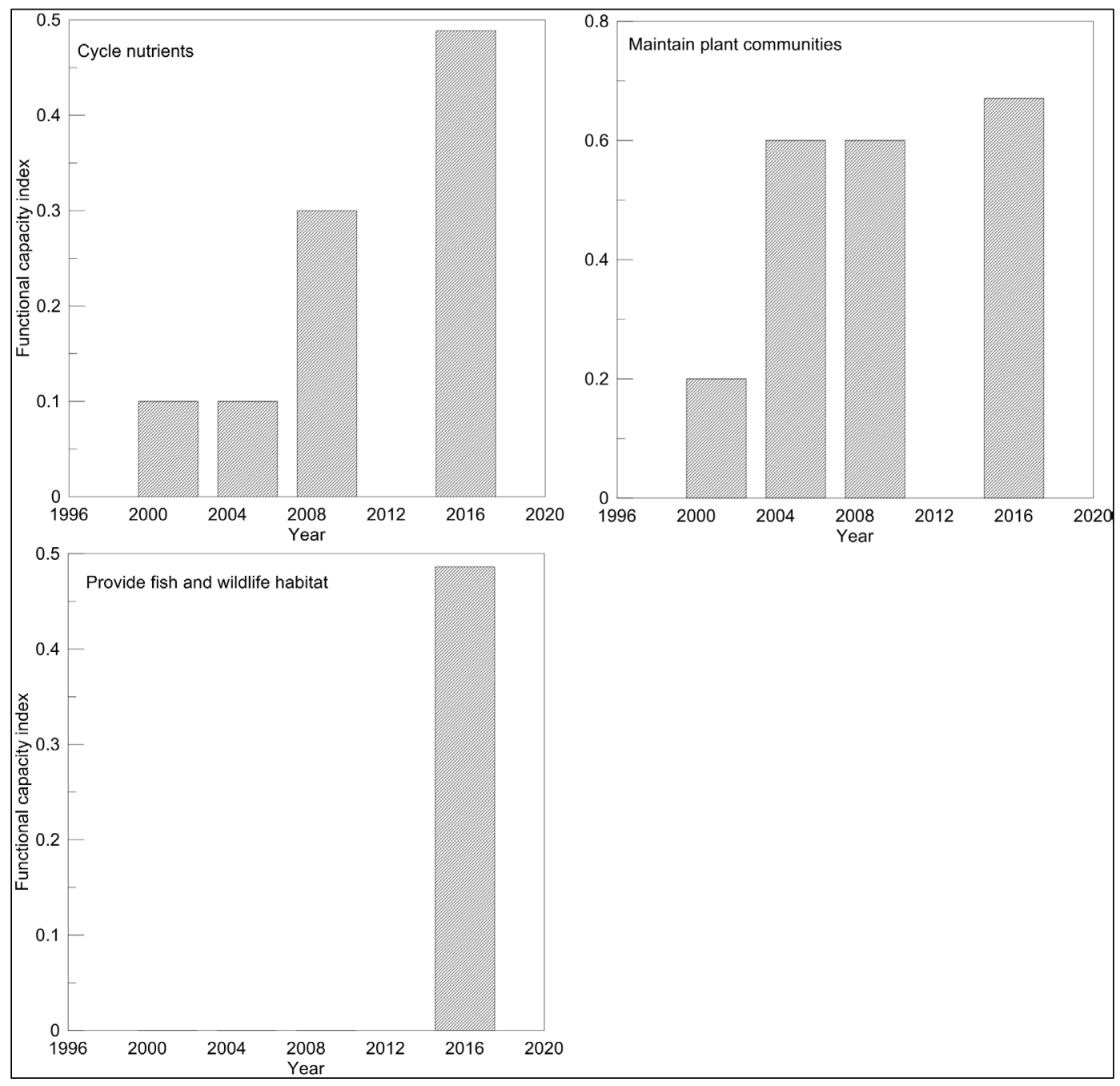


Figure 41. Intrasite changes in functional scores over time Pushmataha restoration area.

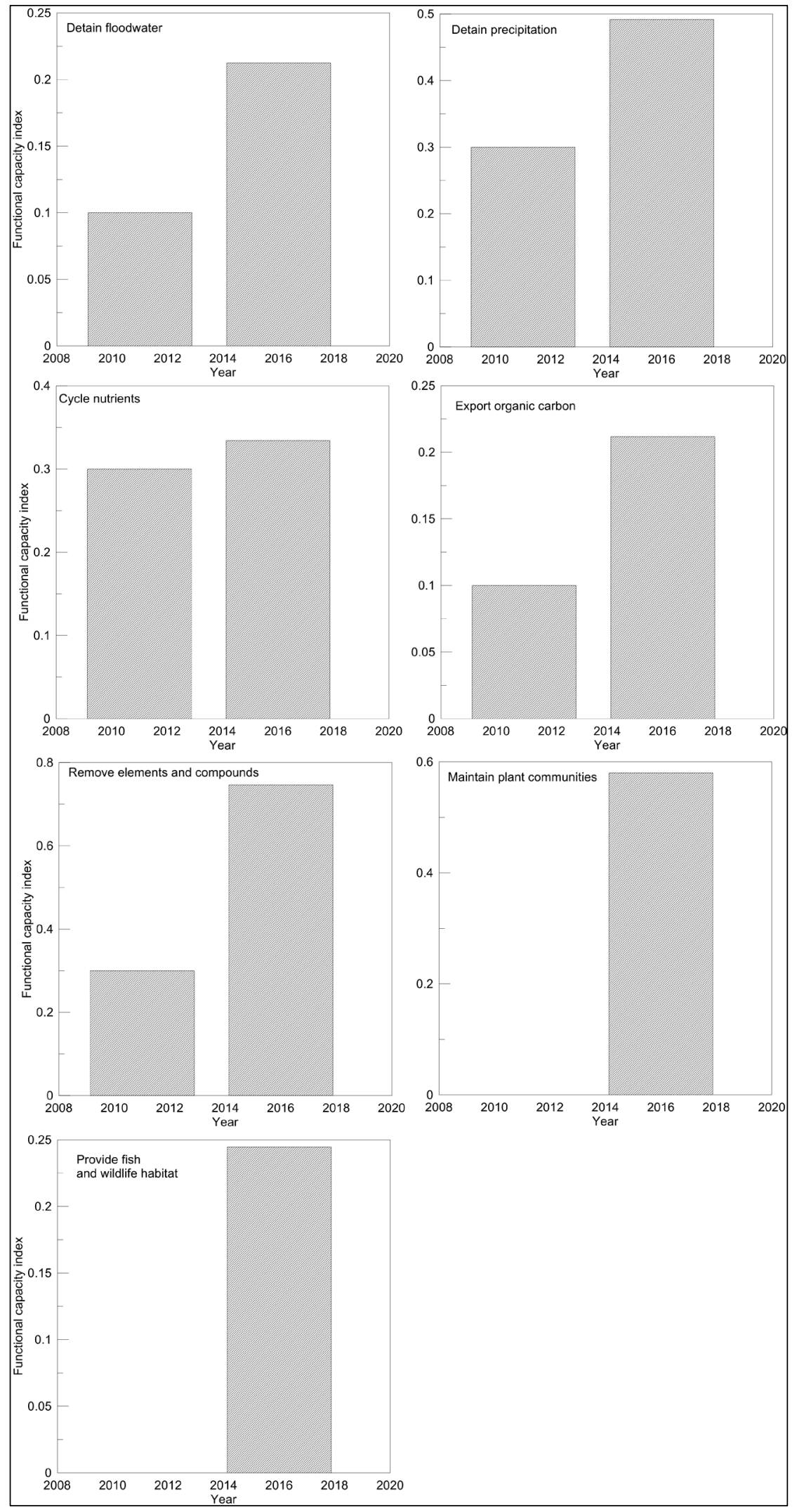


Figure 42. Intrasite changes in functional scores over time Sky Lake restoration area.

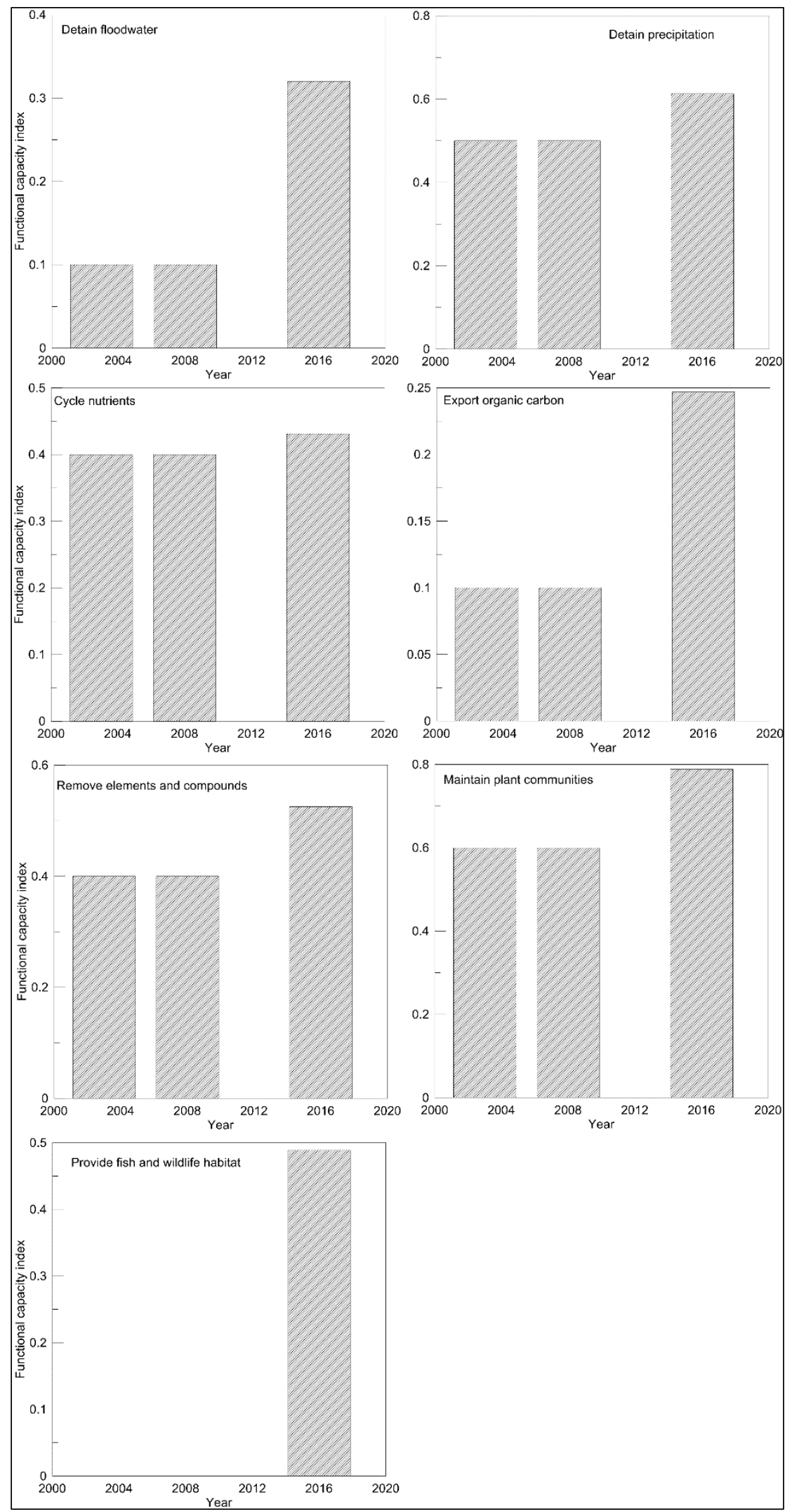


Figure 43. Intrasite changes in functional scores over time Stock restoration area.

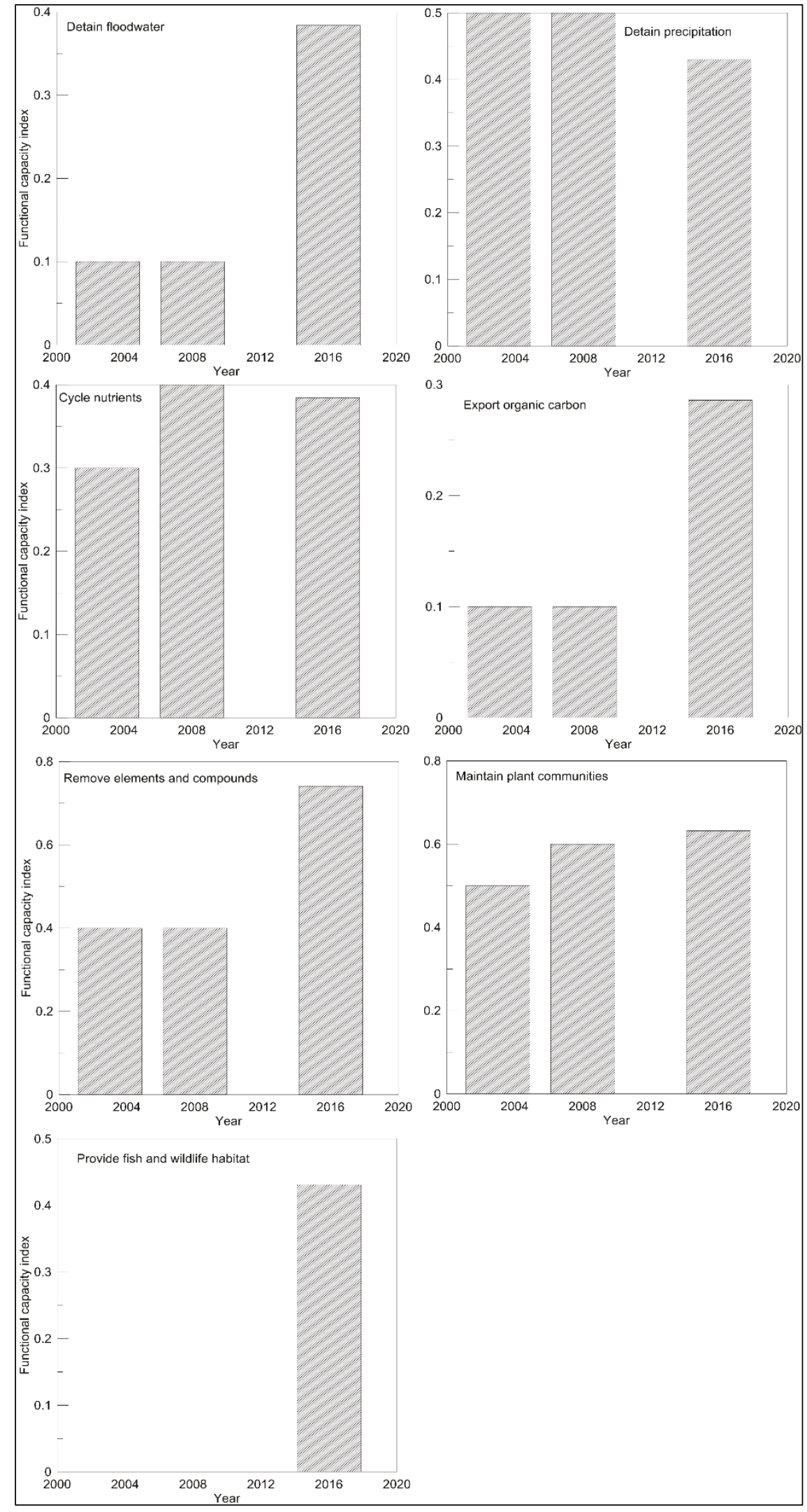


Figure 44. Intrasite changes in functional scores over time Washington restoration area.

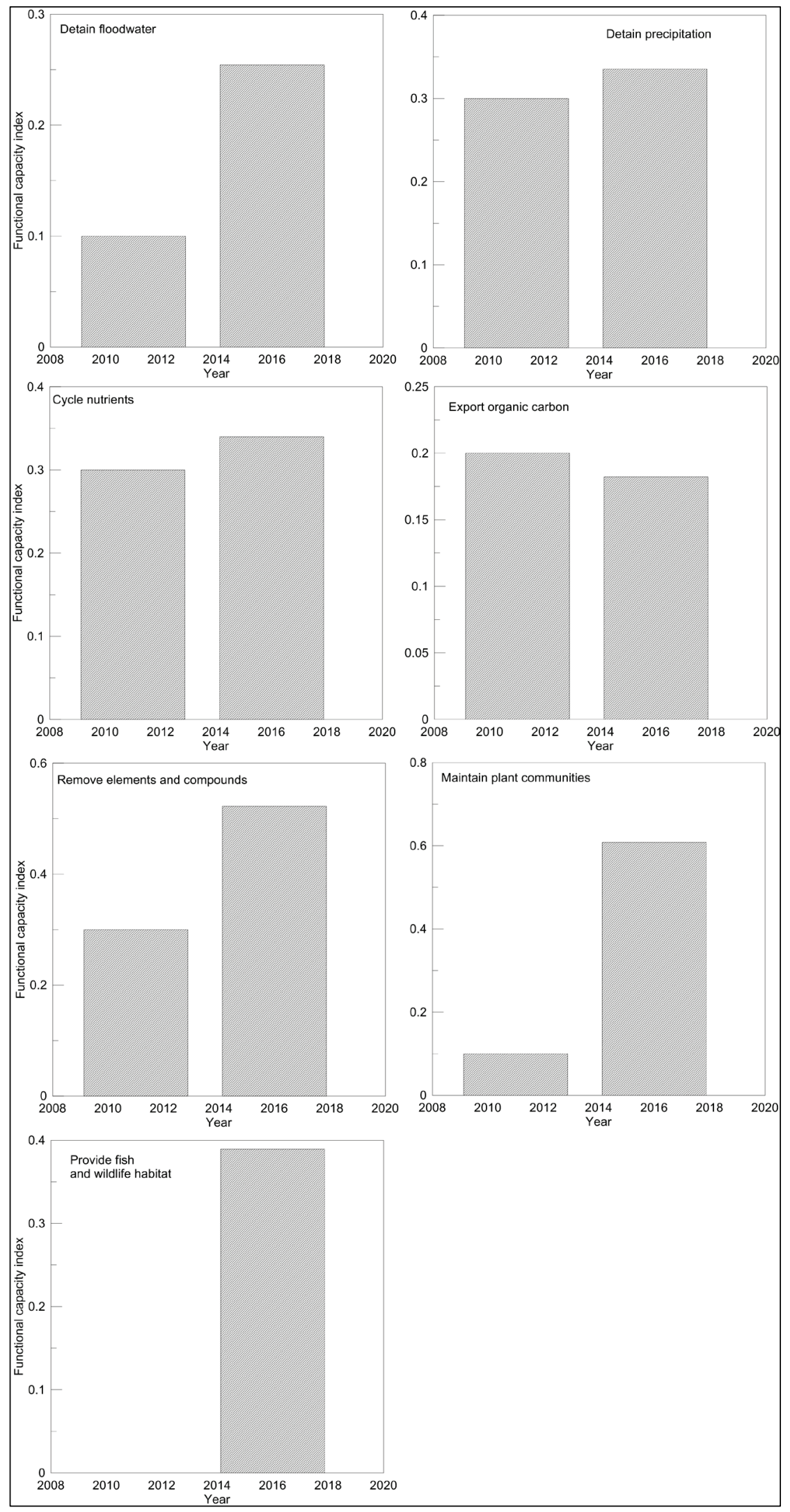




\subsection{Wetland functions in restored and mature bottomland hardwood forests}

As described above, restored wetlands display significant increases in assessment variables and functional scores. However, recently restored areas often fail to achieve the level of function observed in mature ecosystems. The lack of initial functional response in young restored wetlands results from a time lag required for bottomland hardwood forests to progress towards maturity (Gardiner and Oliver 2005). Smith and Klimas (2002) suggest that bottomland hardwood forests in the region require as many as 100 years to reach a fully functional steady state. For example, Berkowitz and White (2013) examined three wetland functions 20 years after restoration, reporting that functional scores remained 16 to $44 \%$ (average 31\%) below the levels observed at mature control sites. The current study shows similar results, with the majority of 25-year-old restored areas displaying lower functional scores than those observed at 21 mature (> 80-year-old) bottomland hardwood forest study locations in the region (Table 5; data adapted from Berkowitz 2013 and Berkowitz and White 2013). Notably, the average functional lag decreased to $20 \%$, indicating that further improvements in restored areas are continuing. Additionally, the maintain plant communities' function exceeded the functional score observed in mature locations. This results from selective restoration plantings, which target high-value species (e.g., Nuttall oak (Quercus nuttallii)). As restoration sites continue to mature, additional gains in wetland function are anticipated, with restored areas approaching reference forest conditions over time. As indicated above, USACE planning activities utilize a 50-year-period of analysis to make projections of site conditions for the purposes of offsetting impacts and conducting mitigation activities. Therefore, comparisons of restoration sites to 80-year-old bottomland hardwood stands do not directly reflect USACE planning projections.

Table 5. Comparison of wetland functional assessment scores at mature bottomland hardwood forests and 25-year-old restoration sites.

\begin{tabular}{|l|c|c|c|c|}
\hline \multirow{2}{*}{$\begin{array}{l}\text { Wetland } \\
\text { function }\end{array}$} & \multicolumn{2}{|c|}{ Mature forest* $\mathbf{8 0 \text { years old) }}$} & \multicolumn{2}{c|}{ Restoration sites (25 years old) } \\
\cline { 2 - 5 } & $\begin{array}{c}\text { Average } \\
\text { assessment score }\end{array}$ & $\begin{array}{c}\text { Standard } \\
\text { deviation }\end{array}$ & $\begin{array}{c}\text { Average assessment } \\
\text { score }\end{array}$ & $\begin{array}{c}\text { Standard } \\
\text { deviation }\end{array}$ \\
\hline $\begin{array}{l}\text { Detain } \\
\text { Floodwater }\end{array}$ & 0.63 & 0.09 & 0.40 & 0.05 \\
\hline $\begin{array}{l}\text { Detain } \\
\text { Precipitation }\end{array}$ & 0.81 & 0.02 & 0.61 & 0.06 \\
\hline Cycle Nutrients & 0.69 & 0.05 & 0.54 & 0.03 \\
\hline
\end{tabular}




\begin{tabular}{|l|c|c|c|c|}
\hline \multirow{2}{*}{$\begin{array}{l}\text { Wetland } \\
\text { function }\end{array}$} & \multicolumn{2}{|c|}{ Mature forest* $\mathbf{8 0 \text { years old) }}$} & \multicolumn{2}{c|}{ Restoration sites (25 years old) } \\
\cline { 2 - 5 } & $\begin{array}{c}\text { Average } \\
\text { assessment score }\end{array}$ & $\begin{array}{c}\text { Standard } \\
\text { deviation }\end{array}$ & $\begin{array}{c}\text { Average assessment } \\
\text { score }\end{array}$ & $\begin{array}{c}\text { Standard } \\
\text { deviation }\end{array}$ \\
\hline $\begin{array}{l}\text { Export Organic } \\
\text { Carbon }\end{array}$ & 0.65 & 0.05 & 0.35 & 0.03 \\
\hline $\begin{array}{l}\text { Remove } \\
\text { Elements and } \\
\text { Compounds }\end{array}$ & 0.83 & 0.03 & 0.64 & 0.02 \\
\hline $\begin{array}{l}\text { Maintain Plant } \\
\text { Communities }\end{array}$ & 0.71 & 0.02 & 0.83 & 0.06 \\
\hline $\begin{array}{l}\text { Provide Fish and } \\
\text { Wildlife Habitat }\end{array}$ & 0.70 & 0.04 & 0.52 & 0.02 \\
\hline
\end{tabular}

*Based upon data from Berkowitz (2013) and Berkowitz and White 2013.

\subsection{Management implications of monitoring results}

The sections above document substantial increases in wetland functional assessment outcomes across the twelve restored bottomland hardwood forests examined. Notably, restored locations (e.g., > 10 years old) are beginning to exceed the 10-cm (4-inch) tree diameter threshold, resulting in the observed functional increases. The development of the tree strata and factors related to above- and belowground biomass resulted in significant increases in assessment scores.

Based on these results, additional improvements in wetland function are anticipated without further management action. However, these findings also highlight opportunities to accelerate additional increases in functional outcomes through forest management practices. For example, selective thinning has been shown to increase the rate of tree growth and tree basal area (Oliver and Larsen 1996), which subsequently improves assessment outcomes. Forest thinning also introduces woody debris and log biomass to the forest floor, further enhancing functional assessment scores. Alterations to site hydrology (e.g., removal of ditches) could increase the flood frequency variable at several restoration sites, supporting increases in four of the seven functions evaluated. Additionally, strategically restoring adjacent areas provides a mechanism to improve functional scores by increasing several assessment variables, including core area, habitat connectivity, and wetland tract. 


\section{Summary}

This report documents increases in wetland functions within restored bottomland hardwood forests in the Lower Mississippi Alluvial Valley. Monitoring results demonstrate that wetland assessment variables progressed towards reference conditions, displaying statistically significant improvements across the restoration chronosequence. Wetland assessment variables followed expected patterns of forest succession, and in general, coincided with predicted results generated from recovery trajectory curves. Wetland functional scores also showed statistically significant increases within the restoration chronosequence. Functional improvements were also observed based upon repeated monitoring efforts conducted over time. Substantial increases in wetland function are occurring within the restored areas, driven by the increase in tree basal area, tree density, and accumulations of above- and belowground biomass. Further increases in wetland functions are anticipated as restoration sites continue to mature and undergo forest succession. 


\section{References}

Allen, J. A., B. D. Keeland, J. A. Stanturf, A. F. Clewell, H. E. Kennedy Jr. 2000. A guide to bottomland hardwood restoration. U.S. Forest Service. General Technical Report SRS-40.

Berkowitz, J. F. 2013. Development of restoration trajectory metrics in reforested bottomland hardwood forests applying a rapid assessment approach. Ecological Indicators 34:600-606.

Berkowitz, J. F., J. R. White. 2013. Linking wetland functional rapid assessment models with quantitative hydrological and biogeochemical measurements across a restoration chronosequence. Soil Science Society of America Journal. 77:14421451.

Berkowitz, J. F., C. V. Noble, E. Summers, J. R. White, R. D. DeLaune, 2014. Investigation of biogeochemical functional proxies in headwater streams across a range of channel and catchment alterations. Environmental Management 53.3: 534-548.

Bigelow, S. W., M. P. North, C. F. Salk, 2011. Using light to predict fuel reduction and group select effects in Sierran mixed conifer forest. Can. J. For. Res. 41: 20512063.

Boul, S. W., R. J. Southard, R. C. Graham, P. A. McDaniel. 2001. Soil Genesis and Classification Sixth Edition. Chapter 13 Histosols: Organic Soils. West Sussex, UK: John Wiley and Sons.

Fischenich, J. M., Lloyd, C. M., Palmero, M. R. eds. Proceedings of the National Wetlands Engineering Workshop; Held at St. Louis, Missouri on 3-5 August 1993. Technical Report WRP-RE-8. Vicksburg, MS: Waterways Experiment Station.

Gardiner, E. S., and J. M. Oliver. 2005. Restoration of bottomland hardwood forests in the Lower Mississippi Alluvial Valley, USA. In Restoration of Boreal and Temperate Forests, ed. J. A. Stanturf, P. Madsen, Boca Raton, FL: CRC Press.

Haynes, R. J., Bridges, R. J., Gard, S. W., Wilkins, T. W., Cook Jr, H. R. 1995. Bottomland hardwood reestablishment efforts for the U.S. Fish and Wildlife Service: Southeast Region.

Hefner, J. M., Brown, J. D. 1995. Wetland trends in the southeastern United States. Wetlands 4:1-11.

Hobbs, R. J., Cramer, V. A. 2008. Restoration ecology: interventionist approaches for restoring and maintaining ecosystem function in the face of rapid environmental change. The Annual Review of Environment and Resources 33:39-61.

King, S. L. and B. D. Keeland. 1999. Evaluation of reforestation in the lower Mississippi River alluvial valley. Restoration Ecology 7(4): 348-359. 
King, S. L., D. J. Twedt, and R. R. Wilson. 2006. The role of the Wetland Reserve Program in conservation efforts in the Mississippi River Alluvial Valley. Wildlife Society Bulletin 34(4): 914-920.

Lockhart, B. R., J. M. Guldin, T. Foti. 2010. Tree species composition and structure in an old bottomland hardwood forest in south-central Arkansas. Castanea 75(3): 315329.

The Nature Conservancy. 1992. Restoration of the Mississippi River Alluvial Plain as a functional ecosystem. Hammond, LA: Southeastern Louisiana University.

Noble, C. V., E. Summers, J. F. Berkowitz. 2014. Validating the operational draft regional guidebook for the functional assessment of high-gradient ephemeral and intermittent headwater streams. ERDC/EL TR-14-7. Vicksburg, MS: US Army Engineer Research and Development Center.

Oliver, C. D., and B. C. Larson. 1996. Forest Stand Dynamics. New York, NY: John Wiley \& Sons, Inc.

Smith D., C. V. Noble, and J. F. Berkowitz. 2013. Hydrogeomorphic (HGM) approach to assessing wetland functions: Guidelines for developing guidebooks. ERDC/EL TR-13-11. Vicksburg, MS: US Army Engineer Research and Development Center.

Smith, M. S., Euliss, N. H., Wilcox, D. A., Brinson, M. M., 2008. Application of a geomorphic and temporal perspective to wetland management in North America. Wetlands 28(3): 563-577.

Smith, R. D., and C. V. Klimas. 2002. A regional guidebook for applying the hydrogeomorphic approach to assessing wetland functions of selected regional wetland subclasses, Yazoo Basin, Lower Mississippi River Alluvial Valley. ERDC/EL TR-02-4. Vicksburg, MS: US Army Engineer Research and Development Center.

Stanturf, J. A., E. S. Gardiner, P. B. Hamel, M. S. Devall, T. D. Leininger, and M. E. Warren. 2000. Restoring bottomland hardwood ecosystems in the Lower Mississippi Alluvial Valley. Journal of Forestry 98(8): 10-16.

Summers, E. A. 2010. Evaluating ecological restoration in Tennessee hardwood bottomland forests. MS Thesis, University of Tennessee.

U.S. Congress. 1985. The Food Security Act of 1985. Public Law 100-233. US Congress. Washington, DC.

Walker, L. R., D. A. Wardle, R. D. Bardgett, and B. D. Clarkson. 2010. The use of chronosequences in studies of ecological succession and soil development. Journal of Ecology 98(4): 725-736. 


\section{Appendix A: Statistical relationships between restoration site age, wetland assessment variables, and wetland functions}

Table A1. Statistical relationships examining assessment variables and functions across the restoration chronosequence. Significance was determined at the $\alpha=0.05$ level. The p-values in italics indicate the Analysis of Variance testing (ANOVA); other values were determined using the non-parametric Kruskal-Wallis test.

\begin{tabular}{|c|c|c|c|c|c|}
\hline \multicolumn{6}{|c|}{ A horizon biomass } \\
\hline Site age & 5 & 10 & 13 & 20 & 25 \\
\hline 5 & & $<0.001$ & 0.007 & 0.082 & $<0.001$ \\
\hline 10 & $<0.001$ & & $<0.001$ & $<0.001$ & 0.411 \\
\hline 13 & 0.007 & $<0.001$ & & 1.000 & $<0.001$ \\
\hline 20 & 0.082 & $<0.001$ & 1.000 & & $<0.001$ \\
\hline 25 & $<0.001$ & 0.411 & $<0.001$ & $<0.001$ & \\
\hline \multicolumn{6}{|c|}{ O horizon biomass } \\
\hline Site age & 5 & 10 & 13 & 20 & 25 \\
\hline 5 & & 0.389 & 0.709 & 0.398 & 0.007 \\
\hline 10 & 0.389 & & 0.849 & 1.000 & 0.001 \\
\hline 13 & 0.709 & 0.849 & & 1.000 & $<0.001$ \\
\hline 20 & 0.398 & 1.000 & 1.000 & & 0.003 \\
\hline 25 & 0.007 & 0.001 & $<0.001$ & 0.003 & \\
\hline \multicolumn{6}{|c|}{ Tree density } \\
\hline Site age & 5 & 10 & 13 & 20 & 25 \\
\hline 5 & & 0.281 & $<0.001$ & $<0.001$ & $<0.001$ \\
\hline 10 & 0.281 & & $<0.001$ & 0.001 & $<0.001$ \\
\hline 13 & $<0.001$ & $<0.001$ & & 0.029 & 0.014 \\
\hline 20 & $<0.001$ & 0.001 & 0.029 & & $<0.001$ \\
\hline 25 & $<0.001$ & $<0.001$ & 0.014 & $<0.001$ & \\
\hline \multicolumn{6}{|c|}{ Tree basal area } \\
\hline Site age & 5 & 10 & 13 & 20 & 25 \\
\hline 5 & & 0.577 & $<0.001$ & $<0.001$ & $<0.001$ \\
\hline 10 & 0.577 & & $<0.001$ & 0.001 & $<0.001$ \\
\hline 13 & $<0.001$ & $<0.001$ & & 0.563 & $<0.001$ \\
\hline
\end{tabular}




\begin{tabular}{|c|c|c|c|c|c|}
\hline 20 & $<0.001$ & 0.001 & 0.563 & & $<0.001$ \\
\hline 25 & $<0.001$ & $<0.001$ & $<0.001$ & $<0.001$ & \\
\hline \multicolumn{6}{|c|}{ Ground vegetation cover } \\
\hline Site age & 5 & 10 & 13 & 20 & 25 \\
\hline 5 & & 0.489 & 0.118 & 1.000 & $<0.001$ \\
\hline 10 & 0.489 & & $<0.001$ & 1.000 & $<0.001$ \\
\hline 13 & 0.118 & $<0.001$ & & 0.065 & $<0.001$ \\
\hline 20 & 1.000 & 1.000 & 0.065 & & \\
\hline 25 & $<0.001$ & $<0.001$ & $<0.001$ & $<0.001$ & \\
\hline \multicolumn{6}{|c|}{ Sapling shrub density } \\
\hline Site age & 5 & 10 & 13 & 20 & 25 \\
\hline 5 & & $<0.001$ & $<0.001$ & 0.029 & 1.000 \\
\hline 10 & $<0.001$ & & 1.000 & $<0.001$ & $<0.001$ \\
\hline 13 & $<0.001$ & 1.000 & & $<0.001$ & $<0.001$ \\
\hline 20 & 0.029 & $<0.001$ & $<0.001$ & & 0.057 \\
\hline 25 & 1.000 & $<0.001$ & $<0.001$ & 0.057 & \\
\hline \multicolumn{6}{|c|}{ Woody debris biomass } \\
\hline Site age & 5 & 10 & 13 & 20 & 25 \\
\hline 5 & & 1.000 & $<0.001$ & $<0.001$ & $<0.001$ \\
\hline 10 & 1.000 & & $<0.001$ & $<0.001$ & $<0.001$ \\
\hline 13 & $<0.001$ & $<0.001$ & & 0.179 & $<0.001$ \\
\hline 20 & $<0.001$ & $<0.001$ & 0.179 & & 0.387 \\
\hline 25 & $<0.001$ & $<0.001$ & $<0.001$ & 0.387 & \\
\hline \multicolumn{6}{|c|}{ Detain floodwater } \\
\hline Site age & 5 & 10 & 13 & 20 & 25 \\
\hline 5 & & $<0.001$ & 0.998 & $<0.001$ & $<0.001$ \\
\hline 10 & $<0.001$ & & $<0.001$ & $<0.001$ & $<0.001$ \\
\hline 13 & 0.998 & $<0.001$ & & 0.001 & $<0.001$ \\
\hline 20 & $<0.001$ & $<0.001$ & 0.001 & & 1.000 \\
\hline 25 & $<0.001$ & $<0.001$ & $<0.001$ & 1.000 & \\
\hline \multicolumn{6}{|c|}{ Detain precipitation } \\
\hline Site age & 5 & 10 & 13 & 20 & 25 \\
\hline 5 & & 0.001 & 0.003 & $<0.001$ & $<0.001$ \\
\hline
\end{tabular}




\begin{tabular}{|c|c|c|c|c|c|}
\hline 10 & 0.001 & & 1.000 & 1.000 & 1.000 \\
\hline 13 & 0.003 & 1.000 & & 0.245 & 1.000 \\
\hline 20 & $<0.001$ & 1.000 & 0.245 & & 1.000 \\
\hline 25 & $<0.001$ & 1.000 & 1.000 & 1.000 & \\
\hline \multicolumn{6}{|c|}{ Cycle nutrients } \\
\hline Site age & 5 & 10 & 13 & 20 & 25 \\
\hline 5 & & 0.005 & 1.000 & 0.001 & $<0.001$ \\
\hline 10 & 0.005 & & 0.001 & $<0.001$ & $<0.001$ \\
\hline 13 & 1.000 & 0.001 & & $<0.001$ & $<0.001$ \\
\hline 20 & 0.001 & 0.001 & $<0.001$ & & $<0.001$ \\
\hline 25 & $<0.001$ & $<0.001$ & $<0.001$ & $<0.001$ & \\
\hline \multicolumn{6}{|c|}{ Export organic carbon } \\
\hline Site age & 5 & 10 & 13 & 20 & 25 \\
\hline 5 & & $<0.001$ & $<0.001$ & 1.000 & $<0.001$ \\
\hline 10 & $<0.001$ & & 0.475 & $<0.001$ & $<0.001$ \\
\hline 13 & $<0.001$ & 0.475 & & $<0.001$ & $<0.001$ \\
\hline 20 & 1.000 & $<0.001$ & $<0.001$ & & 0.002 \\
\hline 25 & $<0.001$ & $<0.001$ & $<0.001$ & 0.002 & \\
\hline \multicolumn{6}{|c|}{ Remove elements and compounds } \\
\hline Site age & 5 & 10 & 13 & 20 & 25 \\
\hline 5 & & 1.000 & $<0.001$ & $<0.001$ & $<0.001$ \\
\hline 10 & 1.000 & & $<0.001$ & 0.005 & $<0.001$ \\
\hline 13 & $<0.001$ & $<0.001$ & & $<0.001$ & $<0.001$ \\
\hline 20 & $<0.001$ & 0.005 & $<0.001$ & & 1.000 \\
\hline 25 & $<0.001$ & $<0.001$ & $<0.001$ & 1.000 & \\
\hline \multicolumn{6}{|c|}{ Maintain plant communities } \\
\hline Site age & 5 & 10 & 13 & 20 & 25 \\
\hline 5 & & 1.000 & $<0.001$ & 0.208 & $<0.001$ \\
\hline 10 & 1.000 & & $<0.001$ & 0.018 & $<0.001$ \\
\hline 13 & $<0.001$ & $<0.001$ & & 0.001 & $<0.001$ \\
\hline 20 & 0.208 & 0.018 & 0.001 & & 0.067 \\
\hline 25 & $<0.001$ & $<0.001$ & $<0.001$ & 0.067 & \\
\hline \multicolumn{3}{|c|}{ Provide fish and wildlife habitat } & & & \\
\hline
\end{tabular}




\begin{tabular}{|c|c|c|c|c|c|}
\hline Site age & 5 & 10 & 13 & 20 & 25 \\
\hline 5 & & 0.016 & $<0.001$ & $<0.001$ & $<0.001$ \\
\hline 10 & 0.016 & & $<0.001$ & 0.006 & $<0.001$ \\
\hline 13 & $<0.001$ & $<0.001$ & & 0.204 & $<0.001$ \\
\hline 20 & $<0.001$ & 0.006 & 0.204 & & $<0.001$ \\
\hline 25 & $<0.001$ & $<0.001$ & $<0.001$ & $<0.001$ & \\
\hline \multicolumn{6}{|c|}{ Average functional score } \\
\hline Site age & 5 & 10 & 13 & 20 & 25 \\
\hline 5 & & 0.678 & $<0.001$ & $<0.001$ & $<0.001$ \\
\hline 10 & 0.687 & & $<0.001$ & $<0.001$ & $<0.001$ \\
\hline 13 & $<0.001$ & $<0.001$ & & 0.339 & $<0.001$ \\
\hline 20 & $<0.001$ & $<0.001$ & 0.339 & & $<0.001$ \\
\hline 25 & $<0.001$ & $<0.001$ & $<0.001$ & $<0.001$ & \\
\hline
\end{tabular}




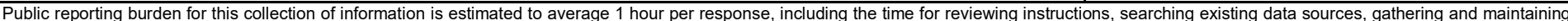

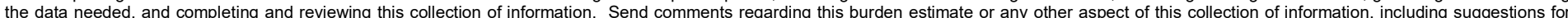

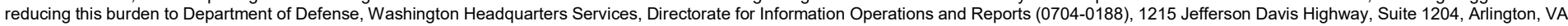

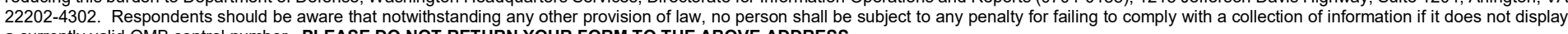
a currently valid OMB control number. PLEASE DO NOT RETURN YOUR FORM TO THE ABOVE ADDRESS.
1. REPORT DATE (DD-MM-YYYY)
March 2018

Restoring Bottomland Hardwood Forests on U.S. Army Corps of Engineers Lands:

2016 Monitoring Report
4. TITLE AND SUBTITLE

\section{DATES COVERED (From - To)}

5a. CONTRACT NUMBER

5b. GRANT NUMBER

5c. PROGRAM ELEMENT NUMBER

5d. PROJECT NUMBER

W807PM71677228

5e. TASK NUMBER

5f. WORK UNIT NUMBER

8. PERFORMING ORGANIZATION REPORT NUMBER

ERDC/EL TR-18-4

U.S. Army Engineer Research and Development Center

3909 Halls Ferry Road, Vicksburg, MS 39108-6499

Nashville District

U.S. Army Corps of Engineers

801 Broadway A415, Nashville, TN 37203

9. SPONSORING / MONITORING AGENCY NAME(S) AND ADDRESS(ES)

U.S. Army Corps of Engineers

Vicksburg District

11. SPONSOR/MONITOR'S REPORT NUMBER(S)

\section{DISTRIBUTION / AVAILABILITY STATEMENT}

Approved for public release; distribution is unlimited.

\section{SUPPLEMENTARY NOTES}

\section{ABSTRACT}

The U.S. Army Corps of Engineers (USACE) - Vicksburg District manages over 12,000 ha of restored bottomland hardwood forests within the Lower Mississippi Alluvial Valley. Restored forest stand ages within the region vary from five 5 to 26 years, providing opportunities to document increases in wetland function across a restoration chronosequence. Additionally, conducting repeated monitoring at restored sites over multiple years allows for an examination of restoration benefits as forest succession occurs. During 2016, wetland functional assessment data was collected and analyzed from 606 sample locations collected within 12 restored bottomland hardwood forest sites. Results indicate that (1) wetland assessment variables show continued progress toward mature forest conditions; (2) wetland assessment variables follow expected recovery trajectories; (3) wetland functional scores display statistically significant increases across the restoration chronosequence; and (4) wetland functional scores improve over multiple years of monitoring. Results display a functional lag between restored areas undergoing ecological succession and mature (e.g., 80-year-old) reference forests. However, a subset of wetland functions in restored sites have attained reference conditions in areas approaching or exceeding tree diameter and canopy closure thresholds.

\section{SUBJECT TERMS}

Restoration ecology

Wetland restoration

16. SECURITY CLASSIFICATION OF:

\section{a. REPORT}

Unclassified

b. ABSTRACT
Unclassified

Forest restoration

Delta (Miss.: Region)

Environmental monitoring

\begin{tabular}{l|c|l|}
$\begin{array}{l}\text { 17. LIMITATION } \\
\text { OF ABSTRACT }\end{array}$ & $\begin{array}{l}\text { 18. NUMBER } \\
\text { OF PAGES }\end{array}$ & $\begin{array}{l}\text { 19a. NAME OF RESPONSIBLE } \\
\text { PERSON }\end{array}$ \\
\cline { 3 - 3 } & 70 & $\begin{array}{l}\text { 19b. TELEPHONE NUMBER (include } \\
\text { area code) }\end{array}$ \\
& & \\
\hline
\end{tabular}

